\title{
The empirical risk-return relation: A factor analysis approach ${ }^{\hbar}$
}

\author{
Sydney C. Ludvigson ${ }^{\mathrm{a}, *}$, Serena $\mathrm{Ng}^{\mathrm{b}}$ \\ ${ }^{a}$ New York University, New York, NY 10003, USA \\ ${ }^{\mathrm{b}}$ University of Michigan, Ann Arbor, MI 48109, USA
}

Received 30 June 2005; received in revised form 24 August 2005; accepted 6 December 2005

Available online 8 September 2006

\begin{abstract}
Existing empirical literature on the risk-return relation uses relatively small amount of conditioning information to model the conditional mean and conditional volatility of excess stock market returns. We use dynamic factor analysis for large data sets, to summarize a large amount of economic information by few estimated factors, and find that three new factors - termed "volatility," "risk premium," and "real" factors - contain important information about one-quarter-ahead excess returns and volatility not contained in commonly used predictor variables. Our specifications predict $16-20 \%$ of the one-quarter-ahead variation in excess stock market returns, and exhibit stable and statistically significant out-of-sample forecasting power. We also find a positive conditional risk-return correlation.
\end{abstract}

(C) 2006 Elsevier B.V. All rights reserved.

JEL classification: G12; G10

Keywords: Stock market volatility; Expected returns; Sharpe ratio

\footnotetext{
th Ludvigson acknowledges financial support from the Alfred P. Sloan Foundation and the CV Starr Center at NYU. Ng acknowledges financial support from the National Science Foundation (SES-0345237). We thank G. William Schwert (the editor) and an anonymous referee for helpful comments, Kenneth French for providing the portfolio data, and Massimiliano Croce for excellent research assistance. Any errors or omissions are the responsibility of the authors.

${ }^{*}$ Corresponding author. Tel.: + 1212998 8927; fax: + 12129954186.

E-mail address: sydney.ludvigson@nyu.edu (S.C. Ludvigson).
} 


\section{Introduction}

Financial economists have long been interested in the empirical relation between the conditional mean and conditional volatility of excess stock market returns, often referred to as the risk-return relation. The risk-return relation is an important ingredient in optimal portfolio choice, and is central to the development of theoretical models aimed at explaining observed patterns of stock market predictability and volatility. Among those theoretical models that have become standard-bearers in finance, a positive risk-return relation is the benchmark prediction, so that times of predictably higher risk coincide with times of predictably higher excess returns, and vice versa. Unfortunately, the body of empirical evidence on the risk-return relation is mixed and inconclusive. Some evidence supports the theoretical prediction of a positive risk-return tradeoff, but other evidence suggests a strong negative relation. Yet a third strand of the literature finds that the relation is unstable and varies substantially through time. We summarize the existing evidence below.

Several criticisms of the existing empirical literature relate to the relatively small amount of conditioning information used to model the conditional mean and conditional volatility of excess stock market returns. First, the conditional expectations underlying the conditional mean and conditional volatility are typically measured as projections onto predetermined conditioning variables; but, as Harvey (2001) points out, the decision as to which predetermined conditioning variables to use in the econometric analysis can influence the estimated risk-return relation. In practice, researchers are forced to choose among a few conditioning variables because conventional statistical analyses are quickly overwhelmed by degrees-of-freedom problems as the number rises. Such practical constraints introduce an element of arbitrariness into the econometric modeling of expectations and can lead to omitted-information estimation bias, since a small number of conditioning variables is unlikely to span the information sets of financial market participants. If investors have information not reflected in the chosen conditioning variables used to model market expectations, measures of conditional mean and conditional volatility will be misspecified and possibly highly misleading. This point was made forcibly by Hansen and Richard (1987) in the context of estimating and testing dynamic asset pricing models.

A second and related criticism of the existing empirical literature is that the estimated relation between the conditional mean and conditional volatility of excess returns often depends on the parametric model of volatility, e.g., GARCH, EGARCH, stochastic volatility, or kernel density estimation (Harvey, 2001). Such procedures can impose potentially restrictive parametric assumptions and they often suffer from a curse-ofdimensionality problem that constrains their ability to accommodate large data sets of conditioning information.

Finally, the reliance on a small number of conditioning variables exposes existing analyses to problems of temporal instability in the underlying forecasting relations being modeled. For example, it is commonplace to model market expectations of future stock returns using the fitted values from a forecasting regression of returns on a measure of the market-wide dividend-price ratio. A difficulty with this approach is that the predictive power of the dividend-price ratio for excess stock market returns is unstable and exhibits statistical evidence of a structural break in the mid-1990s (Lettau, Ludvigson, and Wachter, 2005). 
In this paper, we consider one remedy to these problems using the methodology of dynamic factor analysis for large data sets. Recent research on dynamic factor models finds that the information in a large number of economic time series can be effectively summarized by a relatively small number of estimated factors, affording the opportunity to exploit a much richer information base than what has been possible in prior empirical studies of the risk-return relation. In this methodology, "a large number" can mean hundreds or even more than one thousand economic time series. By summarizing the information from a large number of series in a few estimated factors, we eliminate the arbitrary reliance on a small number of exogenous predictors to estimate the conditional mean and conditional volatility of stock returns, and make feasible the use of a vast set of economic variables that is more likely to span the unobservable information sets of financial market participants. In the words of Stock and Watson (2004), dynamic factor analysis permits us to turn dimensionality from a curse into a blessing.

Dynamic factor analysis allows us to escape the limitations of existing empirical analyses on several fronts. First, if a large amount of information can be effectively summarized by a relatively few common factors, then a natural remedy to the omitted information problem is to augment fitted conditional moments with estimated factors. We do so here by including estimated factors in the construction of fitted mean and volatility. Second, by combining dynamic factor analysis with a nonparametric approach to modeling volatility - an approach referred to hereafter as realized volatility - we avoid relying on potentially restrictive parametric structures while at the same time insuring that our measure of conditional volatility effectively summarizes a large amount of information that could be important for predicting the variance of the stock market. Third, there is some evidence (discussed below) that dynamic factor analysis provides robustness against the temporal instability that often plagues low-dimensional forecasting regressions. Indeed, our application appears supportive of this evidence, since the factor-augmented predictive relations we employ are remarkably stable over time, despite the observed temporal instability of many commonly used predictor variables over the sample period we study.

An important question of our study is the degree to which estimated common factors add information about the conditional mean and conditional volatility of stock returns that is not already contained in commonly used predictor variables. If, on the one hand, we find that the factors provide new information, then we have evidence that previous estimates of conditional moments are misspecified and the estimated risk-return relation is potentially contaminated. On the other hand, if we find that the information provided by the factors is largely contained in commonly used predictor variables, then we have evidence that previous estimates are likely to be well specified. Either way, our study contributes to the empirical literature on the risk-return relation by evaluating both the potential role of omitted information in the estimated risk-return relation as well as the robustness of previous results to conditioning on richer information sets.

We estimate common factors from two quarterly post-war data sets of economic activity using the method of principal components. The first data set consists of 209 primarily macroeconomic indicators; the second data set consists of 172 financial indicators. As a result of investigating these data, we find a number of results particularly interesting.

First, in modeling the conditional mean of excess stock market returns, we introduce two new financial factors that are particularly important for forecasting quarterly excess returns on the aggregate stock market. In doing so, we contribute to the continuing debate 
over the predictability of stock market returns. See, e.g., Campbell and Yogo (2002), Campbell and Thompson (2005), Goyal and Welch (2004), and Lewellen (2004). The first financial factor is the square of the first common factor of the data set comprised of financial indicators. This factor explains almost 80 percent of the contemporaneous variation in squared stock market returns, so we label it a "volatility factor." The second financial factor is the third common factor from the data set comprised of financial indicators and is highly correlated with a linear combination of three state variables widely used in the empirical asset pricing literature to explain cross-sectional variation in risk premia. These state variables are market return and the Fama-French factors $S M B_{t}$, and $H M L_{t}$ (Fama and French, 1993). Thus, our second factor connects the time series with the cross-section of expected excess stock market returns. For this reason, we call this second factor a "risk premium factor." When the volatility and risk premium factors are included with the consumption-wealth variable $c a y_{t}$, found elsewhere to predict quarterly stock returns (Lettau and Ludvigson, 2001a), the statistical model predicts an unusually high $16 \%$ of the variation in one-quarter-ahead excess returns. Moreover, the two factors on their own exhibit remarkably stable, strongly statistically significant out-of-sample forecasting power for quarterly excess returns that is found to be strongest in data after 1995, a period in which the predictive power of many traditional forecasting variables is exceptionally poor.

Second, in modeling the conditional volatility of excess stock market returns, we find one macroeconomic factor that, when combined with other predictor variables, is especially useful for forecasting stock market volatility. This factor is the first common factor from the macroeconomic data set, known to be a "real factor," since it is highly correlated with measures of real output and employment but not highly correlated with prices (Stock and Watson, 2002b).

Third, we find that distinguishing between the conditional correlation (conditional on lagged mean and lagged volatility) and unconditional correlation between the conditional mean stock return and its conditional volatility is crucial for understanding the empirical risk-return relation. This finding is consistent with that of Brandt and Kang (2004) who argue that the distinction could explain the disagreement in the literature about the contemporaneous correlation between risk and return. In contrast to some previous studies, however (e.g., Brandt and Kang, 2004; Lettau and Ludvigson, 2003) we find a positive conditional correlation that is strongly statistically significant, whereas the unconditional correlation is weakly negative and statistically insignificant. We show here that the findings in Lettau and Ludvigson (2003) can be attributed to the omission of the volatility and risk premium factors, which contain important information about onequarter-ahead returns.

Finally, our results imply that the conditional Sharpe ratio has an unmistakable countercyclical pattern, increasing sharply in recessions and declining at the onset of expansions. These findings are consistent with those in Brandt and Kang (2004) and Lettau and Ludvigson (2003).

The rest of this paper is organized as follows. In the next section we briefly review related literature. Section 3 lays out the econometric framework, discusses the use of principal components analysis to estimate common factors, and explains how factors are chosen for modeling the conditional mean and conditional volatility of stock returns. Section 4 explains the empirical implementation and describes the data. We move on in Section 5 to present our empirical findings, including the results of one quarter-ahead predictive 
relations and our results for the estimated risk-return relation. Two additional analyses are performed as robustness checks: out-of-sample investigations and small-sample inference. Section 6 concludes.

\section{Related literature}

Our empirical investigation is related to several disparate strands of economic literature. On the methodology side, our use of dynamic factor analysis is an application of statistical procedures developed elsewhere for cases in which both the number of economic time series used to construct common factors, $N$, and the number of time periods, $T$, are large and converge to infinity (Stock and Watson, 2002a, b; Bai and Ng, 2002, 2005). Dynamic factor analysis with large $N$ and large $T$ is preceded by a literature studying classical factor analysis when $N$ is relatively small and fixed but $T \rightarrow \infty$, and vice versa. Sargent and Sims (1977), Sargent (1989), and Stock and Watson (1989, 1991) use classical factor analysis with fixed $N$ and $T \rightarrow \infty$. Connor and Korajczyk $(1986,1988)$ pioneer the method of asymptotic principle components analysis when $T$ is fixed and $N \rightarrow \infty$.

The presumption of the dynamic factor model is that the covariation among economic time series is captured by a few unobserved common factors. Stock and Watson (2002b) show that consistent estimates of the space spanned by the common factors can be constructed by principal components analysis. Bai and $\mathrm{Ng}$ (2005) show that the least squares estimates from factor-augmented forecasting regressions are $\sqrt{T}$ consistent and asymptotically normal, and that pre-estimation of the factors does not affect the consistency of the second-stage parameter estimates. Stock and Watson (2002b, 2004) find that predictions of real economic activity and inflation are greatly improved relative to low-dimensional forecasting regressions when the forecasts are based on the estimated factors of large data sets. An added benefit of this approach, mentioned above, is that the use of common factors can provide robustness against the structural instability that plagues low-dimensional forecasting regressions. Stock and Watson (2002a) provide both theoretical arguments and empirical evidence that the principal components factor estimates are consistent even in the face of temporal instability in the individual time series used to construct the factors. The reason is that such instabilities can "average out" in the construction of common factors if the instability is sufficiently dissimilar from one series to the next.

Our use of realized volatility to model return volatility is motivated by recent findings in the volatility modeling literature. Andersen, Bollerslev, and Diebold (2002) and Andersen, Bollerslev, Diebold, and Labys (2003) argue that nonparametric volatility measures such as realized volatility benefit from being free of tightly parametric functional form assumptions and provide a consistent estimate of expost return variability. Realized volatility, in turn, permits the use of traditional time-series methods for modeling and forecasting, making possible the employment of estimated common factors from large data sets to measure conditional, or expected, volatility. Earlier studies of realized stock market volatility include French, Schwert, and Stambaugh (1987) and Schwert (1989).

Finally, our work is connected to a large literature examining the empirical relation between the conditional mean and conditional volatility of excess stock market returns. Bollerslev, Engle, and Wooldridge (1988), Harvey (1989), Campbell and Hentschel (1992), and Ghysels, Santa-Clara, and Valkanov (2005) find a positive risk-return relation, while Campbell (1987), Breen, Glosten, and Jagannathan (1989), Pagan and Hong (1991), 
Glosten, Jagannathan, and Runkle (1993), Whitelaw (1994), Lettau and Ludvigson (2003), and Brandt and Kang (2004) find a negative relation. French, Schwert, and Stambaugh (1987) find a negative relation between returns and the unpredictable component of volatility, a result they interpret as indirect evidence that ex ante volatility is positively related to ex ante excess returns. Campbell (1987), Harvey (1989), and Kandel and Stambaugh (1990) argue that the relation between the conditional mean and conditional volatility varies over time. Yet most of these studies use a small number of predetermined conditioning variables to form estimates of the conditional mean and the conditional volatility, potentially subjecting the findings to the omitted-information problems emphasized by Hansen and Richard (1987) and Harvey (2001). One study that does not rely on predetermined conditioning variables is Brandt and Kang (2004), in which the conditional mean and conditional volatility are modeled as latent state variables identified only from the history of return data. An advantage of this approach is that it eliminates the reliance on a few arbitrary conditioning variables in forming estimates of conditional moments. A corresponding disadvantage is that potentially useful information is discarded. Perhaps more important, even the latent state variable methodology is not immune to the general criticism of omitted information, since the latent variables must in practice be modeled as following low-order, linear time-series representations of known probability distribution. For example, Brandt and Kang assume that the conditional mean and conditional volatility evolveaccording to first-order Gaussian vector autoregressive processes. If the true representation is of higher order, nonlinear, or non-Gaussian, we again face an omitted-information problem.

\section{Econometric framework}

In this section we describe our econometric framework, which involves estimating common factors from large data sets of macroeconomic and financial information. As in previous work in financial economics (e.g., Connor and Korajczyk, 1986), estimation of factors is carried out using principal component analysis, a procedure that has also been implemented for forecasting measures of macroeconomic activity and inflation (e.g., Stock and Watson, 2002a, b, 2004). We refer the reader to those papers for a detailed description of this procedure; here we only outline how the implementation relates to our application.

The goal of our procedure is to estimate the conditional mean and conditional volatility of excess stock market returns and, ultimately, the relation between these two variables. For $t=1, \ldots, T$, let $m_{t+1}$ denote continuously compounded excess returns in period $t+1$ and let $V O L_{t+1}$ be an estimate of their volatility. The objective is to estimate $E_{t} m_{t+1}$, the conditional mean of $m_{t+1}$, and conditional volatility $E_{t} V O L_{t+1}$, using information up to time $t$. We confine ourselves to estimation of $E_{t} m_{t+1}$ and $E_{t} V O L_{t+1}$ using linear parametric models.

First consider estimation of the conditional mean $E_{t} m_{t+1}$. A standard approach is to select a set of $K$ predetermined conditioning variables at time $t$, given by the $K \times 1$ vector $Z_{t}$, and then estimate

$$
m_{t+1}=\beta^{\prime} Z_{t}+\varepsilon_{t+1}
$$

by least squares. The estimated conditional mean is then the fitted value from this regression, $\widehat{m}_{t+1 \mid t}=\hat{\beta}^{\prime} Z_{t}$. The issue at hand is whether we can go beyond (1) to make use of the substantially more information that is available to market participants. That is, 
suppose we observe a $T \times N$ panel of data with elements $x_{i t}, i=1, \ldots, N, t=1, \ldots, T$, where the cross-sectional dimension, $N$, is large, and possibly larger than the number of time periods, $T$. How to use this information is not immediately obvious because, unless we have a way of ordering the importance of the $N$ series in forming conditional expectations (as in an autoregression), there are potentially $2^{N}$ possible combinations to consider. Furthermore, with $x_{t}$ denoting the $N \times 1$ vector of panel observations at time $t$, estimates from the regression

$$
m_{t+1}=\gamma^{\prime} x_{t}+\beta^{\prime} Z_{t}+\varepsilon_{t+h}
$$

quickly run into degrees-of-freedom problems as the dimension of $x_{t}$ increases, and estimation is not even feasible when $N+K>T$.

The approach we consider is to posit that $x_{i t}$ has a factor structure taking the form

$$
x_{i t}=\lambda_{i}^{\prime} f_{t}+e_{i t},
$$

where $f_{t}$ is an $r \times 1$ vector of latent common factors, $\lambda_{i}$ is a corresponding $r \times 1$ vector of latent factor loadings, and $e_{i t}$ is a vector of idiosyncratic errors. ${ }^{1}$ The crucial point here is that $r \ll N$, so that substantial dimension reduction can be achieved by considering the regression

$$
m_{t+1}=\alpha^{\prime} F_{t}+\beta^{\prime} Z_{t}+\varepsilon_{t+1},
$$

where $F_{t} \subset f_{t}$. Eq. (1) is nested within the factor-augmented regression, making (3) a convenient framework to assess the importance of $x_{i t}$ via $F_{t}$, even in the presence of $Z_{t}$. But the distinction between $F_{t}$ and $f_{t}$ is important, because factors that are pervasive for the panel of data $x_{i t}$ need not be important for predicting $m_{t+1}$.

As common factors are not observed, we replace $f_{t}$ by $\widehat{f}_{t}$, estimates that, when $N, T \rightarrow \infty$, span the same space as $f_{t}$. (Since $f_{t}$ and $\lambda_{i}$ cannot be separately identified, the factors are only identifiable up to an $r \times r$ matrix.) In practice, the $f_{t}$ are estimated by principal components analysis. ${ }^{2}$ Let $\Lambda$ be the $N \times r$ matrix defined as $\Lambda \equiv\left(\lambda_{1}^{\prime}, \ldots, \lambda_{N}^{\prime}\right)^{\prime}$. Intuitively, the estimated time $t$ factors $\widehat{f}_{t}$ are linear combinations of each element of the $N \times 1$ vector $x_{t}=\left(x_{1 t}, \ldots, x_{N t}\right)^{\prime}$, where the linear combination is chosen optimally to minimize the sum of squared residuals $x_{t}-\Lambda f_{t}$.

To determine the composition of $\widehat{F}_{t}$, we form different subsets of $\widehat{f}_{t}$, and/or functions of $\widehat{f}_{t}$ (such as $\widehat{f}_{1 t}^{2}$ ). For each candidate set of factors, $\widehat{F}_{t}$, we regress $m_{t+1}$ on $\widehat{F}_{t}$ and $Z_{t}$ and evaluate the corresponding BIC and $\bar{R}^{2}$. Following Stock and Watson (2002b), minimizing the BIC yields the preferred set of factors $\widehat{F}_{t}$. The final model for returns is based on $Z_{t}$

\footnotetext{
${ }^{1}$ We consider an approximate dynamic factor structure, in which the idiosyncratic errors $e_{i t}$ are permitted to have a limited amount of cross-sectional correlation. The specification limits the contribution of the idiosyncratic covariances to the total variance of $x$ as $N$ gets large:

$$
N^{-1} \sum_{i=1}^{N} \sum_{j=1}^{N}\left|\mathrm{E}\left(e_{i t} e_{j t}\right)\right| \leqslant M
$$

${ }^{2}$ To be precise, the $T \times r$ matrix $\widehat{f}$ is $\sqrt{T}$ times the $r$ eigenvectors corresponding to the $r$ largest eigenvalues of the $T \times T$ matrix $x x^{\prime} /(T N)$ in decreasing order. Let $\Lambda$ be the $N \times r$ matrix of factor loadings $\left(\lambda_{1}^{\prime}, \ldots, \lambda_{N}^{\prime}\right)^{\prime} . \Lambda$ and $f$ are not separately identifiable, so the normalization $f^{\prime} f / T=I_{r}$ is imposed, where $I_{r}$ is the $r$-dimensional identity matrix. With this normalization, we can additionally obtain $\widehat{\Lambda}=x^{\prime} \widehat{f} / T$, and $\widehat{\chi}_{i t}=\widehat{\lambda}_{i}^{\prime} \widehat{f}_{t}$ denotes the estimated common component in series $i$ at time $t$. The number of common factors $r$ is determined by the panel information criteria developed in Bai and $\mathrm{Ng}$ (2002).
} 
plus this optimal $\widehat{F}_{t}$. That is,

$$
m_{t+1}=\alpha^{\prime} \widehat{F}_{t}+\beta^{\prime} Z_{t}+\varepsilon_{t+1}
$$

To conserve notation, we use $\widehat{F}_{t}$ to denote the factors used in the final model, but it should be understood that the components of $\widehat{F}_{t}$ are selected using formal statistical procedures. In what follows, we denote the fitted conditional mean

$$
\mu_{t} \equiv \widehat{m}_{t+1 \mid t}=\widehat{\alpha}^{\prime} \widehat{F}_{t}+\widehat{\beta}^{\prime} Z_{t} \text {. }
$$

Under the assumption that $N, T \rightarrow \infty$ with $\sqrt{T} / N \rightarrow 0$, Bai and $\mathrm{Ng}$ (2005) show that (i) $(\hat{\alpha}, \hat{\beta})$ obtained from least squares estimation of (4) are $\sqrt{T}$ consistent and asymptotically normal, and the asymptotic variance is such that inference can proceed as though $f_{t}$ is observed; (ii) the estimated conditional mean, $\mu_{t}=\widehat{F}_{t}^{\prime} \hat{\alpha}+Z_{t}^{\prime} \hat{\beta}$, is $\min [\sqrt{N}, \sqrt{T}]$ consistent and asymptotically normal, and (iii) the $h$ period forecast error $m_{t+h}-m_{t+h \mid t}$ from (4) is dominated in large samples by the variance of the error term, just as if $f_{t}$ is observed. The importance of a large $N$ must be stressed, however, as without it, the factor space cannot be consistently estimated however large $T$ becomes.

Given a measure, $V O L_{t}$, of the volatility of excess returns at time $t$, estimation of conditional volatility is carried out in the same way as estimation of the conditional mean, and the same asymptotic results for conducting inference apply. That is, we estimate a final model for volatility based on $Z_{t}$ plus an optimally chosen (by the BIC criterion) set of factors $\widehat{F}_{t}$,

$$
V O L_{t+1}=a^{\prime} \widehat{F}_{t}+b^{\prime} Z_{t}+u_{t+1},
$$

where it should be noted that the variables in $\widehat{F}_{t}$ and $Z_{t}$ can differ from those in (4). In what follows, we denote the fitted conditional volatility

$$
\sigma_{t} \equiv \widehat{V O L}_{t+1 \mid t}=\widehat{a}^{\prime} \widehat{F}_{t}+\widehat{b}^{\prime} Z_{t}
$$

Our analysis is based on quarterly data. To obtain a measure of quarterly volatility for excess returns, we follow French, Schwert, and Stambaugh (1987) and Schwert (1989) and use the time-series variation of daily returns:

$$
V O L_{t}=\sqrt{\sum_{k \in t}\left(R_{s k}-\bar{R}_{s}\right)^{2}},
$$

where $V O L_{t}$ is the sample volatility of the market return in quarter $t, R_{s k}$ is the daily return minus the implied daily yield on the three-month Treasury bill rate, $\bar{R}_{s}$ is the mean of $R_{s k}$ over the whole sample, and $k$ represents a day. Following Andersen, Bollerslev, and Diebold (2002) and Andersen, Bollerslev, Diebold, and Labys (2003), we call this measure realized volatility. Andersen, Bollerslev, Diebold, and Labys (2003) demonstrate, using the theory of quadratic variation, that realized volatility is an unbiased estimator of actual volatility and often performs better than parametric GARCH or stochastic volatility models at capturing volatility. Most important for our application, realized volatility permits us to use the estimated common factors from large data sets to model conditional volatility, by constructing these estimates as fitted values from statistical models of form (5).

The final aspect of our econometric framework is a reduced-form linear equation for the conditional mean as a function of the contemporaneous conditional volatility and lags of the two:

$$
\mu_{t}=\delta+\beta_{1} \sigma_{t}+\beta_{2} \sigma_{t-1}+\alpha \mu_{t-1}+\varepsilon_{t}
$$


This is a generalization of the more common volatility-in-mean model that relates the conditional mean to the conditional volatility of returns. Here, we follow Whitelaw (1994) and Brandt and Kang (2004) and include lags of $\mu_{t}$ and $\sigma_{t}$ in modeling the risk-return relation. Both Whitelaw and Brandt and Kang find important lead-lag interactions between the conditional mean and conditional volatility. Since Whitelaw uses a small number of exogenous predictors to model these moments, an important question is whether his results are specific to the exogenous predictors he used. The results of Brandt and Kang, who do not rely on exogenous predictors, suggest that this might not be the case, since some of their findings are similar. Our application provides further evidence on this question by exploiting a vast database of information in forming conditional moments. The coefficient $\beta_{1}$ measures the volatility-in-mean effect; the coefficient $\beta_{2}$ measures the lag-volatility-in-mean effect. ${ }^{3}$

Notice that, while our estimates of the risk-return relation will clearly depend on the fitted moments we construct, the combination of dynamic factor analysis applied to very large data sets, along with a robust statistical criterion for choosing parsimonious models of relevant factors and conditioning variables, makes our analysis less dependent than previous applications on only a handful of predetermined conditioning variables. The use of dynamic factor analysis allows us to entertain a much larger set of predictor variables than what has been entertained in previous applications, while the BIC criterion provides a means of choosing among summary factors and conditioning variables by indicating whether these variables have important additional explanatory power that should not be omitted in the construction of fitted moments.

Notice also that the procedure described above explicitly recognizes the possibility that the conditional mean might not be proportional to conditional volatility. If they were proportional, as in the capital asset pricing model of Sharpe (1964) and Lintner (1965), then any and all variation in the conditional mean excess return would be driven by variation in the conditional variance of the excess return. In this case the risk-return relation could be estimated by regressing ex post excess returns on a measure of ex ante volatility. But in more general models that produce countercyclical variation in the conditional Sharpe ratio $\mu_{t} / \sigma_{t}$, the conditional mean is not perfectly correlated with conditional volatility. ${ }^{4}$ This motivates our search for possibly distinct state variables to forecast mean and volatility, as well as our use of ex ante rather than ex post excess returns on the left-hand side of (7). Below, we estimate equations of the form (7) using either ordinary least squares (OLS) or two-stage least squares (2SLS), where in the latter we instrument for $\sigma_{t}$ with variables known at time $t-1$.

\section{Empirical implementation and data}

A detailed description of the data and our sources is given in the appendix. We study quarterly data. The continuously compounded excess return $m_{t+1}$ is the log return on the

${ }^{3}$ We have also studied an analogous mean-in-volatility equation taking the form

$$
\sigma_{t}=\delta+\alpha_{1} \mu_{t}+\alpha_{2} \mu_{t-1}+\beta \sigma_{t-1}+\xi_{t+1} .
$$

The empirical results lead to the same conclusions about the risk-return relation as the volatility-in-mean equation (7). We therefore omit those results to conserve space.

${ }^{4}$ The conditional Sharpe ratio varies over time if changing risk or risk aversion provide good descriptions of dynamic asset market behavior (e.g., Constantinides, 1990; Constantinides and Duffie, 1996; Campbell and Cochrane, 1999; Chang and Sundaresan, 1999). 
Center for Research in Security Prices (CRSP) value-weighted price index for NYSE, AMEX, and NASDAQ in excess of three-month Treasury bill rate. Our measure of volatility, $V O L_{t}$, from (6), uses the daily CRSP return minus the implied daily yield on the three-month Treasury bill rate.

We estimate two sets of factors from two quarterly post-war data sets, one comprising of 209 series of macroeconomic indicators, and one comprising of 172 series financial indicators, both spanning the first quarter of 1960 through the fourth quarter of 2002, denoted hereafter as 1960:1 to 2002:4. Following Stock and Watson (2002b, 2004), the macro series are selected to represent broad categories of macroeconomic time series: real output and income, employment and hours, real retail, manufacturing and trade sales, consumer spending, housing starts, inventories and inventory sales ratios, orders and unfilled orders, compensation and labor costs, capacity utilization measures, price indexes, and foreign exchange measures. The financial database consists of a broad number of indicators measuring the aggregate time-series behavior of the stock market as well as the behavior of a broad cross-section of asset returns. The data include valuation ratios such as the dividend-price ratio and the earnings-price ratio, growth rates of aggregate dividends and prices, default and term spreads, yields on corporate bonds of different ratings grades, yields on Treasuries and yield spreads, a broad cross-section of industry equity returns, returns on 100 portfolios of equities sorted into ten size and ten book-tomarket categories (Fama and French, 1992), and a group of variables we call "riskfactors," since they have been used in cross-sectional or time-series studies to uncover variation in the market risk premium. These risk factors include the three risk factors in Fama and French (1993), namely the excess return on the market $M K T_{t}$, the "smallminus-big" $\left(S M B_{t}\right)$ and "high-minus-low" $\left(H M L_{t}\right)$ portfolio returns, ${ }^{5}$ as well as the momentum factor $U M D_{t},{ }^{6}$ the consumption-wealth variable $c a y_{t}$ of Lettau and Ludvigson $(2001 \mathrm{a}),{ }^{7}$ the bond risk premia factor of Cochrane and Piazzesi (2005), ${ }^{8}$ and the small stock value spread $R 15-R 11 .{ }^{9}$ We also include the small-stock value spread as a risk-factor in the financial data set, the difference between returns in the smallest size/highest book-tomarket quintile and returns in the smallest size/lowest book-to-market quintile. Campbell and Voulteenaho (2005) use the small-stock value spread to predict monthly stock market returns. The complete list of series is given in the appendix, where for the macro variables a

\footnotetext{
${ }^{5} S M B$ is the difference between the returns on small and big stock portfolios with the same weighted-average book-to-market equity. $H M L$ is the difference between returns on high and low book-equity/market-equity portfolios with the same weighted-average size. Further details on these variables can be found in Fama and French (1993).

${ }^{6}$ This factor is available from Kenneth French's Dartmouth web page. It is created from portfolios, formed monthly, that are the intersections of two portfolios formed on size (market equity) and three portfolios formed on prior (2-12 month) return. UMD (Up Minus Down) is the average return on the two high prior return portfolios minus the average return on the two low prior return portfolios.

${ }^{7}$ The variable $c a y_{t}$ is measured as a cointegrating residual between log consumption, log asset wealth, and log labor income, all in real per capita terms. The presence of labor income accounts for the role of human capital in aggregate wealth; see Lettau and Ludvigson (2001a) for details.

${ }^{8}$ The bond risk factor is a linear combination of forward rates of different maturities, here measured as the quarterly average of monthly data.

${ }^{9}$ This variable is created from 25 size and book-to-market sorted portfolio returns taken from Kenneth French's Dartmouth web site, by subtracting the portfolio return in the smallest size and lowest book-to-market category $(R 11)$, from the return in the smallest size and highest book-to-market category $(R 15)$.
} 
coding system indicates how the data are transformed to insure stationarity. All of the raw data in $x_{t}$ are standardized prior to estimation.

Since we decompose our time-series information into two panel data sets, we postulate two factor structures of the form (2) above. For the macro data set, we follow the notation introduced above. That is, we denote the estimated factors formed from the macro data set as $\widehat{f}_{i t,}, i=1, \ldots, r_{f}$, where $r_{f}$ is the number of common factors for the macro data set and $\widehat{f}_{t}$ is an $r_{f} \times 1$ vector of these latent common factors. The subset $\widehat{F}_{t} \subset \widehat{f}_{t}$ comprises those estimated factors from the macro data set that are used in modeling fitted mean and fitted volatility. To distinguish the factors estimated from the financial data set from these macro factors, we introduce a new notation for financial factors that is directly analogous to the notation for macro factors. Denote the estimated factors formed from the financial data set $\widehat{g}_{i t}, i=1, \ldots, r_{g}$, where $r_{g}$ is the number of common factors for the financial data set and $\widehat{g}_{t}$ is an $r_{g} \times 1$ vector of these latent common factors. The subset $\widehat{G}_{t} \subset \widehat{g}_{t}$ comprises those estimated factors from the financial data set that are used in modeling fitted mean and fitted volatility. We then form estimates of the conditional mean and conditional volatility by computing the fitted values from regressions of mean and volatility on both sets of factors:

$$
m_{t+1}=\alpha_{1}^{\prime} \widehat{F}_{t}+\alpha_{2}^{\prime} \widehat{G}_{t}+\beta^{\prime} Z_{t}+\varepsilon_{t+1},
$$

and

$$
V O L_{t+1}=a_{1}^{\prime} \widehat{F}_{t}+a_{2}^{\prime} \widehat{G}_{t}+b^{\prime} Z_{t}+u_{t+1},
$$

where, as described above, minimizing the BIC over models with different combinations of the variables in $\widehat{F}_{t}, \widehat{G}_{t}$, and $Z_{t}$ yields the preferred specification. Notice that, in using the BIC criterion to choose the best model, we include many of the predictors used elsewhere to forecast returns or volatility both in the set of financial data used to estimate the factors $\widehat{G}_{t}$ and in the set of possible independent predictors, $Z_{t}$. This permits us to assess the extent to which the factors contain information independent of that contained in commonly used predictive variables.

In estimating the time- $t$ common factors, we face a decision as to how much of the timeseries dimension of the panel to use. We use the full sample of time-series information to estimate the common factors at each date $t$, instead of using data only up to date $t$ (recursive estimates). This approach can be thought of as providing smoothed estimates of the latent factors, and ultimately smoothed estimates of $\mu_{t}$ and $\sigma_{t}$, as in Brandt and Kang (2004). ${ }^{10}$ The advantage of this approach over recursive information is that estimates of $f_{t}$ are available for the entire sample $t=1, \ldots, T .{ }^{11}$ More important, smoothed estimates of the latent factors, $f_{t}$, are the most efficient means of summarizing the covariation in the data $x$ because the estimates do not discard information in the sample. Exploiting this efficiency is appropriate for our application, since we are not interested in real-time forecasting per se, but rather in an accurate estimate of the population risk-return relation.

\footnotetext{
${ }^{10}$ The same smoothed estimate approach is taken in Bernanke et al. (2005), who use common factor analysis to summarize the information in the Federal Reserve's time- $t$ policy reaction function.

${ }^{11}$ Recursive estimates would significantly restrict the sample over which we could obtain observations on $\mu_{t}$ and $\sigma_{t}$. Recursive estimation requires estimation of (8) and (9) over some initial number, $R$, of observations of our full data set, with fitted values formed over the remaining $T-R$ observations, using one-step-ahead recursive regressions. Thus, observations on $\mu_{t}$ and $\sigma_{t}$ would be available only over the last $T-R$ periods of our sample rather than over the full sample.
} 
We do, however, assess the robustness of our forecasting results relative to an out-ofsample investigation in which the predictive factors are reestimated recursively each period using data only up to time $t$. A description of this procedure is given below.

In estimating (8) and (9), a question also arises as to what variables should be included in $Z_{t}$. The empirical asset pricing literature has uncovered a number of variables that have been shown, in one sample or another, to contain predictive power for excess stock returns. Shiller (1981), Fama and French (1988), Campbell and Shiller (1989), Campbell (1991), and Hodrick (1992) find that the ratios of price to dividends or earnings have predictive power for U.S. excess returns, and Harvey (1991) finds that similar financial ratios predict stock returns in many different countries. Thus we often include the dividend-price ratio in $Z_{t}$ (results using the earnings-price ratio are similar). Campbell (1991) and Hodrick (1992) find that the relative $\mathrm{T}$-bill rate (the 30 -day $\mathrm{T}$-bill rate minus its 12 -month moving average) predicts returns, thus we often include a quarterly version of it (the three-month Treasury bill rate minus its four-quarter moving average) in $Z_{t}$; denote this variable $R R E L_{t}$. Fama and French (1988) study the forecasting power of the term spread (the 10-year Treasury bond yield minus the 1-year Treasury bond yield) and the default spread (the difference between the BAA and AAA corporate bond rates). Thus, we also consider specifications in which these variables, denoted $T R M_{t}$ and $D E F_{t}$, respectively, are part of $Z_{t}$. Lettau and Ludvigson (2001a) find that the consumption-wealth variable $c a y_{t}$ is a strong predictor of quarterly excess returns, and Lettau and Ludvigson (2001b) find that it is a predictor of portfolio returns, therefore we include this variable in some specifications of $Z_{t}$. Finally, in addition to several of the variables already discussed, Whitelaw (1994) finds that the 1-year Treasury yield, YIELD $D_{t}$, has predictive power for volatility at both monthly and quarterly horizons.

\section{Empirical results}

Table 1 presents summary statistics for our estimated factors $\widehat{f}_{t}$ and $\widehat{g}_{t}$. The number of factors, $r_{f}$, and $r_{g}$, is determined by the information criteria developed in Bai and $\mathrm{Ng}$ (2002). The criteria indicate that the factor structures of both data sets are well described by eight common factors. The first factor explains the largest fraction of the total variation in the panel of data $x$, where total variation is measured as the sum of the variances of the individual $x_{i t}$. The second factor explains the largest fraction of variation in $x$, controlling for the first factor, and so on, where the estimated factors are mutually orthogonal by construction. Table 1 reports the fraction of variation in the data explained by factors 1 to $i$, This is given as the sum of the first $i$ largest eigenvalues of the matrix $x x^{\prime}$ divided by the sum of all eigenvalues. Table 1 shows that a small number of factors account for much of the variance in the two panel data sets we explore. The first five common factors of the macro data set account for almost $60 \%$ of the variation in the macroeconomic series, and the first five factors of the financial data set account for almost $80 \%$ of the variability in the financial series.

To give an idea of the persistence of the estimated factors, Table 1 also displays the firstorder autoregressive (AR(1)) coefficient for each factor. None of the factors have a persistence greater than 0.85 , but there is considerable heterogeneity across estimated factors, with coefficients ranging from slightly negative (first factor of the financial data set) to positive in excess of 0.8 (the second factor of both data sets). 
Table 1

Summary statistics for $\widehat{f}_{i t}$ and $\widehat{g}_{i t}$

\begin{tabular}{|c|c|c|c|c|}
\hline$i$ & $\operatorname{AR} 1\left(\widehat{f}_{i t}\right)$ & $R_{i}^{2}$ & $\operatorname{AR} 1\left(\widehat{g}_{i t}\right)$ & $R_{i}^{2}$ \\
\hline 1 & 0.672 & 0.245 & -0.032 & 0.657 \\
\hline 2 & 0.803 & 0.432 & 0.845 & 0.700 \\
\hline 3 & 0.550 & 0.500 & 0.166 & 0.739 \\
\hline 4 & 0.165 & 0.539 & 0.284 & 0.774 \\
\hline 5 & -0.028 & 0.569 & 0.762 & 0.792 \\
\hline 6 & 0.152 & 0.594 & 0.492 & 0.807 \\
\hline 7 & 0.088 & 0.617 & 0.428 & 0.820 \\
\hline 8 & -0.284 & 0.649 & 0.262 & 0.831 \\
\hline
\end{tabular}

For $i=1, \ldots 8, \widehat{f}_{i t}$ is estimated by the method of principal components using a panel of data with 209 indicators of economic activity from $t=1960: 1-2002: 4$ (172 time series observations). The data are transformed (taking logs and differenced where appropriate) and standardized prior to estimation. $\widehat{g}_{i t}$ is estimated using a panel of 159 series consisting primarily of financial data. AR1 $\left(F_{i t}\right)$, AR $1\left(\widehat{g}_{i t}\right)$ are the first order autocorrelation coefficients for factors $i$. The relative importance of the common component, $R_{i}^{2}$, is calculated as the fraction of total variance in the data explained by factors 1 to $i$.

As mentioned, we formally choose among a range of possible specifications for the conditional mean and conditional volatility using these variables and the estimated common factors (and possibly nonlinear functions of those factors such as $\widehat{f}_{1 t}^{2}$ ) using the BIC criterion. Given the large number of possible specifications, we report only the subset of those specifications analyzed that are most interesting. Specifications that include lagged values of the factors beyond the first were also examined, but additional lags were found to contain very little information for either returns or volatility that was not already contained in the one-period lag specifications. We present the results next.

\subsection{One-quarter-ahead predictive regressions}

Tables 2 and 3 present results from estimating various specifications for models (8) and (9). For each specification, the regression coefficient, heteroskedasticity and serialcorrelation robust $t$ statistics, the adjusted $R^{2}$ statistic, and BIC criterion are reported.

We begin with the results in Table 2, predictive regressions for excess returns. As benchmarks, Columns $a$ through $d$ of Table 2 report the results of specifications for forecasting one-quarter-ahead excess returns, without including any estimated factors. Column $a$ shows that the consumption-wealth variable $c a y_{t}$ is a strong predictor of quarterly excess returns, explaining $8 \%$ of the variation in one-quarter-ahead returns with a $t$-statistic in excess of four. These results are essentially the same as those reported in Lettau and Ludvigson (2001a). Unlike studies using older data, however, the dividend-price ratio displays little predictive ability for future returns in this sample (Column $b$ ). It is well known that data from the 1990s have substantially weakened the forecasting power of the dividend-price ratio for returns. Columns $c$ and $d$ include lagged realized volatility $V O L_{t}$ as an additional predictor, along with $c a y_{t}$ and $R R E L_{t}$. All three variables have marginal predictive power and together explain $12 \%$ of the variation in next quarter's return. This is consistent with the findings of Guo (2005), who reports that predictive regressions that include $c a y_{t}$ along with a measure of aggregate stock market 
volatility as predictor variables exhibit strong out-of-sample forecasting power for quarterly excess returns. However, there is little evidence that either the term spread $T R M_{t}$ or the default spread $D E F_{t}$ have important predictive power for returns, as studies using previous samples of data have found.

The remaining columns of Table 2 include estimated common factors as predictive variables, in addition to several of the exogenous predictors discussed above. Column $e$

Table 2

Regressions of quarterly excess returns on lagged conditioning variables and factors

\begin{tabular}{|c|c|c|c|c|c|c|c|c|c|c|c|}
\hline \multicolumn{12}{|c|}{ Model: $m_{t+1}=\alpha_{0}+\alpha_{1}^{\prime} \widehat{F}_{t}+\alpha_{2}^{\prime} \widehat{G}_{t}+\beta^{\prime} Z_{t}+\varepsilon_{t+1}$} \\
\hline Row & \multicolumn{2}{|c|}{ Regressor } & (a) & \multicolumn{2}{|c|}{ (b) } & (c) & \multicolumn{2}{|c|}{$(d)$} & \multicolumn{2}{|l|}{ (e) } & $(f)$ \\
\hline 1 & \multicolumn{2}{|c|}{$\begin{array}{c}c a y_{t} \\
(t \text {-stat })\end{array}$} & $\begin{array}{c}\mathbf{1 . 9 8} \\
(4.01)\end{array}$ & & & $\begin{array}{c}\mathbf{2 . 0 9} \\
(4.52)\end{array}$ & \multicolumn{2}{|c|}{$\begin{array}{c}\mathbf{2 . 1 5} \\
(4.22)\end{array}$} & & & $\begin{array}{c}\mathbf{1 . 4 6} \\
(2.35)\end{array}$ \\
\hline 2 & \multicolumn{2}{|c|}{$\begin{array}{c}d_{t}-p_{t} \\
(t \text {-stat })\end{array}$} & & \multicolumn{2}{|c|}{$\begin{array}{c}0.03 \\
(1.62)\end{array}$} & & \multicolumn{2}{|c|}{$\begin{array}{c}0.00 \\
(0.89)\end{array}$} & & & \\
\hline 3 & \multicolumn{2}{|c|}{$\begin{array}{l}R R E L_{t} \\
(t \text {-stat })\end{array}$} & & & & $\begin{array}{c}-\mathbf{5 . 8 7} \\
(-2.29)\end{array}$ & \multicolumn{2}{|c|}{$\begin{array}{l}-7.31 \\
(-2.47)\end{array}$} & & & $\begin{array}{l}-3.84 \\
(-1.58)\end{array}$ \\
\hline 4 & \multicolumn{2}{|c|}{$\begin{array}{c}V O L_{t} \\
(t \text {-stat })\end{array}$} & & & & $\begin{array}{c}\mathbf{0 . 4 4} \\
(2.18)\end{array}$ & \multicolumn{2}{|c|}{$\begin{array}{c}\mathbf{0 . 4 4} \\
(2.21)\end{array}$} & & & $\begin{array}{c}\mathbf{0 . 4 6} \\
(2.51)\end{array}$ \\
\hline 5 & \multicolumn{2}{|c|}{$\begin{array}{c}D E F_{t} \\
(t \text {-stat })\end{array}$} & & & & & \multicolumn{2}{|c|}{$\begin{array}{c}0.64 \\
(0.11)\end{array}$} & & & \\
\hline 6 & \multicolumn{2}{|c|}{$\begin{array}{l}T R M_{t} \\
(t \text {-stat })\end{array}$} & & & & & \multicolumn{2}{|c|}{$\begin{array}{l}-2.12 \\
(-0.61)\end{array}$} & & & \\
\hline 7 & \multicolumn{2}{|c|}{$\begin{array}{c}\widehat{F}_{2 t} \\
(t \text {-stat })\end{array}$} & & & & & & & $\begin{array}{c}-\mathbf{0 . 0 2} \\
(-2.89)\end{array}$ & & $\begin{array}{l}-0.01 \\
(-1.44)\end{array}$ \\
\hline 8 & \multicolumn{2}{|c|}{$\begin{array}{c}\widehat{F}_{5 t} \\
(t \text {-stat })\end{array}$} & & & & & & & $\begin{array}{c}\mathbf{0 . 0 1} \\
(-3.00)\end{array}$ & & $\begin{array}{c}0.01 \\
(1.34)\end{array}$ \\
\hline 9 & \multicolumn{2}{|c|}{$\underset{(t \text {-stat })}{\widehat{G}_{3 t}}$} & & & & & & & $\begin{array}{c}\mathbf{0 . 0 2} \\
(3.44)\end{array}$ & & $\begin{array}{c}\mathbf{0 . 0 2} \\
(2.95)\end{array}$ \\
\hline 10 & \multicolumn{2}{|c|}{$\begin{array}{c}\widehat{G}_{6 t} \\
(t \text {-stat })\end{array}$} & & & & & & & $\begin{array}{c}-\mathbf{0 . 0 1} \\
(-2.70)\end{array}$ & & $\begin{array}{c}-0.01 \\
(-1.29)\end{array}$ \\
\hline 11 & \multirow{2}{*}{\multicolumn{2}{|c|}{$\begin{array}{c}\bar{R}^{2} \\
\text { BIC }\end{array}$}} & 0.08 & \multirow{2}{*}{\multicolumn{2}{|c|}{$\begin{array}{r}0.01 \\
-2.00\end{array}$}} & 0.12 & \multicolumn{2}{|c|}{0.11} & 0.11 & & 0.15 \\
\hline 12 & & & -2.07 & & & -2.06 & \multicolumn{2}{|c|}{-2.01} & -2.03 & & -2.01 \\
\hline \multicolumn{12}{|c|}{ Model: $m_{t+1}=\alpha_{0}+\alpha_{1}^{\prime} \widehat{F}_{t}+\alpha_{2}^{\prime} \widehat{G}_{t}+\beta^{\prime} Z_{t}+\varepsilon_{t+1}$} \\
\hline Row & Regressor & $(g)$ & (h) & (i) & (j) & $(k)$ & $(l)$ & $(m)$ & (n) & $(o)$ & $(p)$ \\
\hline 13 & $\begin{array}{c}\text { cay }_{t} \\
(t \text {-stat })\end{array}$ & & & $\begin{array}{c}\mathbf{1 . 7 0} \\
(3.20)\end{array}$ & & $\begin{array}{c}\mathbf{1 . 8 4} \\
(4.04)\end{array}$ & $\begin{array}{c}1.59 \\
(3.50)\end{array}$ & $\begin{array}{l}\mathbf{1 . 7 9} \\
(4.00)\end{array}$ & $\begin{array}{l}\mathbf{1 . 6 4} \\
(3.48)\end{array}$ & $\begin{array}{c}\mathbf{1 . 8 1} \\
(3.89)\end{array}$ & $\begin{array}{c}\mathbf{1 . 8 2} \\
(3.94)\end{array}$ \\
\hline 14 & $\begin{array}{l}R R E L_{t} \\
(t \text {-stat })\end{array}$ & & & $\begin{array}{c}\mathbf{- 5 . 5 9} \\
(-2.27)\end{array}$ & & $\begin{array}{c}-\mathbf{5 . 4 0} \\
(-2.26)\end{array}$ & $\begin{array}{l}-4.95 \\
(-2.02)\end{array}$ & $\begin{array}{l}-\mathbf{5 . 4 2} \\
(-2.28)\end{array}$ & & & \\
\hline 15 & $\begin{array}{c}V O L_{t} \\
(t \text {-stat })\end{array}$ & & & $\begin{array}{c}0.19 \\
(0.79)\end{array}$ & & $\begin{array}{c}0.14 \\
(0.60)\end{array}$ & & & & & \\
\hline 16 & $\begin{array}{c}\widehat{G}_{1 t}^{2} \\
(t \text {-stat })\end{array}$ & $\begin{array}{c}\mathbf{0 . 0 1} \\
(4.11)\end{array}$ & $\begin{array}{c}\mathbf{0 . 0 1} \\
(4.06)\end{array}$ & $\begin{array}{c}\mathbf{0 . 0 1} \\
(2.02)\end{array}$ & $\begin{array}{c}\mathbf{0 . 0 1} \\
(3.73)\end{array}$ & $\begin{array}{c}\mathbf{0 . 0 1} \\
(2.15)\end{array}$ & $\begin{array}{c}\mathbf{0 . 0 1} \\
(3.35)\end{array}$ & $\begin{array}{l}\mathbf{0 . 0 1} \\
(3.68)\end{array}$ & $\begin{array}{l}\mathbf{0 . 0 1} \\
(3.57)\end{array}$ & $\begin{array}{c}\mathbf{0 . 0 1} \\
(3.86)\end{array}$ & $\begin{array}{c}\mathbf{0 . 0 1} \\
(3.88)\end{array}$ \\
\hline 17 & $\underset{(t \text {-stat })}{\widehat{G}_{3 t}}$ & $\begin{array}{c}\mathbf{0 . 0 2} \\
(3.73)\end{array}$ & $\begin{array}{c}\mathbf{0 . 0 2} \\
(3.78)\end{array}$ & $\begin{array}{c}\mathbf{0 . 0 2} \\
(3.11)\end{array}$ & $\begin{array}{c}\mathbf{0 . 0 2} \\
(3.40)\end{array}$ & $\begin{array}{c}\mathbf{0 . 0 2} \\
(3.04)\end{array}$ & $\begin{array}{c}\mathbf{0 . 0 2} \\
(2.86)\end{array}$ & $\begin{array}{l}\mathbf{0 . 0 2} \\
(3.11)\end{array}$ & $\begin{array}{l}\mathbf{0 . 0 2} \\
(2.90)\end{array}$ & $\begin{array}{c}\mathbf{0 . 0 2} \\
(3.09)\end{array}$ & $\begin{array}{c}\mathbf{0 . 0 2} \\
(3.13)\end{array}$ \\
\hline
\end{tabular}


Table 2 (continued)

Model: $m_{t+1}=\alpha_{0}+\alpha_{1}^{\prime} \widehat{F}_{t}+\alpha_{2}^{\prime} \widehat{G}_{t}+\beta^{\prime} Z_{t}+\varepsilon_{t+1}$

\begin{tabular}{cccccccccccc}
\hline Row & Regressor & $(g)$ & $(h)$ & $(i)$ & $(j)$ & $(k)$ & $(l)$ & $(m)$ & $(n)$ & $(o)$ & $(p)$ \\
\hline \multirow{2}{*}{18} & $\widehat{G}_{6 t}$ & & $-\mathbf{0 . 0 1}$ & -0.01 & & & & & & & \\
& $(t$-stat $)$ & & $(-2.44)$ & $(-0.82)$ & & & & & & & \\
19 & $\widehat{G}_{3 t} \cdot \widehat{G}_{4 t}$ & & & & $\mathbf{0 . 0 1}$ & & $\mathbf{0 . 0 1}$ & & $\mathbf{0 . 0 1}$ & & \\
& $(t$-stat $)$ & & & & $(3.77)$ & & $(2.63)$ & & $(2.80)$ & & \\
20 & $\widehat{F}_{3 t} \cdot \widehat{F}_{6 t}$ & & & & & & 0.00 & & & 0.00 & \\
& $(t$-stat $)$ & & & & & & $(0.58)$ & & $(0.67)$ & \\
21 & $\bar{R}^{2}$ & 0.09 & 0.10 & 0.16 & 0.12 & 0.16 & 0.18 & 0.17 & 0.17 & 0.17 & 0.16 \\
22 & BIC & -2.06 & -2.05 & -2.04 & -2.07 & -2.07 & -2.06 & -2.10 & -2.10 & -2.10 & -2.11 \\
\hline
\end{tabular}

Notes: The table reports estimates from OLS regressions of excess stock returns on lagged variables named in column 2. The dependent variable $m_{t+1}$ is the log return on the CRSP value-weighted stock market index over the three-month Treasury-bill rate. The regressors $\widehat{F}_{i t}$ and $\widehat{G}_{i t}$ are estimated by the method of principal components using a panel of data with 209 and 159 individual series, respectively, over the period 1960:1-2002:4. $\widehat{F}_{i t}$ are constructed from a panel of data on economic activity, $\widehat{G}_{i t}$ from a panel of data on .nancial returns. The exogenous conditioning variables in $Z_{t}$ are $c a y_{t}$, the consumption-wealth variable of Lettau and Ludvigson (2001), $d_{t}-p_{t}$ the CRSP $\log$ dividend-price ratio, $R R E L_{t}$, the yield on the 3-month Treasury bill rate minus its 4 quarter moving average, $D E F_{t}$, the BAA corporate bond rate minus the AAA corporate bond rate, $T R M_{t}$, the difference between the 10-year Treasury bond yield and the 3-month Treasury bill yield. Newey and West (1987) corrected $t$-statistics are reported in parentheses. Coefficients that are statistically significant at the $5 \%$ level are highlighted in bold. A constant is always included in the regression even though its estimate is not reported in the Table. The sample spans the period from the first quarter of 1960 to the fourth quarter of 2002.

shows that several factors have marginal predictive power for returns when included without non-factor predictor variables. But much of the information about future returns that is contained in these factors is subsumed by $c a y_{t}$ and $V O L_{t}($ Column $f$ ). The exception is the third estimated factor from the financial database $\widehat{G}_{3 t}$, which has statistically significant predictive power beyond that contained in $c a y_{t}$ and $V O L_{t}$.

A number of specifications using various polynomial bases of the estimated factors are also considered. Two factors in particular stand out as containing important information about future returns that is not already contained in commonly used predictor variables. These are the square of the first estimated factor from the financial database, $\widehat{G}_{1 t}^{2}$, and the third estimated factor $\widehat{G}_{3 t}$ from the financial database. Column $g$ shows that these two factors alone explain an unusual $9 \%$ of next quarter's excess return, and they retain their marginal predictive power no matter what other commonly used predictor variables are included in the regression. The information in these two factors is largely independent of that in the consumption-wealth variable $c a y_{t}$. Thus, when combined with $c a y_{t}$, the regression model explains $16 \%$ of one-quarter-ahead excess stock market returns, achieving the lowest BIC criterion of all the models studied. In addition to these two factors, the product of the third and fourth estimated factors from the financial database, and the product of the third and sixth estimated factors from the macro database, contain information about future returns that is not already contained in any of $\widehat{G}_{1 t}^{2}, \widehat{G}_{3 t}, R R E L_{t}$ or $\operatorname{cay}_{t}($ Column $l$ ). This statistical model explains a striking $19 \%$ of one-quarter-ahead excess returns, but the BIC criterion gives a higher penalty for the additional variables. As a 
Table 3

Regressions of quarterly volatility on lagged conditioning variables and factors

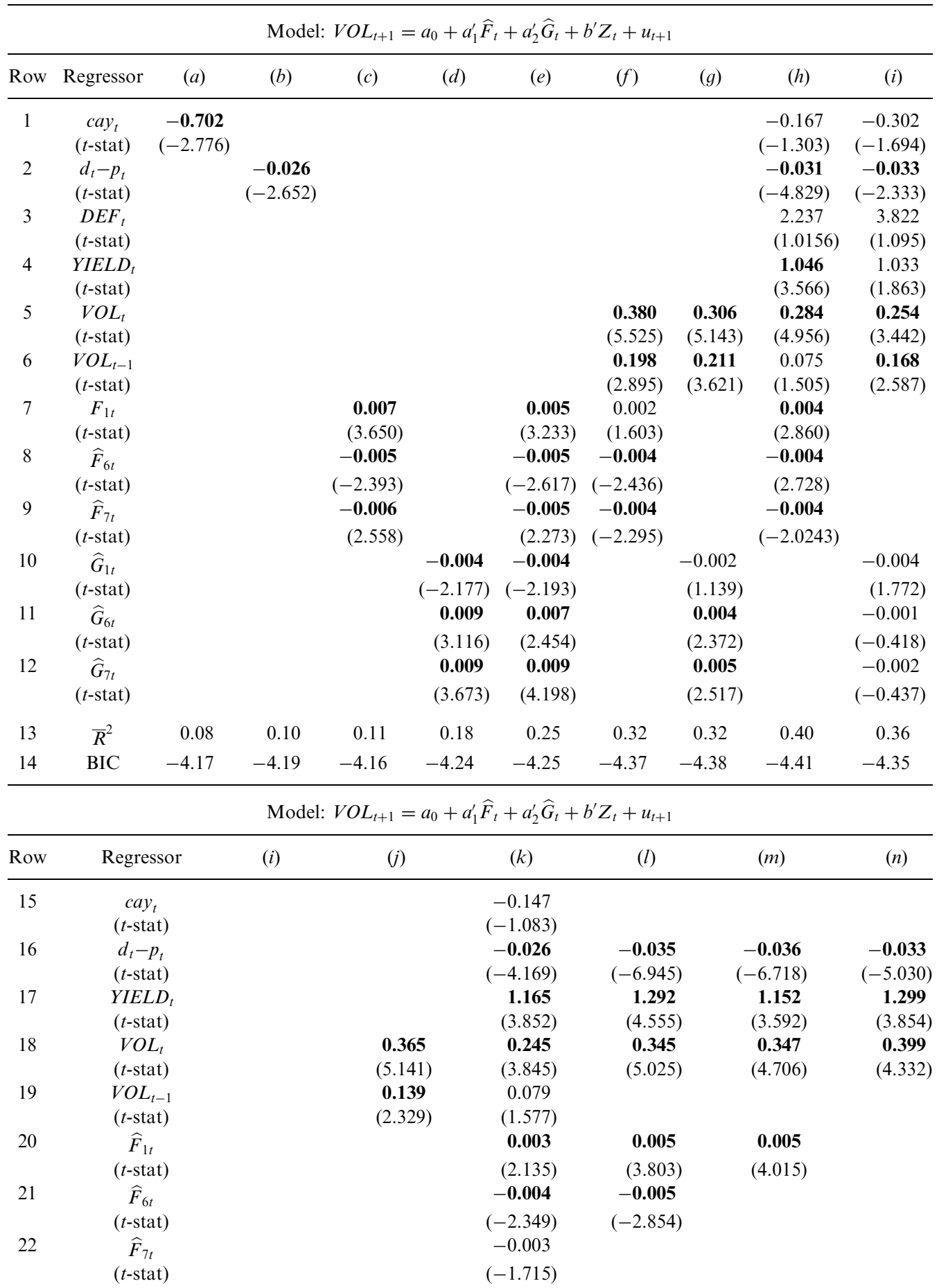


Table 3 (continued)

\begin{tabular}{cccccccr}
\hline \multicolumn{7}{c}{ Model: $V O L_{t+1}=a_{0}+a_{1}^{\prime} \widehat{F}_{t}+a_{2}^{\prime} \widehat{G}_{t}+b^{\prime} Z_{t}+u_{t+1}$} \\
\hline Row & Regressor & $(i)$ & $(j)$ & $(k)$ & $(l)$ & $(m)$ & $(n)$ \\
\hline 23 & $\widehat{G}_{1 t}^{2}$ & $\mathbf{0 . 0 0 2}$ & -0.001 & 0.000 & & & \\
& $(t$-stat) & $(2.525)$ & $(-1.407)$ & $(0.176)$ & & & \\
24 & $\widehat{G}_{2 t} \cdot \widehat{G}_{7 t}$ & $-\mathbf{0 . 0 0 6}$ & $-\mathbf{0 . 0 0 4}$ & -0.001 & & & \\
& $(t$-stat) & $(-6.192)$ & $(-5.053)$ & $(-1.285)$ & & & \\
25 & $\widehat{G}_{3 t}^{2}$ & $\mathbf{0 . 0 0 5}$ & $\mathbf{0 . 0 0 3}$ & $\mathbf{0 . 0 0 2}$ & & & \\
& $(t$-stat $)$ & $(4.892)$ & $(2.662)$ & $(2.545)$ & & & \\
26 & $\widehat{G}_{5 t} \cdot \widehat{G}_{7 t}$ & $\mathbf{0 . 0 1 0}$ & $\mathbf{0 . 0 0 7}$ & $\mathbf{0 . 0 0 4}$ & & & \\
& $(t$-stat $)$ & $(3.023)$ & $(2.628)$ & $(1.982)$ & & & \\
27 & $\bar{R}^{2}$ & 0.25 & 0.35 & 0.41 & 0.39 & 0.37 & -4.48 \\
28 & BIC & -4.30 & -4.40 & -4.35 & -4.49 & -4.48 & \\
\hline
\end{tabular}

Notes: The table reports estimates from OLS regressions of excess stock returns on lagged variables named in the column 2. The dependent variable $V O L_{t+1}$ is realized volatility for the CRSP value-weighted stock market index. The regressors $\widehat{F}_{i t}$ and $\widehat{G}_{i t}$ are estimated by the method of principal components using a panel of data with 209 and 159 individual series, respectively, over the period of 1960:1-2002:4. $\widehat{F}_{i t}$ are constructed from a panel of data on economic activity, $\widehat{G}_{i t}$ from a panel of data on financial returns. The exogenous conditioning variables in $Z_{t}$ are $c a y_{t}$, the consumption-wealth variable of Lettau and Ludvigson (2001); $d_{t}-p_{t}$ the CRSP log dividend-price ratio $D F F_{t}$; the BAA corporate bond rate minus the AAA corporate bond rate YIELD $D_{t}$; the one year Treasury bill yield. Newey and West (1987) corrected $t$-statistics are reported in parentheses. Coefficients that are statistically significant at the $5 \%$ level are given in italics. A constant is always included in the regression even though its estimate is not reported in the table. The sample spans the period from the first quarter of 1960 to the fourth quarter of 2002.

consequence, the model ranks lower than the more parsimonious three-factor specification that includes only $c a y_{t}, \widehat{G}_{1 t}^{2}$, and $\widehat{G}_{3 t}$. By contrast, a four-factor specification that includes cay $_{t}, \widehat{G}_{1 t}^{2}, \widehat{G}_{3 t}$, and the product $\widehat{F}_{3 t} \cdot \widehat{F}_{6 t}$ has a BIC statistic that is almost as small as the three-factor specification $(-2.10$ versus -2.11$)$ but an $\bar{R}^{2}$ that is slightly higher $(0.17$ versus $0.16)$. We thus consider both statistical models of future returns when forming estimates of $\mu_{t}$ below.

A similar analysis is conducted for stock market volatility, with results reported in Table 3. Column $a$ of Table 3 shows that $c a y_{t}$ has predictive power for quarterly volatility, as found in Lettau and Ludvigson (2003), explaining about 8\% of one-quarter-ahead volatility. The dividend-price ratio also has predictive power for future volatility, explaining $10 \%$ of one-quarter-ahead volatility. The predictive coefficients in the volatility equation are both negative for $c a y_{t}$ and $d_{t}-p_{t}$. Since these variables are positively related with future returns, the finding that they are negatively related with future volatility could at first suggest that the conditional mean is negatively correlated with conditional volatility. However, as we shall see, such a conclusion ignores the information contained in the estimated factors for future returns and future volatility. We show below that this information is important for properly identifying the risk-return relation.

Table 3 shows that a number of estimated common factors contain information about future volatility. The factors $\widehat{F}_{1 t}, \widehat{F}_{6 t}$, and $\widehat{F}_{7 t}$ together explain about $11 \%$ of one-quarter ahead volatility (Column $c$ ), and $\widehat{G}_{1 t}, \widehat{G}_{6 t}$ and $\widehat{G}_{7 t}$ explain about $18 \%$ of one-quarter-ahead 
volatility (Column $d$ ). All six together explain $25 \%$ of one-quarter ahead volatility. Of course, stock market volatility is known to be persistent, and its lags explain a large fraction of future volatility. This can be seen in the results reported in Columns $f$ through $n$ where one- and sometimes two-period lagged volatility is shown to be strongly statistically significant and their inclusion increases the adjusted $R$-squared statistic considerably. Columns $h$ and $i$ include the estimated common factors of Columns $c$ and $d$, respectively, along with a number of other variables used elsewhere to predict volatility: $c a y_{t}, d_{t}-p_{t}$, $D E F_{t}, Y I E L D_{t}$, and lagged volatility. The estimated factors $\widehat{G}_{1 t}, \widehat{G}_{6 t}$, and $\widehat{G}_{7 t}$ appear to contain much of the same information contained in these other predictor variables, as they no longer have marginal predictive power when included along with the other predictors. $c a y_{t}, D E F_{t}$, and $Y I E L D_{t}$ are also driven out of the regression that includes all the variables mentioned above, including the factors. By contrast, the factors constructed from the macro data set $\widehat{F}_{1 t}, \widehat{F}_{6 t}$, and $\widehat{F}_{7 t}$ retain marginal predictive power, while $c a y_{t}$ and $D E F_{t}$ are never important once these factors and the dividend-price ratio are included. The last six columns of Table 3 show that a number of nonlinear functions of estimated factors also contain information about future volatility. In some cases, however, the information is largely common to that in the dividend yield or the 1-year Treasury bill rate, and the best specifications according to the BIC criterion contain just $\widehat{F}_{1 t}$ and $\widehat{F}_{6 t}$, along with $d_{t}-p_{t}$, $Y I E L D_{t}$, and $V O L_{t}$. This model explains almost $40 \%$ of one-quarter-ahead volatility. But a model containing just $\widehat{F}_{1 t}, d_{t}-p_{t}, Y I E L D_{t}$ and $V O L_{t}$, performs equally well, so we often use this more parsimonious statistical model when forming estimates of $\sigma_{t}$. (The conclusions are unchanged if we include $\widehat{F}_{6 t}$.)

In summary, the results reported in Tables 2 and 3 indicate that good forecasts of returns and volatility can be made with only a few factors, and that the best forecasts often contain combinations of factors and commonly used conditioning variables. It is reassuring that many of our estimated factors are found to contain information that is largely common to that in many predictor variables that have long served as conditioning variables in asset pricing applications, suggesting that the standard variables do indeed summarize a large body of information about economic and financial activity. At the same time, however, the evidence in Tables 2 and 3 suggests that the information in commonly used predictors is still incomplete, because a few factors contain important information about future returns and future volatility that is not contained in these other variables.

Can we given an economic interpretation to the common factors? Because the factors are only identifiable up to an $r \times r$ matrix, a detailed interpretation of the individual factors is inappropriate. Nonetheless, it is useful to briefly characterize the factors that emerge from our formally chosen specification procedure that are most important for forecasting returns and volatility. For forecasting returns, the results indicate that two financial factors stand out, $\widehat{G}_{1 t}^{2}$ and $\widehat{G}_{3 t}$. $\widehat{G}_{1 t}^{2}$ explains almost $80 \%$ of the contemporaneous variation in squared stock market returns, so we label this factor a "volatility factor." We adopt this naming convention even though the factor is more highly correlated with squared returns than with realized volatility $V O L_{t} . \widehat{G}_{1 t}^{2}$ is still relatively highly correlated with $V O L_{t}$, explaining $40 \%$ of its quarterly variation. The second important factor, $\widehat{G}_{3 t}$, is highly correlated with a linear combination of three state variables used in the empirical asset pricing literature to explain cross-sectional variation in risk premia. When $\widehat{G}_{3 t}$ is regressed on the three cross-sectional risk factors in Fama and French (1993), MKT, $S M B_{t}$, and $H M L_{t}$, we find the following results (heteroskedasticity and serial correlation 
robust $t$-statistics in parentheses):

$$
\widehat{G}_{3 t}=\underset{(3.87)}{0.212}+\underset{(4.26)}{0.052} \cdot M K T_{t}-\underset{(-17.39)}{0.322} \cdot S M B_{t}-\underset{(-23.27)}{0.404} \cdot H M L_{t}+u_{t}, \quad \bar{R}^{2}=86 \% .
$$

In addition, if the 3-month Treasury bill rate, $R F_{t}$, is included as an explanatory variable, the four variables together explain $96 \%$ of the variation in the factor $\widehat{G}_{3 t}$ in our sample:

$$
\begin{aligned}
& \widehat{G}_{3 t}=\underset{(-8.19)}{0.460}+\underset{(7.07)}{0.062} \cdot M K T_{t}-\underset{(-29.65)}{0.320} \cdot S M B_{t}-\underset{(-33.65)}{0.403} \cdot H M L_{t}+\underset{(12.50)}{1.41} \cdot R F_{t}+u_{t}, \\
& \bar{R}^{2}=96 \% .
\end{aligned}
$$

The factor $\hat{G}_{3 t}$ loads heavily on cross-sectional asset pricing factors, and therefore connects the time series and the cross-section of expected stock returns. It is of interest that this factor is so well explained by time variation in well-established cross-sectional risk factors, since factors that spuriously explain the cross-section are unlikely to also spuriously explain the time series. Thus, we call this second factor a "risk premium factor."

For forecasting volatility, the results above indicate that at least one macroeconomic factor is a useful predictor when it is combined with other predictor variables, such as the dividend yield, the 1-year Treasury yield, and lagged volatility. This factor, $F_{1 t}$, is the first common factor from the data set composed of macroeconomic indicators. Stock and Watson (2002b) form factors from similar data sets of monthly data, and find that the first common factor is a "real factor" that is highly correlated with measures of real output and employment but not highly correlated with prices. This is also the case in our application using quarterly data, where the first macro factor explains $73 \%$ of the contemporaneous variation in an index of manufacturing output. Thus, we follow this naming convention and call $\widehat{F}_{1 t}$ a "real factor."

\subsection{The empirical risk-return relation}

We now turn our attention to the estimated risk-return relation, modeling the conditional mean and conditional volatility using the state variables chosen with the BIC criterion, as described above. Based on the BIC criterion, the conditional mean is measured by fitted values from a regressions of excess returns on the state variables $c a y_{t}$, $\widehat{G}_{1 t}^{2}$, and $\widehat{G}_{3 t}$. We refer to the statistical model of conditional mean based on these state variables as MOD1. Similarly, based on the BIC criterion, conditional volatility is measured by fitted values from a regression of realized volatility on the state variables $d_{t}-p_{t}, Y I E L D_{t}, \widehat{F}_{1 t}$, and $V O L_{t}$. We refer to the statistical model of conditional volatility based on these state variables as SPECl. We also consider two alternative models of the conditional mean and conditional volatility, denoted $M O D 2$ and $S P E C 2$, respectively. $M O D 2$ uses the three state variables used in $M O D 1$, but adds the product of two estimated macro factors $\widehat{F}_{3 t} \cdot \widehat{F}_{6 t}$ based on the predictive power found in Column $o$ of Table 2. $S P E C 2$ uses the same state variables used in SPEC1, but omits the real factor $\widehat{F}_{1 t}$. With these specifications for the conditional moments in hand, econometric models of the form (7) are used to evaluate the empirical risk-return relation. In addition to (7), we follow Ghysels, Santa-Clara, and Valkanov (2005) and consider regressions of the form

$$
\mu_{t}=\delta+\beta_{1} \sigma_{t}+\beta_{2} \sigma_{t-1}+\alpha \mu_{t-1}+\gamma m_{t-1}+\varepsilon_{t+1},
$$

where the lagged excess return is included as an additional explanatory variable. 
Table 4

Relation between conditional mean and conditional volatility

\begin{tabular}{|c|c|c|c|c|c|c|c|c|c|c|}
\hline \multicolumn{11}{|c|}{ Model: $\mu_{t}=\delta+\beta_{1} \sigma_{t}+\beta_{2} \sigma_{t-1}+\alpha \mu_{t-1}+\gamma m_{t-1}+\varepsilon_{t+1}$} \\
\hline \multirow[b]{2}{*}{ Row } & \multirow[b]{2}{*}{$\begin{array}{c}\text { Regressand } \\
\quad \mu_{t}=\end{array}$} & \multicolumn{7}{|c|}{ Regressor } & \multirow[b]{2}{*}{$\bar{R}^{2}$} & \multirow[b]{2}{*}{$\mathrm{BIC}$} \\
\hline & & $\begin{array}{c}\sigma_{1, t} \\
(t \text {-stat })\end{array}$ & $\begin{array}{c}\sigma_{1, t-1} \\
(t \text {-stat })\end{array}$ & $\begin{array}{c}\mu_{1, t-1} \\
(t \text {-stat })\end{array}$ & $\begin{array}{c}\sigma_{2, t} \\
(t \text {-stat })\end{array}$ & $\begin{array}{c}\sigma_{2, t-1} \\
(t \text {-stat })\end{array}$ & $\begin{array}{c}\mu_{2, t-1} \\
(t \text {-stat })\end{array}$ & $\begin{array}{c}m_{t-1} \\
(t \text {-stat })\end{array}$ & & \\
\hline 1 & $\mu_{1, t}$ & $\begin{array}{c}\mathbf{1 . 4 0} \\
(4.80)\end{array}$ & $\begin{array}{c}-\mathbf{1 . 4 6} \\
(-7.67)\end{array}$ & $\begin{array}{c}\mathbf{0 . 6 2} \\
(10.03)\end{array}$ & & & & & 0.41 & -4.23 \\
\hline 2 & $\mu_{1, t}$ & $\begin{array}{c}\mathbf{1 . 0 7} \\
(4.14)\end{array}$ & $\begin{array}{l}-\mathbf{1 . 1 8} \\
(-7.25)\end{array}$ & $\begin{array}{c}\mathbf{0 . 7 1} \\
(11.32)\end{array}$ & & & & $\begin{array}{c}-\mathbf{0 . 1 1} \\
(-3.40)\end{array}$ & 0.46 & -4.30 \\
\hline 3 & $\mu_{1, t}$ & $\begin{array}{l}-0.05 \\
(-0.14)\end{array}$ & & & & & & & -0.005 & -3.76 \\
\hline 4 & $\mu_{1, t}$ & & & & $\begin{array}{c}\mathbf{1 . 3 1} \\
(4.57)\end{array}$ & $\begin{array}{c}-\mathbf{1 . 3 8} \\
(-7.09)\end{array}$ & $\begin{array}{c}\mathbf{0 . 6 3} \\
(10.60)\end{array}$ & & 0.42 & -4.25 \\
\hline 5 & $\mu_{1, t}$ & & & & $\begin{array}{c}\mathbf{1 . 0 0} \\
(4.05)\end{array}$ & $\begin{array}{c}-\mathbf{1 . 1 4} \\
(-7.35)\end{array}$ & $\begin{array}{c}\mathbf{0 . 7 1} \\
(11.71)\end{array}$ & $\begin{array}{l}-\mathbf{0 . 1 1} \\
(-3.39)\end{array}$ & 0.47 & -4.32 \\
\hline 6 & $\mu_{1, t}$ & & & & $\begin{array}{c}-0.08 \\
(-0.22)\end{array}$ & & & & 0.00 & -3.76 \\
\hline 7 & $\mu_{2, t}$ & $\begin{array}{c}\mathbf{1 . 4 0} \\
(4.80)\end{array}$ & $\begin{array}{l}-\mathbf{1 . 4 5} \\
(-7.52)\end{array}$ & $\begin{array}{c}\mathbf{0 . 6 2} \\
(9.53)\end{array}$ & & & & & 0.40 & -4.22 \\
\hline 8 & $\mu_{2, t}$ & $\begin{array}{c}\mathbf{1 . 0 8} \\
(4.17)\end{array}$ & $\begin{array}{l}-\mathbf{1 . 1 9} \\
(-7.11)\end{array}$ & $\begin{array}{c}\mathbf{0 . 7 0} \\
(10.46)\end{array}$ & & & & $\begin{array}{c}-\mathbf{0 . 1 1} \\
(-3.22)\end{array}$ & 0.45 & -4.28 \\
\hline 9 & $\mu_{2, t}$ & $\begin{array}{l}-0.04 \\
(-0.11)\end{array}$ & & & & & & & -0.01 & -3.75 \\
\hline 10 & $\mu_{2, t}$ & & & & $\begin{array}{c}\mathbf{1 . 3 1} \\
(4.66)\end{array}$ & $\begin{array}{c}-\mathbf{1 . 3 9} \\
(-7.23)\end{array}$ & $\begin{array}{c}\mathbf{0 . 6 3} \\
(10.11)\end{array}$ & & 0.42 & -4.24 \\
\hline 11 & $\mu_{2, t}$ & & & & $\begin{array}{c}\mathbf{1 . 0 2} \\
(4.15)\end{array}$ & $\begin{array}{c}-\mathbf{1 . 1 5} \\
(-7.51)\end{array}$ & $\begin{array}{c}\mathbf{0 . 7 1} \\
(10.84)\end{array}$ & $\begin{array}{l}-\mathbf{0 . 1 0} \\
(-3.16)\end{array}$ & 0.46 & -4.30 \\
\hline 12 & $\mu_{2, t}$ & & & & $\begin{array}{l}-0.07 \\
(-0.18)\end{array}$ & & & & -0.00 & -3.75 \\
\hline 13-2SLS & $\mu_{1, t}$ & $\begin{array}{c}\mathbf{2 . 2 2} \\
(4.86)\end{array}$ & $\begin{array}{l}-\mathbf{2 . 1 5} \\
(-5.53)\end{array}$ & $\begin{array}{c}\mathbf{0 . 6 8} \\
(11.58)\end{array}$ & & & & & 0.36 & - \\
\hline
\end{tabular}

Notes: This table reports regressions of estimated conditional mean excess returns $\mu_{t} \equiv \widehat{E}_{t}\left(m_{t+1}\right)$, $m_{t+1} \equiv r_{t+1}-r_{f, t+1}$, on the CRSP value-weighted stock market index over the 3-month Treasury bill rate on estimated conditional volatility $\sigma_{t} \equiv \widehat{E}_{t}\left(V O L_{t+1}\right)$ and one-period lags of these variables. The conditional mean and volatility are estimated as fitted values from regressions of excess returns and realized volatility on information variables known at time $t . \mu_{1, t}$ denotes the fitted value from a regression of excess returns on the information variables $c a y_{t}, G_{1 t}^{2}$, and $G_{3 t} . \mu_{2, t}$ denotes the fitted value from a regression of excess returns on the information variables used to form $\mu_{1, t}$ plus $F_{3 t} \cdot F_{6 t} \cdot \sigma_{1, t}$ denotes the fitted value from a regression of realized quarterly volatility, $V O L_{t+1}$, on the information variables $d_{t}-p_{t}$, the CRSP $\log$ dividend-price ratio, YIELD , the one year Treasury bill yield, $F_{1 t}$ and $V O L_{t} . \sigma_{2, t}$ denotes the fitted value from a regression of realized quarterly volatility, $V O L_{t+1}$, on the information variables $d_{t}-p_{t}$, the CRSP log dividend-price ratio, YIELD , the one year Treasury bill yield, and $V O L_{t}$. Newey and West (1987) corrected $t$-statistics are reported in parentheses. Coefficients that are statistically significant at the $5 \%$ level are given in italics. A constant is always included in the regression even though its estimate is not reported in the table. All estimation is by OLS except for results reported in row 13, where two-stage least squares (2SLS) is used with instruments $\mu_{1, t-1}, \mu_{1, t-2}, \sigma_{1, t-1}, \sigma_{1, t-2}, m_{t-1}$, and $V O L_{t-1}$. The sample spans the period from the first quarter of 1960 to the fourth quarter of 2002 . 
The conditional correlation between the conditional mean and conditional volatility is positive in all cases. Table 4 shows that, conditional on lagged volatility and the lagged mean, the coefficient on contemporaneous volatility is positive and strongly statistically significant regardless of which specification is used to model mean or volatility. Moreover, the $t$-statistics for $\beta_{1}$ are all in excess of four. This positive contemporaneous trade-off between risk and return is consistent with the results of French, Schwert, and Stambaugh (1987), Bollerslev, Engle, and Wooldridge (1988), Harvey (1989), Campbell and Hentschel (1992), and Ghysels, Santa-Clara, and Valkanov (2005) but not those of Campbell (1987), Breen, Glosten, and Jagannathan (1989), Pagan and Hong (1991), Glosten, Jagannathan, and Runkle (1993), Whitelaw (1994), Lettau and Ludvigson (2003), and Brandt and Kang (2004). The coefficient on $m_{t-1}$ in (10) is also strongly statistically significant and negative, but the inclusion of $m_{t-1}$ does not alter the strong positive contemporaneous relation between the conditional mean and conditional volatility. Thus, we find a strong positive volatility-in-mean effect for all specifications. By contrast, the lag-volatility-in-mean effect is strongly negative. Both lagged volatility and lagged mean are important explanatory variables for the conditional mean, and all the same conclusions arise if $\sigma_{t}$ is used as the left-hand side variable instead of $\mu_{t}$. The conditional correlation points to significant lead-lag interactions in the relation between conditional mean and conditional volatility, again consistent with Brandt and Kang (2004) and also Whitelaw (1994), and suggests that $\mu_{t}$ and $\sigma_{t}$ are highlypersistent.

Although we emphasize the importance of lead-lag interactions in the risk-return relation, our results on the sign of the contemporaneous relation between $\mu_{t}$ and $\sigma_{t}$ contrast with those of Brandt and Kang (2004) and also Lettau and Ludvigson (2003), who report a negative correlation between conditional mean and conditional volatility. Moreover, although Brandt and Kang find a negative conditional correlation between $\mu_{t}$ and $\sigma_{t}$ (conditional on lagged mean and volatility), they find a positive unconditional correlation between $\mu_{t}$ and $\sigma_{t}$. These results are the opposite of those reported in Table 4, where the conditional correlation is positive and the unconditional correlation (omitting lags of $\mu_{t}$ and $\sigma_{t}$ ) is negative. Thus, somewhat ironically, like Brandt and Kang (2004), we find that distinguishing between the conditional (on lagged mean and lagged volatility) and unconditional correlation between the conditional mean stock return and its conditional volatility is crucial for understanding the empirical risk-return relation.

There are a number of possible reasons why our results differ from those of Brandt and Kang. First, as mentioned, the econometric methodologies differ. Brandt and Kang use a latent VAR approach to model the conditional mean and conditional volatility, assuming that these variables follow first-order, linear, Gaussian processes. This approach relies on the history of returns to infer $\mu_{t}$ and $\sigma_{t}$ and does not condition upon the vast set of exogenous conditioning variables we employ in this study. Second, Brandt and Kang model the log moments, whereas we follow the bulk of the literature and model the relation between the mean and volatility in levels. Brandt and Kang use their assumption that the $\log$ moments are bivariate normally distributed to infer the relation between the level moments, which under this assumption must be bivariate log-normally distributed. With this distributional assumption, they approximate the correlation between the level moments and conclude that the level moments also display a negative conditional correlation. Third, our sample size and data frequency differ: Brandt and Kang studied monthly data from January 1946 through December 1998, while we study quarterly data from the first quarter of 1960 to the fourth quarter of 2002. Several variables that are 
Table 5

Relation between conditional mean and conditional volatility, omitting factors

\begin{tabular}{|c|c|c|c|c|c|c|c|}
\hline \multicolumn{8}{|c|}{ Model: $\mu_{t}=\delta+\beta_{1} \sigma_{t}+\beta_{2} \sigma_{t-1}+\alpha \mu_{t-1}+\gamma m_{t-1}+\varepsilon_{t+1}$} \\
\hline \multirow[b]{2}{*}{ Row } & \multirow[b]{2}{*}{$\begin{array}{c}\text { Regressand } \\
\mu_{t}=\end{array}$} & \multicolumn{4}{|c|}{ Regressor } & \multirow[b]{2}{*}{$\bar{R}^{2}$} & \multirow[b]{2}{*}{ BIC } \\
\hline & & $\begin{array}{c}\sigma_{2, t} \\
(t \text {-stat })\end{array}$ & $\begin{array}{c}\sigma_{2, t-1} \\
(t \text {-stat })\end{array}$ & $\begin{array}{c}\mu_{3, t-1} \\
(t \text {-stat })\end{array}$ & $\begin{array}{c}m_{t-1} \\
(t \text {-stat })\end{array}$ & & \\
\hline 1 & $\mu_{3, t}$ & $\begin{array}{c}\mathbf{0 . 2 3} \\
(2.42)\end{array}$ & $\begin{array}{c}-0.25 \\
(-2.46)\end{array}$ & $\begin{array}{c}\mathbf{0 . 8 5} \\
(20.45)\end{array}$ & & 0.71 & -5.63 \\
\hline 2 & $\mu_{3, t}$ & $\begin{array}{c}-0.10 \\
(-1.32)\end{array}$ & $\begin{array}{c}0.04 \\
(0.59)\end{array}$ & $\begin{array}{c}\mathbf{0 . 9 2} \\
(26.69)\end{array}$ & $\begin{array}{c}-\mathbf{0 . 1 0} \\
(-6.75)\end{array}$ & 0.81 & -6.00 \\
\hline 3 & $\mu_{3, t}$ & $\begin{array}{c}-\mathbf{0 . 4 8} \\
(-2.54)\end{array}$ & & & & 0.11 & -4.56 \\
\hline 4 & $\mu_{3, t}$ & $\begin{array}{c}-\mathbf{0 . 5 5} \\
(-2.92)\end{array}$ & & & $\begin{array}{c}-\mathbf{0 . 0 5} \\
(-2.27)\end{array}$ & 0.14 & -4.56 \\
\hline
\end{tabular}

Notes: This table reports regressions of estimated conditional mean excess returns $\mu_{t} \equiv \widehat{E}_{t}\left(m_{t+1}\right)$ on the CRSP value-weighted stock market index over the 3-month Treasury bill rate on estimated conditional volatility $\sigma_{t} \equiv$ $\widehat{E}_{t}\left(V O L_{t+1}\right)$ and one-period lags of these variables. The conditional mean and volatility are estimated as fitted values from regressions of excess returns and realized volatility on information variables known at time $t$. $\mu_{3, t}$ denotes the fitted value from a regression of excess returns on $c a y_{t}$, the best-fitting conditional mean specification omitting factors, according to the BIC criterion. $\sigma_{2, t}$ is the best-fitting conditional volatility specification omitting factors, according to the BIC criterion, and denotes the fitted value from a regression of realized quarterly volatility, $V O L_{t+1}$, on the information variables $d_{t}-p_{t}$, the CRSP log dividend-price ratio, YIELD $D_{t}$, the one year Treasury bill yield, and $V O L_{t}$. Newey and West (1987) corrected $t$-statistics are reported in parentheses. Coefficients that are statistically significant at the $5 \%$ level are highlighted in bold. A constant is always included in the regression even though its estimate is not reported in the table. The sample spans the period from the first quarter of 1960 to the fourth quarter of 2002.

important for predicting returns and volatility (e.g., $c a y_{t}$ ) are only available at quarterly frequency and the predictable dynamics can vary from monthly to quarterly horizons.

Our econometric approach is more closely related to that of Lettau and Ludvigson (2003), who consider a wide range of commonly used predictor variables for returns and volatility in modeling the risk-return relation. Yet, unlike Lettau and Ludvigson, we find a strong positive conditional correlation between $\mu_{t}$ and $\sigma_{t}$, whereas they report a negative relation. Since Lettau and Ludvigson survey a broad range of models studied in the literature (distinguished by the particular conditioning variables used to measure conditional moments), the differences in our results suggest that the conditioning information introduced by our estimated factors could be especially important for properly measuring the risk-return relation in methodologies that rely on exogenous predictors.

To illustrate this point, Table 5 presents the results from estimating the risk-return relation using the best fitting specifications (according to the BIC criterion) omitting estimated factors. The table shows that the findings in Lettau and Ludvigson (2003) can be largely attributed to the omission of the volatility and risk premium factors $\widehat{G}_{1 t}^{2}$ and $\widehat{G}_{3 t}$, which contain important information about one-quarter-ahead returns. First, consider Rows 3 and 4, which report the relation between $\mu_{t}$ and $\sigma_{t}$. These rows reproduce the qualitative findings of Lettau and Ludvigson (2003), who focus on the unconditional 
contemporaneous correlation: the coefficient in a regression of $\mu_{t}$ on $\sigma_{t}$ is negative and statistically different from zero. This result holds anytime the estimated volatility and combination factors are omitted when modeling $\mu_{t}$ and $\sigma_{t}$. By contrast, the results in Table 4 , based on models that make use of information in $\widehat{G}_{1 t}^{2}$ and $\widehat{G}_{3 t}$, show that the contemporaneous relation is slightly negative but not statistically different from zero. Instead, in Table 4, it is the conditional correlation between the mean and volatility that is strongly statistically significant, but this correlation is not negative but positive. Interestingly, Row 1 of Table 5 shows that this positive conditional correlation carries over to the case where the estimated factors are omitted in modeling $\mu_{t}$ and $\sigma_{t}$, but differs from the case where estimated factors are employed in that this result is not robust to the inclusion of lagged returns $m_{t}$ as a right-hand side variable. These results suggest that the factor-augmented specifications of $\mu_{t}$ and $\sigma_{t}$ are important for properly identifying the empirical risk-return relation. In addition, Table 4 indicates that our conclusions about the estimated risk-return relation are robust to using a variety of statistically relevant factors and conditioning variables in the modeling of fitted moments, as long as we include the two new financial factors (volatility and risk premium) in modeling the conditional mean. This is because the BIC criterion clearly indicates that these variables have important additional explanatory power for future returns that should not be omitted when modeling the conditional mean.

The results discussed so far are all based on OLS estimation. We also estimate the specifications (7) and (10) using two-stage least squares, instrumenting for $\sigma_{t}$ using lagged variables as instruments: $\mu_{t-1}, \mu_{t-2}, \sigma_{t-1}, \sigma_{t-2}, m_{t-1}, V O L_{t-1}$. Because the results from 2SLS estimation are very similar to those using OLS estimation, we present only one set of findings from 2SLS estimation in Table 4, reported in Row 13. As with the OLS estimation, the conditional correlation between $\mu_{t}$ and $\sigma_{t}$ is found to be strongly statistically significant and positive, indicating a positive volatility-in-mean relation. By contrast, the lag-volatility-in-mean relation is also strongly negative, as is also found using OLS estimation.

Fig. 1 depicts variation over time in the conditional mean, based on the factoraugmented specification $M O D 1$, along with $95 \%$ confidence intervals formed from 10,000 bootstrapped observations on our exogenous predictors and factors. The conditional mean rises in all seven of the NBER recession periods in our sample. This countercyclical pattern in the conditional mean is consistent with findings in Fama and French (1989), Lettau and Ludvigson (2003), and Brandt and Kang (2004). The conditional mean itself varies between -0.04 and 0.08 over most of the sample, and there are a number of negative observations. As one would expect, negative observations on the conditional mean are common in linear empirical models (e.g., Harvey, 2001; Lettau and Ludvigson, 2001b, 2003). One might be more comfortable with fewer negative observations, but it should be noted that an occasional negative risk premium on stock market wealth is not necessarily inconsistent with equilibrium asset pricing models (Boudoukh, Richardson, and Whitelaw, 1997; Whitelaw, 2000).

The dynamics of conditional volatility, based on SPEC1, are displayed in Fig. 2. In most recessions, conditional volatility tends to be high and increasing, consistent with the results of Schwert $(1989,1990)$. But there are a few recessions for which this is not the case with our measure of $\sigma_{t}$, notably the recessions of early 1960 and 2001. The cyclical movements in conditional volatility are, however, swamped by large, low-frequency fluctuations. This feature likely contributes to the weak unconditional risk-return relation in our sample, 


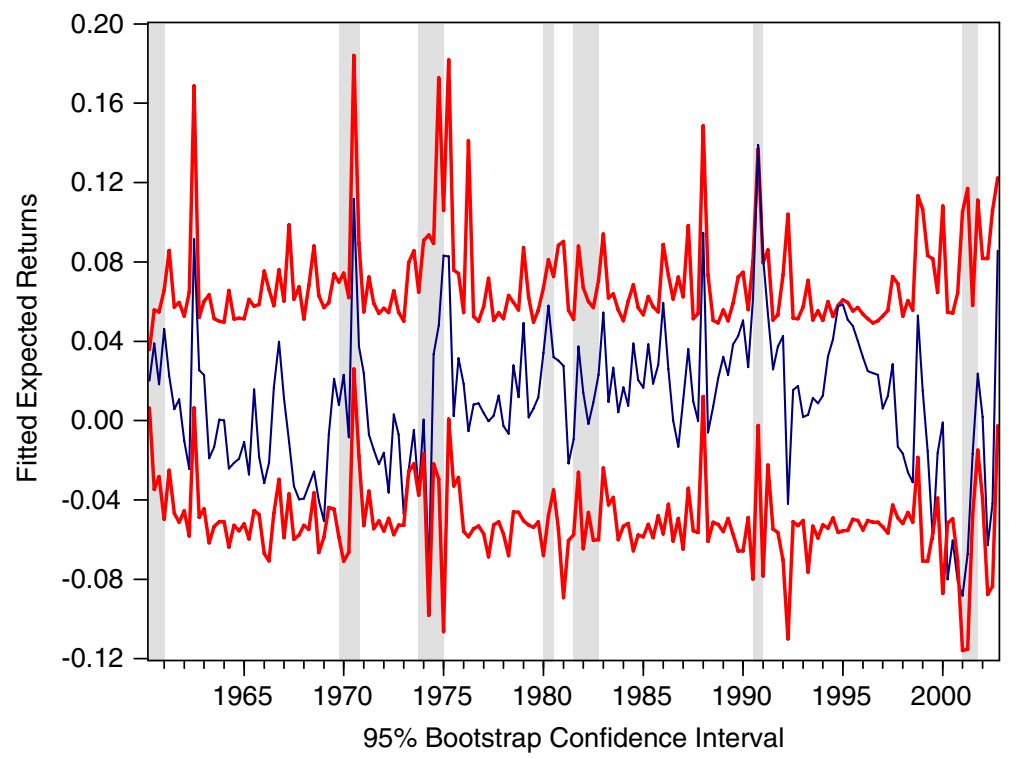

Fig. 1. Note: the figure shows the estimated conditional mean excess return of the CRSP value-weighted stock market index, based on the factor-augmented specification $M O D 1$, along with $95 \%$ confidence intervals formed from 10,000 bootstrapped observations. Shading denotes quarters designated recessions by the NBER. Source: authors' calculations.

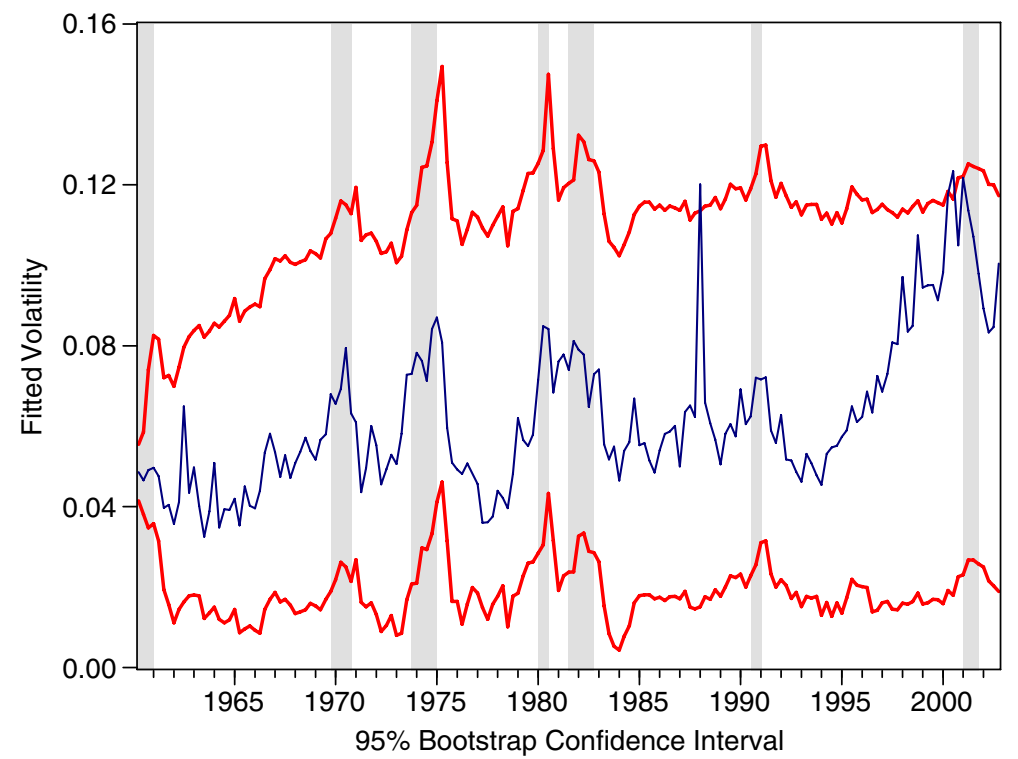

Fig. 2. Note: the figure shows the estimated conditional volatility of the CRSP value-weighted stock market index, based on the factor-augmented specification SPEC1, along with $95 \%$ confidence intervals formed from 10,000 bootstrapped observations. Shading denotes quarters designated recessions by the NBER. Source: authors' calculations. 


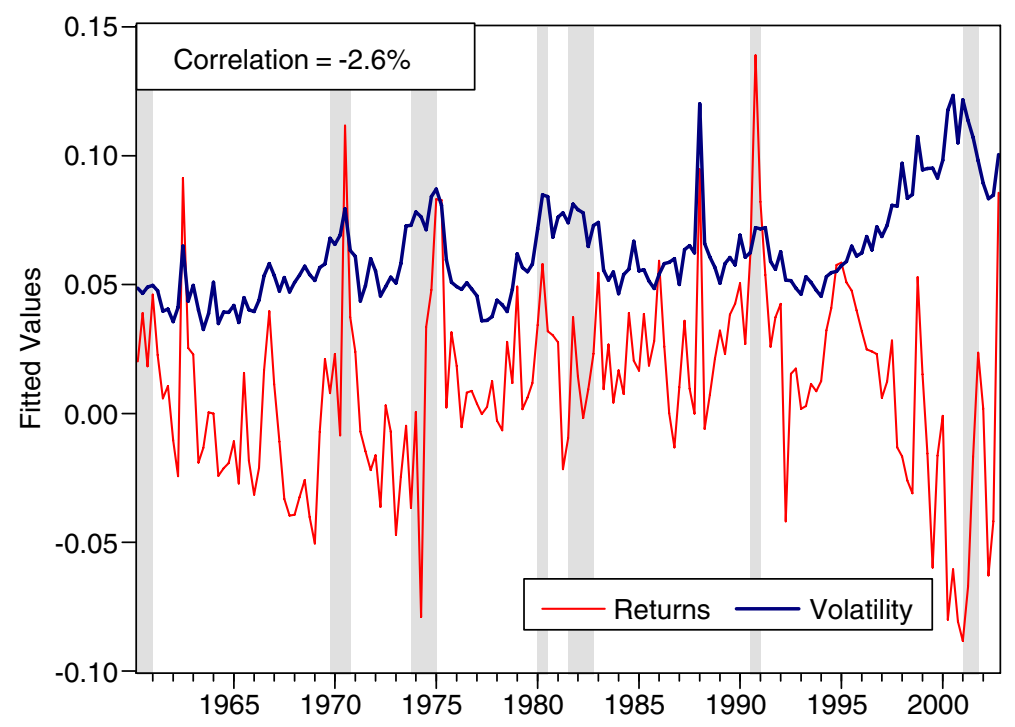

Fig. 3. Note: the figure shows the estimated conditional mean excess return of the CRSP value-weighted stock market index and the estimated conditional volatility of the same index. The estimate of the conditional mean is based on the factor-augmented specification MOD1; the estimate of the conditional volatility is based on the factor-augmented specification SPEC1. Shading denotes quarters designated recessions by the NBER. Source: authors' calculations.

since the conditional mean appears far less persistent. Fig. 3 plots the conditional volatility and conditional mean on the same graph, displaying the weak negative contemporaneous correlation in our sample. Interestingly, the negative correlation appears largely attributable to the period between 1995 and 2000, when the conditional mean trended up and conditional volatility trended down. The countercyclical variation in volatility is not as distinct as that in the conditional mean; as a result, the conditional Sharpe ratio (the ratio of conditional mean to conditional volatility) is distinctly countercyclical (Fig. 4). In particular, the Sharpe ratio rises sharply in every recession, with noticeable spikes in the 1970-1971 and 1990-1991 recessions. Such countercyclical variation in the Sharpe ratio arises naturally in models with countercyclical risk or risk aversion.

Before closing this section, we comment on our use of historical, fully revised, macro data in cay and to form macro factors. The use of historical macro data is always a possible caveat if one is interested in a pure forecasting question concerning a practitioner who relies solely on information as it is released by the Bureau of Economic Analysis. (Unfortunately, real-time data do not exist for more than a handful of economic series.) Such an analysis, however, is not the focus of our paper. From a rational expectations equilibrium perspective, investors have historical information and know the time- $t$ values of equilibrium variables such as income, consumption, investment, etc. Since we are interested in population parameters pertaining to equilibrium quantities, it is appropriate that we use fully revised historical data. One caveat with this argument is that announcements of macroeconomic data appear to have significant effects on asset prices (e.g., Boyd, Hu, and Jagannathan, 2005). We show in the appendix that none of our main conclusions about the risk-return relation are changed when we use macro variables and 


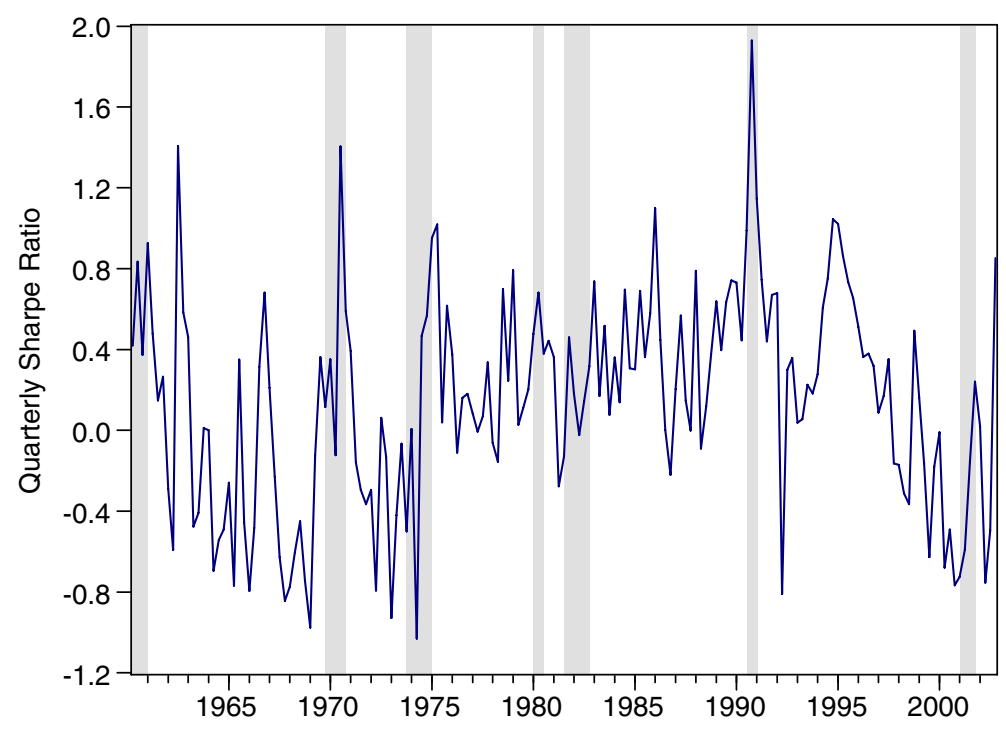

Fig. 4. Note: the figure shows the estimated conditional Sharpe ratio, defined as the estimated conditional mean excess return of the CRSP value-weighted stock market index divided by the estimated conditional volatility of the same index. The estimate of the conditional mean is based on the factor-augmented specification MOD1; the estimate of the conditional volatility is based on the factor-augmented specification SPEC1. Shading denotes quarters designated recessions by the NBER. Source: authors' calculations.

lag them more than one period, or when we use only financial variables (which are never revised) in the estimation of factors and in the construction of fitted moments.

In summary, we find a strongly positive linear relation between the conditional mean and conditional volatility, once empirically important lags of these variables are controlled for in the regression analysis. These findings support the theoretical prediction of a positive risk-return tradeoff, but also indicate a negative relation between mean and lagged volatility. Our next two subsections present additional results that pertain to the robustness of our underlying forecasting relations: out-of-sample analysis and small-sample inference.

\subsection{Out-of-sample analysis}

In the analysis above, we formally select models for estimating the conditional mean and conditional volatility of stock returns using the BIC criterion from predictive regressions over the full sample. In this section we report results on the out-of-sample forecasting power of our formally selected models. This procedure involves fully recursive factor estimation and parameter estimation using data only through time $t$ for forecasting at time $t+1$. In order to focus on the predictive power of the volatility and risk-premium factors $G_{1 t}^{2}$ and $G_{3 t}$, in this out-of-sample analysis we remove $c a y_{t}$ both as an independent predictor and from the set of indicators over which we form financial factors, since the outof-sample forecasting power of $c y_{t}$ for future excess returns has been extensively studied elsewhere (see Lettau and Ludvigson, 2001a; Campbell and Thompson, 2005; Guo, 2005). The results from this two-factor forecasting model are compared to a constant expected returns benchmark. For forecasting volatility, we focus on the predictive power of one of 
Table 6

Out-of-sample predictive power

\begin{tabular}{|c|c|c|c|c|c|}
\hline Row & Forecast sample & Comparison & $M S E_{u} / M S E_{r}$ & Test statistic & 95\% Asympt. CV \\
\hline \multicolumn{6}{|c|}{ Excess Returns } \\
\hline 1 & 1975:1-2003:2 & $\left(\widehat{G}_{1}^{2}, \widehat{G}_{3}\right)^{\prime}$ vs. const & 0.918 & $11.56^{* *}$ & 2.79 \\
\hline 2 & 1985:1-2003:2 & $\left(\widehat{G}_{1}^{2}, \widehat{G}_{3}\right)^{\prime}$ vs. const & 0.911 & $7.69^{* *}$ & 1.90 \\
\hline 3 & 1995:1-2003:2 & $\left(\widehat{G}_{1}^{2}, \widehat{G}_{3}\right)^{\prime}$ vs. const & 0.786 & $5.97^{* *}$ & 1.03 \\
\hline \multicolumn{6}{|c|}{ Volatility } \\
\hline 4 & 1975:1-2003:2 & $S P E C 1$ vs. $A R$ & 0.902 & $16.58^{* *}$ & 3.46 \\
\hline 5 & 1985:1-2003:2 & SPECIVs. $A R$ & 0.821 & $9.75^{* *}$ & 4.35 \\
\hline 6 & 1995:1-2003:2 & $S P E C 1$ vs. $A R$ & 0.706 & $10.04^{* *}$ & 1.28 \\
\hline
\end{tabular}

Notes: The table reports results from one-quarter-ahead out-of-sample forecast comparisons of log excess returns, $m_{t+1}$ and volatility, $\operatorname{VOL}_{t+1}$. $\left(G_{1}^{2}, G_{3}\right)^{\prime}$ denotes a predictive model for excess returns that uses the squared value of $G_{1 t}$ and $G_{3 t}$ as predictive variables. These factors are formed from the financial data set with $c a y_{t}$ removed. $S P E C 1$ denotes a forecasting model for volatility that includes as predictive variables $d_{t}-p_{t}$, the CRSP log dividend-price ratio, YIELD $D_{t}$, the one year Treasury bill yield, $F_{1 t}$, and $V O L_{t-1}$. Rows 1 through 3 report forecast comparisons of an unrestricted model, which includes $\left(G_{1}^{2}, G_{3}\right)^{\prime}$ as predictors for excess returns, with the constant expected returns benchmark (const). Rows 4 through 6 report forecast comparisons of the unrestricted model Spec1 for predicting volatility, with a first-order autoregressive benchmark $(A R) . M S E_{u}$ is the mean-squared forecasting error of the unrestricted model; $M S E_{r}$ is the mean squared forecasting error of the restricted model that excludes additional forecasting variables. In the column labeled " $M S E_{u} / M S E_{r}$ " a number less than one indicates that the models that use the additional forecasting variables have lower forecast error than the benchmark to which it is compared. In Rows 1 and 4, the parameters and factors are estimated recursively, using only data available from 1960:1 through 1975:1. The forecasting regressions are run for $t=1960: 1, \ldots, 1975: 1$, then the values of the regressors at $t=1975: 1$ are used to forecast $m_{1975: 2}$ (row 1) or $V O L_{1975: 2}$. All parameters and factors are then reestimated from 1960:1 through 1975:2, and forecasts are recomputed for $m_{1975: 3}$ and $V O L_{1975: 3}$, and so on, until the final out-of-sample forecast is made for $m_{2003: 2}$ and $V O L_{2003: 2}$. The same procedure is used to compute results reported in Rows 2, 3, 5, and 6 where the initial estimation period is either $t=1960: 1, \ldots, 1985: 1$ (Rows 2 and 5) or $t=1960: 1, \ldots, 1995: 1$ (Rows 3 and 6). The column labeled "Test Statistic" reports the ENCNEW test statistic of Clark and McCracken (2001) for the null hypothesis that the benchmark model encompasses the unrestricted model with additional predictors. The alternative is that the unrestricted model contains information that could be used to improve the benchmark model's forecast. "95\% Asympt. CV" gives the 95th percentile of the asymptotic distribution of the test statistic.

${ }^{* *}$ Significant at the $1 \%$ or better level.

our formally chosen specifications that includes the real factor along with other predictor variables. The real factor alone is not a significant predictor of volatility, but is when combined with the variables in Column $m$ of Table 3 . Since volatility is known to be persistent, this model is compared with a first-order autoregressive benchmark.

Table 6 reports results from one-quarter-ahead out-of-sample forecast comparisons of $\log$ excess returns $m_{t+1}$ and volatility $V O L_{t+1}$. For the purpose of this out-of-sample analysis, the factors $G_{1 t}^{2}$ and $G_{3 t}$ are formed recursively from the financial data set omitting $c a y_{t}$. Since the cointegrating coefficients on $c a y_{t}$ are estimated over the full sample, omitting $c a y_{t}$ insures that the time- $t$ factors used to forecast returns at time $t+1$ are formed using data only up to time $t$. SPECl denotes a forecasting model for volatility that uses the following variables as predictors: the CRSP $\log$ dividend-price ratio $d_{t}-p_{t}$, the 1 -year Treasury bill yield $Y I E L D_{t}$, the real factor $\widehat{F}_{1 t}$, and lagged volatility $V O L_{t}$. This 
corresponds to the model in Column $m$ of Table 3. For each forecast, $M S E_{u}$ denotes the mean squared forecasting error of the unrestricted model including predictor factors; $M S E_{r}$ denotes the mean squared forecasting error of the restricted benchmark model that excludes additional forecasting variables. In the Column labeled " $M S E_{u} / M S E_{r}$ " a number less than one indicates that the models that uses the additional forecasting variables have lower forecast error than the benchmark to which it is compared.

Results for three forecast samples are reported: 1975:1-2003:2; 1985:1-2003:2; 1995:1-2003:2. The results for the first forecast sample are reported in Rows 1 and 4. Here the parameters and factors are estimated recursively, with the initial estimation period using only data available from 1960:1 through 1975:1. Next, the forecasting regressions are run over the period $t=1960: 1, \ldots, 1975: 1$, and the values of the regressors at $t=1975: 1$ are used to forecast $m_{1975: 2}$ (Row 1) or $V O L_{1975: 2}$. All parameters and factors are then reestimated from 1960:1 through 1975:2, and forecasts are recomputed for $m_{1975: 3}$ and $V O L_{1975: 3}$, and so on, until the final out-of-sample forecast is made for $m_{2003: 2}$ and $V O L_{2003: 2}$. The same procedure is used to compute results reported in Rows 2, 3, 5, and 6 where the initial estimation period is either $t=1960: 1, \ldots, 1985: 1$ (Rows 2 and 5) or $t=1960: 1, \ldots, 1995: 1$ (Rows 3 and 6). The Column labeled "Test Statistic" in Table 6 reports the encompassing test statistic (ENC-NEW) of Clark and McCracken (2001) for the null hypothesis that the benchmark model encompasses the unrestricted model with additional predictors. The alternative is that the unrestricted model contains information that could be used to improve the benchmark model's forecast. The column labeled " $95 \%$ Asympt. CV" gives the 95th percentile of the asymptotic distribution of the ENC-NEW test statistic.

Consider the forecasts of excess returns in Rows 1-3 of Table 6. The two-factor model that uses only $G_{1 t}^{2}$ and $G_{3 t}$ as predictors improves substantially over the constant expected returns benchmark. These models have a forecast error variance that is $92 \%$ and $91 \%$, respectively, of the constant expected returns benchmark for the forecast periods 1975:1-2003:2 and 1985:1-2003:2. For the period 1995:1-2003:2, the model has a forecast error variance that is only $79 \%$ of the constant expected returns benchmark. This is rather surprising, since it implies that the two-factor model exhibits the greatest relative improvement over the benchmark during a period in which the forecasting power of many conventional predictor variables breaks down. No matter what subperiod the model is evaluated over, the ENCNEW test statistic always indicates that the improvement in forecast power is strongly statistically significant, at the $1 \%$ level or better. These results show that the relative forecast improvement afforded by the estimated factors is stable over time and both statistically and economically significant. Fig. 5 gives a graphical impression of the predictive power of these two factors by plotting the forecasted value of excess returns along with the actual value over the period 1975:1-2003:2. Of course, the fitted value is less volatile than actual value, but the figure shows that the estimated factors do a remarkable job of forecasting the increase in excess returns in the late 1990s and the decline in early 2000-2002.

Rows 4-6 report the of out-of-sample volatility forecasts. As for excess returns, there is substantial improvement in forecasting power relative to the autoregressive benchmark that is strongly statistically significant. Interestingly, as for returns, the model outperforms the benchmark by the largest margin in the period 1995:1-2003:2, displaying a forecast error variance that is just $70 \%$ of the benchmark. These results are displayed graphically in Fig. 6. The model does an excellent job of capturing the low-frequency shift upward in volatility over the period 1995-2003. 


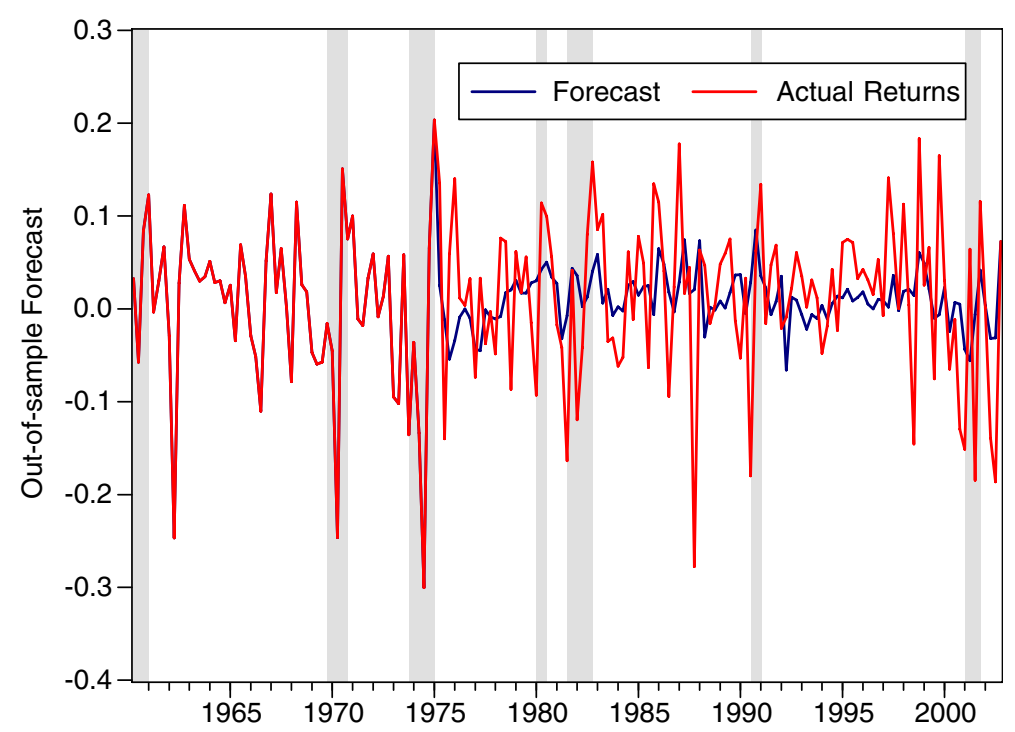

Fig. 5. Note: the figure plots the forecasted value of excess returns on the CRSP value-weighted index along with the actual value for the period 1975:1-2003:2. Forecasts are made using as predictor variables only the volatility and risk-premium factors discussed in the text. Shading denotes quarters designated recessions by the NBER. Source: authors' calculations.

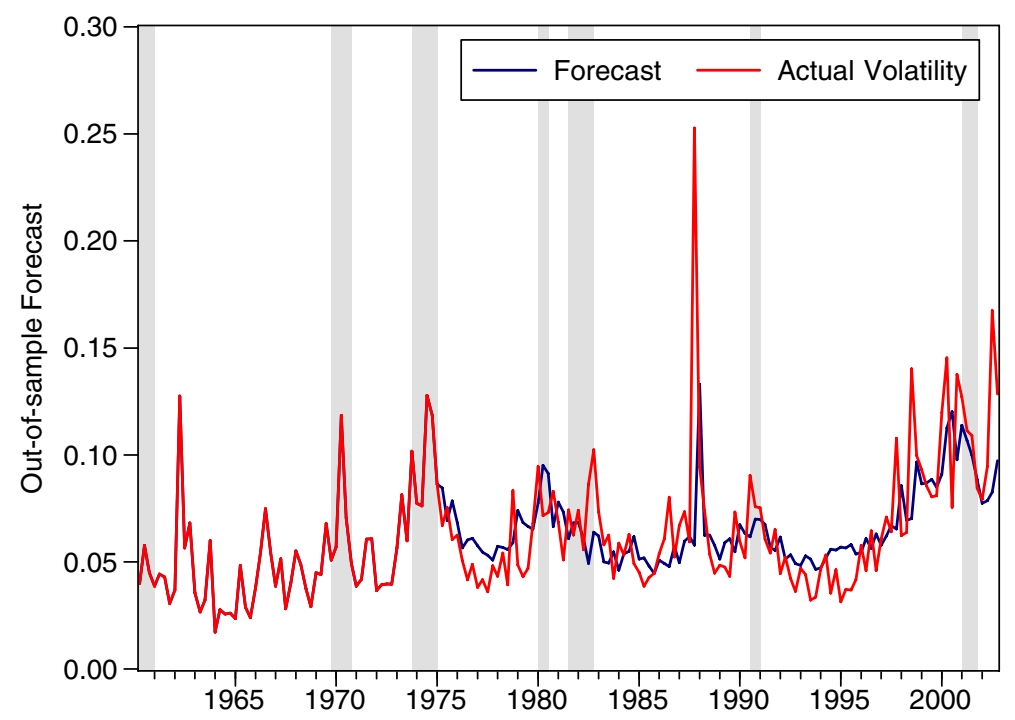

Fig. 6. Note: the figure plots the forecasted value of volatility on the CRSP value-weighted index along with the actual value for the period 1975:1-2003:2. Forecasts are made using as predictor variables the dividend-price ratio, one-year Treasury yield, one-quarter lagged volatility, and the real factor from the macro data set. Shading denotes quarters designated recessions by the NBER. Source: authors' calculations. 


\subsection{Small sample inference}

According to the asymptotic theory for principal components analysis discussed in Section 2, heteroskedasticity and autocorrelation consistent standard errors can be used to obtain robust $t=$ statistics that are asymptotically $\mathrm{N}(0,1)$. To guard against inadequacy of the asymptotic approximation in finite samples, we also consider bootstrap inference for two of our formally chosen specifications, those in Column $p$ of Table 2 (returns) and Column $m$ of Table 3 (volatility). The model in Column $p$ of Table 2 uses $c a y_{t}, \widehat{G}_{1 t}^{2}$, and $\widehat{G}_{3 t}$ as state variables for estimating the conditional mean; we refer to this model as MOD1 for conditional expected returns. The volatility model in Column $m$ of Table 3 uses $d_{t}-p_{t}$, $Y_{E L L D}, \widehat{F}_{1 t}$, and $V O L_{t}$ as state variables for estimating conditional volatility; we refer to this specification as SPEC1 for conditional volatility. Small-sample inference is especially important when the right-hand side variables are highly persistent (e.g., Ferson, Sarkissian, and Simin, 2003) but, as Table 1 demonstrates, none of the factors from our preferred specifications are highly persistent. Nevertheless, we proceed with a bootstrap analysis as a robustness check, by generating bootstrap samples of the exogenous predictors $Z_{t}$ as well as the estimated factors $\widehat{F}_{t}$ and $\widehat{G}_{t}$.

We consider two bootstrap procedures. First, we take the factors as given and generate bootstrap samples of $Z_{t}, \widehat{F}_{t}$, and $\widehat{G}_{t}$ from univariate first-order autoregressive models. This allows us to isolate the potential role of persistence in contaminating inference. Bootstrap samples of $m_{t+1}$ are obtained in two ways, first by imposing the null hypothesis of no predictability (i.e., $\alpha_{1}, \alpha_{2}$ and $\beta$ in (8) are zero vectors and residuals from regression on a constant are resampled), and second without imposing the null by resampling the residuals of (8). A regression using the bootstrap data gives new estimates of $\alpha_{1}, \alpha_{2}$, and $\beta$, and new $\bar{R}^{2}$ statistics. A directly analogous investigation is conducted for the volatility (9). This is repeated $B=10,000$ times. The results are reported in Table 7 .

In the second procedure, we take into account the pre-estimation of the factors by resampling the $T \times N$ panel of data, $x_{i t}$. This creates bootstrapped samples of the factors themselves. For each $i$, least squares estimation of $\widehat{e}_{i t}=\rho_{i} \widehat{e}_{i t-1}+v_{i t}$ yields the estimates $\widehat{\rho}_{i}$ and $\widehat{v}_{i t}, t=2, \ldots, T$, where recall that $\widehat{e}_{i t}=x_{i t}-\widehat{\lambda}_{i}^{\prime} \widehat{f}_{t}$. Then $\widehat{v}_{i t}$ is re-sampled (while preserving the cross-section correlation structure) to yield bootstrap samples of $\widehat{e}_{i t}$. In turn, bootstrap values of $x_{i t}$ are constructed by adding the bootstrap estimates of the idiosyncratic errors, $\widehat{e}_{i t}$, to $\widehat{\lambda}_{i}^{\prime} \widehat{F}_{t}$. Estimation by the method of principal components on the bootstrapped data then yields a new set of estimated factors. Together with bootstrap samples of $Z_{t}$ (based on AR(1) models as above), this delivers a set of bootstrap regressors. Samples of $m_{t+1}$ are again obtained in two ways, either by imposing or not imposing the null of no predictability, and bootstrap $\bar{R}^{2}$ and $t$ statistics are obtained by performing a regression on the bootstrap data. Bootstrap confidence intervals for the parameter estimates and $\bar{R}^{2}$ statistics can be calculated from $B=10,000$ replications. A directly analogous investigation is conducted for the volatility (9). These results are reported in Table 8.

Both Tables 7 and 8 indicate that the results based on bootstrap inference are consistent with those based on asymptotic inference. Using either procedure, the coefficients on the exogenous predictors and estimated factors are statistically different from zero at the $95 \%$ level and are well outside the $95 \%$ confidence interval under the no-predictability null. The three-factor model for returns generates an adjusted $R$-squared statistic of $16 \%$ in historical data; by contrast, using bootstrapped data, the $95 \%$ bootstrapped confidence interval for this statistic under the no-predictability null ranges from just $-2-4 \%$. 
Table 7

Small sample inference: bootstrapping the regressors

\begin{tabular}{|c|c|c|c|c|c|}
\hline \multicolumn{6}{|c|}{ Excess returns } \\
\hline \multirow[b]{2}{*}{$x_{i t}$} & \multirow[b]{2}{*}{$\hat{\beta}$} & \multicolumn{2}{|c|}{ Unrestricted model } & \multicolumn{2}{|c|}{ Under the null } \\
\hline & & $95 \% \mathrm{CI}$ & $90 \% \mathrm{CI}$ & $95 \% \mathrm{CI}$ & $90 \% \mathrm{CI}$ \\
\hline$c$ & -0.001 & $(-0.0160 .013)$ & $\left(\begin{array}{ll}-0.013 & 0.011)\end{array}\right.$ & $\left(\begin{array}{lll}-0.006 & 0.025)\end{array}\right.$ & $\left(\begin{array}{lll}-0.003 & 0.023\end{array}\right)$ \\
\hline$\widehat{G}_{1 t}^{2}$ & 0.011 & $\left(\begin{array}{l}0.003 \\
0.018\end{array}\right)$ & (0.004 0.017) & $\left(\begin{array}{lll}-0.008 & 0.008\end{array}\right)$ & $(-0.0070 .006)$ \\
\hline$\widehat{G}_{3 t}^{1 t}$ & 0.019 & $\left(\begin{array}{lll}0.007 & 0.032\end{array}\right)$ & $\left(\begin{array}{lll}0.009 & 0.030)\end{array}\right.$ & $\left(\begin{array}{lll}-0.013 & 0.014)\end{array}\right.$ & $\left(\begin{array}{lll}-0.011 & 0.012\end{array}\right)$ \\
\hline$c a y_{t}$ & 1.822 & $(0.7932 .836)$ & $(0.9862 .659)$ & $\left(\begin{array}{lll}-1.135 & 1.109)\end{array}\right.$ & $\left(\begin{array}{lll}-0.936 & 0.927\end{array}\right)$ \\
\hline$R^{2}$ & 0.170 & $\left(\begin{array}{lll}0.068 & 0.287\end{array}\right)$ & $\left(\begin{array}{lll}0.081 & 0.266\end{array}\right)$ & $\left(\begin{array}{lll}0.001 & 0.055\end{array}\right)$ & $\left(\begin{array}{ll}0.002 & 0.046)\end{array}\right.$ \\
\hline \multirow[t]{2}{*}{$\bar{R}^{2}$} & 0.16 & $\left(\begin{array}{lll}0.051 & 0.274\end{array}\right)$ & $\left(\begin{array}{lll}0.065 & 0.253\end{array}\right)$ & $\left(\begin{array}{lll}-0.017 & 0.038)\end{array}\right.$ & $\left(\begin{array}{lll}-0.016 & 0.029\end{array}\right)$ \\
\hline & & & Volatility & & \\
\hline$c$ & -0.106 & $(-0.177-0.047)$ & $(-0.165-0.059)$ & $(-0.0170 .141)$ & $\left(\begin{array}{lll}-0.002 & 0.126\end{array}\right)$ \\
\hline$d_{t}-p_{t}$ & -0.036 & $(-0.056-0.021)$ & $(-0.053-0.024)$ & $\left(\begin{array}{lll}-0.022 & 0.020\end{array}\right)$ & $(-0.0170 .016)$ \\
\hline$Y I E L D_{t}$ & 1.152 & $(0.4462 .022)$ & $(0.584$ 1.853) & $(-0.9070 .974)$ & $\left(\begin{array}{lll}-0.758 & 0.791)\end{array}\right.$ \\
\hline$\widehat{F}_{1 t}$ & 0.005 & $\left(\begin{array}{ll}0.001 & 0.010\end{array}\right)$ & (0.002 0.009$)$ & $(-0.0050 .005)$ & $\left(\begin{array}{lll}-0.004 & 0.004)\end{array}\right.$ \\
\hline$V O L_{t}$ & 0.347 & $\left(\begin{array}{lll}0.188 & 0.451\end{array}\right)$ & $\left(\begin{array}{lll}0.210 & 0.428\end{array}\right)$ & $(-0.1580 .138)$ & $\left(\begin{array}{lll}-0.138 & 0.110\end{array}\right)$ \\
\hline$R^{2}$ & 0.386 & $\left(\begin{array}{lll}0.189 & 0.694\end{array}\right)$ & $\left(\begin{array}{lll}0.223 & 0.652\end{array}\right)$ & $\left(\begin{array}{lll}0.003 & 0.065\end{array}\right)$ & $\left(\begin{array}{l}0.004 \\
0.056)\end{array}\right.$ \\
\hline $\bar{R}^{2}$ & 0.371 & $\left(\begin{array}{lll}0.170 & 0.686)\end{array}\right.$ & $(0.2040 .644)$ & $\left(\begin{array}{lll}-0.021 & 0.043\end{array}\right)$ & $\left(\begin{array}{lll}-0.020 & 0.033\end{array}\right)$ \\
\hline
\end{tabular}

Let $x_{i t}$ denote the state variables for summarizing the conditional value of $y_{t}$ (either returns or volatility). For each state variable $x_{i t}, i=1, \ldots K-1$, we estimate $x_{i t}=\rho_{i} x_{i t-1}+v_{i t}$. Let $v_{., t}$ be the $1 \times K$ vector of residuals. Let $\tilde{x}_{1, .}=x_{1, .}$. For $t=2, \ldots T, \tilde{x}_{i t}$ is generated as $\tilde{x}_{i t}=\rho_{i} \tilde{x}_{i t-1}+\tilde{v}_{i t}$, where $\tilde{v}_{., t}$ is sampled (with replacement) from $v_{., t}, t=2, \ldots T$. Unrestricted samples of $y_{t}$ are generated recursively as $\tilde{y}_{t}=\tilde{X}(t, 1: K-1) \hat{\beta}(1: K-1)+$ $\hat{\beta}(K) \tilde{y}_{t-1} \tilde{e}(t)$, where $\hat{\beta}$ are the least squares estimates reported in column 2 , and $\tilde{e}$ are resampled from $\hat{e}$, the least squares residuals. Samples under the null are generated as $\tilde{y}=\bar{y}+\tilde{e}^{0}$, where $\tilde{e}^{0}$ is resampled form $\hat{e}=y-\bar{y}$.

Similarly, the four-factor model for volatility generates an adjusted $R$-squared statistic of $37 \%$ in historical data; by contrast, using bootstrapped data, the $95 \%$ bootstrapped confidence interval for this statistic under the no-predictability null ranges from just $-2.1-4.4 \%$. In short, the magnitude of predictability found in historical data is too large to be accounted for by sampling error in samples of the size we have.

Finally, the top panel of Tables 7 and 8 reports a 95\% bootstrapped confidence interval of a $\chi^{2}(2)$ statistic for the null hypothesis that the estimated volatility and combination factors are jointly equal to zero. The corresponding $\chi^{2}(2)$ estimate from historical data of 16.87 is well outside the $95 \%$ confidence interval of $(0.52,7.65)$ under the no-predictability null. The statistical relation of these factors to future returns is strong, even accounting for the small-sample distribution of standard test statistics.

\section{Conclusion}

A large and growing body of empirical work is devoted to estimating the relation between risk and return in the U.S. stock market. Although theory typically predicts a 
Table 8

Small-sample inference: bootstrapping the panel data and regressors

\begin{tabular}{|c|c|c|c|c|c|}
\hline \multicolumn{6}{|c|}{ Excess returns } \\
\hline \multirow[b]{2}{*}{$x_{i t}$} & \multirow[b]{2}{*}{$\hat{\beta}$} & \multicolumn{2}{|c|}{ Unrestricted model } & \multicolumn{2}{|c|}{ Under the null } \\
\hline & & $95 \% \mathrm{CI}$ & $90 \% \mathrm{CI}$ & $95 \% \mathrm{CI}$ & $90 \% \mathrm{CI}$ \\
\hline$c$ & -0.001 & $\left(\begin{array}{lll}-0.015 & 0.013\end{array}\right)$ & $(-0.0130 .011)$ & $(-0.0060 .025)$ & $\left(\begin{array}{lll}-0.003 & 0.023\end{array}\right)$ \\
\hline$\widehat{G}_{1 t}^{2}$ & 0.011 & $\left(\begin{array}{l}0.004 \\
0.017)\end{array}\right.$ & $(0.0050 .016)$ & $(-0.0080 .007)$ & $(-0.0070 .006)$ \\
\hline$\widehat{G}_{3 t}$ & 0.019 & $(0.0070 .032)$ & (0.009 0.029$)$ & $\left(\begin{array}{lll}-0.013 & 0.013\end{array}\right)$ & $\left(\begin{array}{lll}-0.011 & 0.011\end{array}\right)$ \\
\hline $\mathrm{cay}_{t}$ & 1.822 & $\left(\begin{array}{lll}0.802 & 2.835\end{array}\right)$ & $(0.9882 .654)$ & $(-1.1241 .109)$ & $\left(\begin{array}{lll}-0.929 & 0.917)\end{array}\right.$ \\
\hline$R^{2}$ & 0.170 & $(0.0770 .297)$ & $\left(\begin{array}{lll}0.092 & 0.278\end{array}\right)$ & $\left(\begin{array}{lll}0.001 & 0.056\end{array}\right)$ & (0.002 0.046) \\
\hline $\bar{R}^{2}$ & 0.16 & $\left(\begin{array}{lll}0.060 & 0.284\end{array}\right)$ & $\left(\begin{array}{lll}0.076 & 0.265)\end{array}\right.$ & $\left(\begin{array}{lll}-0.017 & 0.039)\end{array}\right.$ & $\left(\begin{array}{lll}-0.016 & 0.029)\end{array}\right.$ \\
\hline \multirow[t]{2}{*}{$\chi^{2}(2)$} & 16.87 & (6.373 44.108) & $(8.01039 .600)$ & $(0.0527 .651)$ & (0.104 6.117) \\
\hline & \multicolumn{5}{|c|}{ Volatility } \\
\hline$c$ & -0.106 & $(-0.177-0.048)$ & $(-0.163-0.060)$ & $(-0.0170 .141)$ & $\left(\begin{array}{ll}-0.002 & 0.125)\end{array}\right.$ \\
\hline$d_{t}-p_{t}$ & -0.036 & $(-0.056-0.021)$ & $(-0.053-0.024)$ & $\left(\begin{array}{lll}-0.022 & 0.020\end{array}\right)$ & $(-0.0170 .016)$ \\
\hline$Y I E L D_{t}$ & 1.152 & $(0.4592 .009)$ & $(0.5961 .855)$ & $\left(\begin{array}{lll}-0.918 & 0.962\end{array}\right)$ & $(-0.7440 .768)$ \\
\hline$\widehat{F}_{1 t}$ & 0.005 & $\left(\begin{array}{ll}0.002 & 0.010\end{array}\right)$ & $\left(\begin{array}{lll}0.002 & 0.009\end{array}\right)$ & $(-0.0050 .005)$ & $(-0.0040 .004)$ \\
\hline$V O L_{t}$ & 0.347 & $\left(\begin{array}{lll}0.191 & 0.453\end{array}\right)$ & $\left(\begin{array}{lll}0.211 & 0.428\end{array}\right)$ & $\left(\begin{array}{lll}-0.158 & 0.138\end{array}\right)$ & $\left(\begin{array}{lll}-0.139 & 0.110)\end{array}\right.$ \\
\hline$R^{2}$ & 0.386 & $\left(\begin{array}{lll}0.208 & 0.709)\end{array}\right.$ & $\left(\begin{array}{lll}0.242 & 0.674\end{array}\right)$ & $\left(\begin{array}{lll}0.003 & 0.066\end{array}\right)$ & $(0.0040 .056)$ \\
\hline $\bar{R}^{2}$ & 0.371 & $\left(\begin{array}{lll}0.189 & 0.702\end{array}\right)$ & $(0.2240 .666)$ & $\left(\begin{array}{lll}-0.021 & 0.044\end{array}\right)$ & $\left(\begin{array}{lll}-0.020 & 0.034\end{array}\right)$ \\
\hline
\end{tabular}

Let $x_{i t}$ denote the state variables for summarizing the conditional value of $y_{t}$ (either returns or volatility). Let $z_{i t}, i=1, \ldots N, t=1, \ldots T$ be standardized data from which the factors are extracted. By definition, $z_{i t}=\lambda_{i}^{\prime} F_{t}+u_{i t}$. Let $\hat{\lambda}_{i}$ and $\hat{F}_{t}$ be the principal components estimators of $\lambda_{i}$ and $F_{t}$, and let $\hat{u}_{i t}$ be the estimated idiosyncratic errors. For each $i=1, \ldots N$, we estimate an $\operatorname{AR}(1)$ model $\hat{u}_{i t}=\rho_{i} \hat{u}_{i t-1}+w_{i t}$. Let $\tilde{u}_{1, \text {, }}=u_{1, \text {. }}$. For $t=2, \ldots T$, let $\tilde{u}_{i t}=\hat{\rho}_{i} \tilde{u}_{i t-1}+\tilde{w}_{i t}$, where $\tilde{w}_{i, t}$ is sampled (with replacement) from $\hat{w}_{., t}, t=2, \ldots T$. Then $\tilde{z}_{i t}=\hat{\lambda}_{i}^{\prime} \hat{F}_{t}+\tilde{u}_{i t}$. Estimation by principal components on the data $\tilde{z}$ yields $\tilde{F}_{t}$. The remaining regressors (other than the factors and the lagged dependent variable) are obtained by first estimating an AR(1), and then resampling the residuals of the autoregressions. Unrestricted samples of $y_{t}$ are generated as $\tilde{y}=\tilde{X} \hat{\beta}+\tilde{e}$, where $\hat{\beta}$ are the least squares estimates reported in column 2, and $\tilde{e}$ are resampled from $\hat{e}$, the least squares residuals, and $\tilde{X}$ is a set of bootstrapped regressors with $\hat{F}_{t}$ replaced by $\tilde{F}_{t}$. Samples under the null are generated as $\tilde{y}=\bar{y}+\tilde{e}^{0}$, where $\tilde{e}^{0}$ is resampled form $\hat{e}=y-\bar{y}$. The row labeled " $\chi^{2}(2)$ " in the top panel reports the Wald statistic for the null hypothesis that the coefficients on $G_{1 t-1}^{2}$ and $G_{3 t-1}$ are jointly zero. The Wald statistic has an asymptotic $\chi^{2}(2)$ distribution.

positive relation, empirical findings are mixed and often suggest a negative relation. An important limitation of existing empirical work, however, pertains to the relatively small amount of conditioning information used to estimate the conditional mean and conditional volatility of excess stock market returns. In turn, the use of such sparse information sets in the construction of fitted moments can translate into an omittedinformation bias in the estimated risk-return relation.

In this paper, we consider one approach to this omitted-information problem by employing a methodology for incorporating a large amount of conditioning information in our estimates of the conditional mean and conditional volatility of excess stock market 
returns. Recent research on dynamic factor models finds that the information in a large number of economic time series can be effectively summarized by a relatively small number of estimated factors, affording the opportunity to exploit a rich base of information more likely to span the information sets of financial market participants than in previous analyses. In doing so, our study contributes to the empirical literature by evaluating both the potential role of omitted information in the estimated risk-return relation as well as the robustness of previous results to conditioning on richer information sets.

Some of our results support the findings of pre-existing studies. For example, we find that the conditional mean return and conditional Sharpe ratio are strongly countercyclical, and that lead-lag dynamics are important elements of the risk-return relation. But other key aspects of our results differ from previous work, suggesting that the factor-augmented approach is important for properly identifying the empirical risk-return relation. In particular, we introduce several new factors that contain significant information about either future returns or future volatility. Two factors stand out as particularly important for quarterly excess returns: a volatility factor that is highly correlated with squared returns, and a risk-premium factor that is highly correlated with well-established risk factors for explaining the cross-section of expected returns. Using the information contained in these estimated factors, we find that the contemporaneous relation between the conditional mean and conditional volatility is strongly positive, once we control for lags of these variables. Our findings therefore support the standard theoretical prediction of a positive volatility-in-mean effect. We also find a strongly negative lag-volatility-inmean effect, about which there is much less theoretical precedent. Finally, we find that the improvement in out-of-sample forecasting power afforded by our estimated factors is strongly statistically significant and remarkably stable over time, even though the relation between many commonly used predictors and future returns is unstable over our sample period, especially during the last half of the 1990s. This evidence reinforces the notion that dynamic factor analysis can provide robustness against the temporal instability that plagues low-dimensional forecasting regressions.

There are several possible directions for future work. The investigation here could be extended to study the potential role of nonlinearities in the risk-return relation (e.g., Harvey, 2001), or to assess the degree of time variation in the risk-return relation (e.g., Campbell, 1987; Harvey, 2001). In addition, the approach taken here-in which common factors from large data sets are combined with measures of realized volatility-could be extended to model conditional covariances, or conditional betas, as in the work of Andersen, Bollerslev, Diebold, and Wu (2005a, b). All of these issues lend themselves well to studies using large data sets of conditioning information, summarized by a few estimated factors.

\section{Appendix A}

\section{A.1. Data}

Below we list the data used to construct the macro factors. The data are quarterly and span 1960:1 to 2002:4. All macro data are from DRI-Global Insight, Basic Economics Database. The format is, series number, series mneonic; transformation code and brief 
series description. The data transformation (DT) codes are, $1=$ no transformation; $2=$ first difference; $4=\log ; 5=\log$ first difference. $\mathrm{GY}=$ national income.

\begin{tabular}{ll}
\multicolumn{2}{l}{ Category } \\
FX (FX) \\
\hline 1 & BPAUS \\
2 & BPB \\
3 & GDFXFC \\
4 & GNET \\
5 & GRFIW \\
6 & GXIM \\
7 & GXMDQF \\
8 & GXMNQF \\
9 & GXMQF \\
10 & GDFMFC
\end{tabular}

DT Description

U.S. ASSETS ABROAD (NET)

BAL OF P'MENT:BALANCE ON MERCHANDISE TRADE,MIL.\$ SA

CHAIN-TYPE QUANTITY INDEX - EXPORTS OF GOODS AND SERVICES

NET EXPORTS OF GOODS AND SERVICES

RECEIPT FACTOR INCOME FROM REST OF

WORLD(BIL.\$,SAAR)(T1.9)

$\%$ CHG FRM PRECEDING PERIOD: IMPORTS

(CURRENT\$)

EXPORTS-DURABLE GOODS,SRC:BEA,BIL OF

1996 DOLLARS

EXPORTS-NONDURABLE GOODS,SRC:BEA,BIL

OF 1996 DOLLARS

EXPORTS-GOODS(FIXED),SRC:BEA,BIL OF 1996

DOLLARS

Consumption (Cons)

$11 \quad$ GDFCDC 5

CHAIN-TYPE QUANTITY INDEX - IMPORTS OF

GOODS AND SERVICES

12 GXDAQF 5

CHAIN-TYPE QUANTITY INDEX - PCE, DURABLE GOODS

AUTO OUTPUT-EXPORTS,SRC:BEA,BIL OF 1996

DOLLARS

13 GXPC 1

\% CHG FROM PRECEDING PERIOD:PERSONAL

CONSUMPTION EXPENDS.(CURR.\$)

$14 \quad$ GDFCFC 5

CHAIN-TYPE QUANTITY INDEX - PERSONAL

CONSUMPTION EXPENDITURES

Prices (Pri)

$15 \quad$ EXRJAN 5

FOREIGN EXCHANGE RATE: JAPAN (YEN PER U.S.\$)

16 EXRUK 5

FOREIGN EXCHANGE RATE: UNITED KINGDOM

(CENTS PER POUND)

17 EXRUS 5

UNITED STATES:EFFECTIVE EXCHANGE

RATE(MERM)(INDEX NO.)

$18 \quad$ GD $\quad 5$

IMPLICIT PR DEFLATOR: GROSS NATIONAL

PRODUCT

$19 \quad$ GDC $\quad 5$

IMPLICITPR DEFLATOR: PERSONAL

CONSUMPTION EXPENDITURES

$20 \quad$ GDCD 5

21 GDCN 5

$22 \quad$ GDCS 5

IMPLICIT PR DEFLATOR: DURABLE GOODS,PCE

IMPLICIT PR DEFLATOR: NONDURABLE GOODS,PCE

IMPLICIT PR DEFLATOR: SERVICES, PCE 
23 GDEX 5

24 GDEXIM 5

25 GDFCC 5

26 GDFCNC 5

$27 \quad$ GDFCSC 5

28 GDFDCF 5

$29 \quad$ GDFDFC 5

$30 \quad$ GDFDPC 5

$31 \quad$ GDFEXC 5

32 GDFGEC 5

33 GDFGFC 5

$34 \quad$ GDFGOC 5

$35 \quad$ GDFGSC 5

$36 \quad$ GDFICF 5

$37 \quad$ GDFIMC 5

38 GDFIRC 5

39 GDFISC 5

$40 \quad$ GDFNRC 5

41 GDGF 5

42 GDIS 5

43 LBGDPU 5

$44 \quad$ PMCP 5

45 PSCCOM 5

$46 \quad$ PSCFOO 5

$47 \quad$ PSCMAT 5

$48 \quad$ PUCX 5
IMPLICIT PR DEFLATOR: EXPORTS OF GDS \&SER

TERMS OF TRADE

CHAIN-TYPE PRICE INDEX - PERSONAL CONSUMPTION EXPENDITURES

CHAIN-TYPE PRICE INDEX - PCE, NONDURABLE GOODS

CHAIN-TYPE PRICE INDEX - PCE, SERVICES

CHAIN-TYPE PRICE INDEX - NATL DEFENSE

EXPENDITURES \&GROSS INVESTM

CHAIN-TYPE PRICE INDEX - PCE, DURABLE GOODS

CHAIN-TYPE PRICE INDEX- PRODUCERS'

DURABLE EQUIPMENT

CHAIN-TYPE PRICE INDEX - EXPORTS OF

GOODS AND SERVICES

CHAIN-TYPE PRICE INDEX - GOVT

CONSUMPTION EXPENDITURES \&GROSS INV

CHAIN-TYPE PRICE INDEX - FED CONSUMPTION

EXPEND \&GROSS INVESTMENT

CHAIN-TYPE PRICE INDEX - NONDEF CONS

EXPENDITURES \&GROSS INVESTME

CHAIN-TYPE PRICE INDEX - S\&L CONSUMPTION

EXPEND \&GROSS INVESTMENT

CHAIN-TYPE PRICE INDEX - PRIVATE FIXED

INVESTMENT

CHAIN-TYPE PRICE INDEX - IMPORTS OF

GOODS AND SERVICES

CHAIN-TYPE PRICE INDEX - RESIDENTIAL

CHAIN-TYPE PRICE INDEX - NONRESIDENTIAL STRUCTURES

CHAIN-TYPE PRICE INDEX - NONRESIDENTIAL IMPLICIT PR DEFLATOR: FED GOV'T PURCH OF GDS \&SER

IMPLICIT PR DEFLATOR: PRIVATE

NONRESINDENTIAL STRUCTURES

IMPLICIT PRICE DEFLATOR: NONFARM

BUSINESS $(1982=100$, SA $)$

NAPM COMMODITY PRICES INDEX (PERCENT)

SPOT MARKET PRICE INDEX:BLS \&CRB: ALL

COMMODITIES(1967 = 100)

SPOT MARKET PRICE INDEX:BLS \&CRB:

FOODSTUFFS $(67=100$, NSA $)$

SPOT MARKET PRICE INDEX:BLS \&CRB: RAW

INDUSTRIALS $(67=100$, NSA $)$

CPI-U: COMMODITIES LESS FOOD $(82-84=100, \mathrm{SA})$ 


\begin{tabular}{|c|c|}
\hline 49 & PUCXX \\
\hline 50 & PUHS \\
\hline 51 & PUNEW \\
\hline 52 & PUXF \\
\hline 53 & PUXHS \\
\hline 54 & PUXM \\
\hline 55 & PUXX \\
\hline 56 & PWFCSA \\
\hline 57 & PWFPSA \\
\hline 58 & PWFSA \\
\hline 59 & PWIMSA \\
\hline 60 & PWMND \\
\hline 61 & PWSA2X \\
\hline 62 & PWSA3X \\
\hline 63 & PWSA4 \\
\hline 64 & PWSA5 \\
\hline
\end{tabular}

$\underline{\text { Fixed Investment (Inv) }}$

\begin{tabular}{lll}
\hline 65 & GFINO & 5 \\
66 & GIFQF & 5 \\
67 & GINQF & 5 \\
68 & GIRQF & 5 \\
69 & GISQF & 5 \\
70 & GPIQF & 5 \\
71 & GXIFN & 1
\end{tabular}

72 GXIFR 1

CPI-U:COMMODITIES LESS FOOD AND ENERGY $(82-84=100, \mathrm{SA})$

CPI-U: SHELTER $(82-84=100$, SA $)$

CPI-U: ALLITEMS (82-84 = 100,SA)

CPI-U: ALL ITEMS LESS FOOD $(82-84=100, \mathrm{SA})$

CPI-U: ALL ITEMS LESS SHELTER $(82-84=100$, SA)

CPI-U: ALL ITEMS LESS MIDICAL CARE

$(82-84=100$, SA $)$

CPI-U: ALL ITEMS LESS FOOD AND ENERGY

$(82-84=100$, SA $)$

PRODUCER PRICE INDEX:FINISHED CONSUMER GOODS $(82=100$, SA $)$

PRODUCER PRICE INDEX:CAPITAL EQUIPMENT $(82=100, \mathrm{SA})$

PRODUCER PRICE INDEX: FINISHED GOODS

$(82=100, \mathrm{SA})$

PRODUCER PRICE INDEX:INTERMED

MAT.SUPPLIES \&COMPONENTS $(82=100$, SA $)$

PRODUCER PRICE INDEX: TOTAL

NONDURABLE GOODS $(82=100$, NSA $)$

PRODUCER PRICE INDEX:INTERMED MAT.LESS

FOODS \&FEEDS $(82=100$, SA $)$

PRODUCER PRICE INDEX:FINISHED CONSUMER GODS EXCL FOODS $(82=100$, SA $)$

PRODUCER PRICE INDEX:CONSUM NOND GODS LESS FOOD $(82=100$, SA $)$

PRODUCER PRICE INDEX:CONSUMER

DURABLE GOODS $(82=100, \mathrm{SA})$

FIXED INVEST:PRODUCER DURABLE EQUIP.

OTHER(BILSSAAR)(T5.4)

FIXED INVEST, TOTAL(FIXED), SRC:BEA, BIL OF 1996 DOLLARS

FIXED INVEST, NONRESIDENTIAL(FIXED),

SRC:BEA, BIL OF 1996 DOLLARS

FIXED INVEST, RESIDENTIAL(FIXED), SRC:BEA, BIL OF 1996 DOLLARS

PUR OF NONRES STRUCT-TOTAL, SRC:BEA, BIL

OF 1996 DOLLARS

GROSS PRIV DOMESTIC

INVEST(FIXED),SRC:BEA,BIL OF 1996 DOLLLARS $\%$ CHG FRM PRECEDING

PERIOD:NONRESIDENTIAL FIXED

INVEST.(CURR.\$)

\% CHG FRM PRECEDING PERIOD:RESIDENTIAL FIXED INVESTMENT(CURR\$) 


$\begin{array}{lll}73 & \text { GXIPD } & 1 \\ 74 & \text { GXIS } & 1 \\ 75 & \text { GXPI } & 1 \\ 76 & \text { GDFFIC } & 5 \\ 77 & \text { GDFIFC } & 5\end{array}$

Output \& Income (Out)

$78 \quad$ GDFDEC 5

79 GDFEOC 5

$80 \quad$ GDFFGC 5

$81 \quad$ GDFGGC 5

82 GDFGLC 5

83 GDFINC 5

$84 \quad$ GDFNFC 5

85 GDFPDC 5

86 GDFRFC 5

$87 \quad$ GDFSFC 5

88 GDFSTC 5

89 GDPQF 5

90 GPBQF 5

91 GPY 5

92 GWY 5

93 GXNP 1

94 GXSAV 5

95 GXYD 1

96 GYDPCQ 5

$97 \quad$ GYFIR 5

$98 \quad$ GYGGE 5
\% CHG FRM PRECEDING PERIOD:

NONRESID.PRODUCERS'DUR.EQUIP(CURR\$)

$\%$ CHG FRM PRECEDING PERIOD: NONRESIDENTIAL STRUCTURES (CURRENT\$) \% CHG FRM PRECEDING

PERIOD:GROSSPRIV.DOM.INVESTMNT(CURR.\$)

CHAIN-TYPE QUANTITY INDEX - PRIVATE FIXED INVESTMENT

CHAIN-TYPE QUANTITY INDEX - GROSS

PRIVATE DOMESTIC INVESTMENT

CHAIN-TYPE QUANTITY INDEX - NATL DEF

EXPENDITURES \& GROSS INVESTME

CHAIN-TYPE QUANTITY INDEX - NONDEF CONS

EXPEND \& GROSS INVESTMENTS

CHAIN-TYPE QUANTITY INDEX - FED

CONSUMPTION EXPEND \& GROSS INVESTM

CHAIN-TYPE QUANTITY INDEX - GOVT

CONSUMPTION EXPENDITURES \& GROSS

CHAIN-TYPE QUANTITY INDEX - S\&L

CONSUMPTION EXPEND \& GROSS INVESTM

CHAIN-TYPE QUANTITY INDEX -

NONRESIDENTIAL

CHAIN-TYPE QUANTITY INDEX - PCE,

NONDURABLE GOODS

CHAIN-TYPE QUANTITY INDEX - PRODUCERS'

DURABLE EQUIPMENT

CHAIN-TYPE QUANTITY INDEX - RESIDENTIAL

CHAIN-TYPE QUANTITY INDEX - PCE, SERVICES

CHAIN-TYPE QUANTITY INDEX -

NONRESIDENTIAL STRUCTURES

GDP (FIXED),SRC:BEA,BIL OF 1996 DOLLARS

GDP-BUS,SRC:BEA,BIL OF 1996 DOLLARS

PERSONAL INCOME, TOTAL

NAT'L INCOME: WAGES AND SALARIES

$\%$ CHANGE FROM PRECEDING PERIOD, GNP

CURRENT \$

PERSN'L INCOME: PERS SAVING RATE, GPSAV

AS \% OF GYD

\% CHG FRM PRECEDING PERIOD: DISP.

PERSONAL INCOME (CURRENT \$)

DISPOSABLE PERSONAL INCOME PER CAPITA IN CHAINED (1996) DOLLARS

GY BY IND DIV: FINANCE, INSUR AND REAL

ESTATE

GY BY IND DIV: GOV'T AND GOV'T

ENTERPRISES 


$\begin{array}{lll}99 & \text { GYM } & 5 \\ 100 & \text { GYMD } & 5 \\ 101 & \text { GYMN } & 5 \\ & & \\ 102 & \text { GYS } & 5 \\ 103 & \text { GYT } & 5 \\ 104 & \text { GYUT } & 5 \\ 105 & \text { LIPM } & 5 \\ 106 & \text { LIPMD } & 5 \\ 107 & \text { LIPMN } & 5 \\ 108 & \text { LOUTM } & 5 \\ 109 & \text { LOUTMD } & 5 \\ 110 & \text { LOUTMN } & 5\end{array}$

GY BY IND DIV: MANUFACTURING INDUSTRY GY BY IND DIV: DURABLE GOODS MANUFACTURING INDUSTRY

GY BY IND DIV: NONDURABLE GOODS MANUFACTURING INDUSTRY GY BY IND DIV: SERVICE INDUSTRIES GY BY IND DIV: TRANSPORTATION INDUSTRY GY BY IND DIV: ELECTRIC, GAS AND SANITARY SEW INDUSTRY

OUTPUT INDEX - MANUFACTURING (PC) $($ INDEX, $92=100$, SA $)$

OUTPUTINDEX - DURABLE MANUFACTURING (PC) $($ INDEX,92 = 100,SA)

OUTPUT INDEX - NONDURABLE

MANUFACTURING (PC) (INDEX,92 = 100,SA)

OUTPUT PER HOUR OF ALL PERSONS, INDEX MANUFACTURING (PC) (INDEX,92 = 100,SA) OUTPUT PER HOUR OF ALL PERSONS, INDEX DURABLE MANUFACTURING (PC) (INDEX,92 = 1 OUTPUT PER HOUR OF ALL PERSONS, INDEX, NONDURABLES;INDEX: $1992=100$, SA;SRC: BLS

$\underline{\text { Sales, Orders, Purchases (SOP) }}$

\begin{tabular}{|c|c|c|c|}
\hline 111 & GNSAQF & 5 & $\begin{array}{l}\text { AUTO OUTPUT-FINAL SALES,SRC:BEA,BIL OF } \\
1996 \text { DOLLARS }\end{array}$ \\
\hline 112 & GNSQF & 5 & $\begin{array}{l}\text { FINAL SALES OF DOMESTIC PRODUCT (BILL } \\
1996 \$ \text {, SAAR) }\end{array}$ \\
\hline 113 & GNSQF & 5 & $\begin{array}{l}\text { FINAL SALES OF DOMESTIC PRODUCT (BILL } \\
1996 \text { \$, SAAR) }\end{array}$ \\
\hline 114 & GODSQF & 5 & $\begin{array}{l}\text { FINAL SALES OF DURABLES,SRC:BEA,BIL OF } \\
1996 \text { DOLLARS }\end{array}$ \\
\hline 115 & GONSQF & 5 & $\begin{array}{l}\text { FINAL SALES OF NONDURABLES,SRC:BEA,BIL } \\
\text { OF } 1996 \text { DOLLARS }\end{array}$ \\
\hline 116 & GXNPD & 1 & $\begin{array}{l}\text { GROSS DOM PURCH:CURRENT } \\
\text { DOLLARS(\%,CHANGE)(T8.1) }\end{array}$ \\
\hline 117 & GXNS & 1 & $\begin{array}{l}\text { FINAL SALES OF DOM PROD:CURRENT } \\
\text { DOLLARS( } \%, \text { CHANGE)(T8.1) }\end{array}$ \\
\hline 118 & GXNSD & 1 & $\begin{array}{l}\text { FINAL SALE TO DOM PURCH:CURRENT } \\
\text { DOLLARS }(\%, \text { CHANGE)(T8.1) }\end{array}$ \\
\hline 119 & MOCMQ & 5 & $\begin{array}{l}\text { NEW ORDERS (NET) - CONSUMER GOODS \& } \\
\text { MATERIALS, } 1996 \text { DOLLARS (BCI) }\end{array}$ \\
\hline 120 & MSONDQ & 5 & $\begin{array}{l}\text { NEW ORDERS, NONDEFENSE CAPITAL GOODS, } \\
\text { IN } 1996 \text { DOLLARS (BCI) }\end{array}$ \\
\hline 121 & MTQ & 5 & $\begin{array}{l}\text { SALES - MANUFACTURING \& TRADE, CHAINED } \\
1996 \text { DOLLARS (BCI) }\end{array}$ \\
\hline 122 & PMNO & 5 & NAPM NEW ORDERS INDEX (PERCENT) \\
\hline
\end{tabular}


123 RISMAT 1 REAL INVENTORY-SALES RATIO-

MANUFACTURING and TRADE INDUSTRIES, RATIO, SAAR

124 RZTRU 5 RETAIL SALES: NEW MOTOR TRUCKS, TOTAL (\# OF UNITS,NSA)

125 SMB $\quad 5 \quad$ SHIPMENTS - ALL MANUFACTURING

INDUSTRIES NAICS (M3)

126 SMU $\quad 5 \quad$ SHIPMENTS - ALL MANUFACTURING

INDUSTRIES NAICS (M3)

127 LBOUT 5 OUTPUT PER HOUR ALL PERSONS: BUSINESS $\operatorname{SEC}(1982=100, \mathrm{SA})$

128 LBOUTU 5 OUTPUT PER HOUR ALL PERSONS: NONFARM $\operatorname{BUSINESS}(82=100, \mathrm{SA})$

Employment and Hours (EMP)

129 LBMN 2 HOURSOF ALL PERSONS: BUSINESS SECTOR $(1982=100$, SA $)$

130 LBMNU 2 HOURS OF ALL PERSONS: NONFARM BUSINESS SEC $(1982=100$, SA $)$

131 LHEL 2 INDEX OF HELP-WANTED ADVERTISING IN NEWSPAPERS $(1967=100 ;$ SA $)$

132 LHEM 5 CIVILIAN LABOR FORCE: EMPLOYED, TOTAL (THOUS.,SA)

133 LHEMF 5 CIVILIAN LABOR FORCE: EMPLOYED, WOMEN, 16 YEARS + (THOUS.,SA)

134 LHEMM 5 CIVILIAN LABOR FORCE: EMPLOYED, MEN, 16 YEARS + (THOUS.,SA)

135 LHEMPA 5 RATIO, CIV.EMPLOYMNT/TOTAL NONINST.POPUL.,INC.ARMED FORCES(SA)

136 LHME25 2
EMPLOYED PERSONS: MALES, 25 TO 54 YEARS (THOUS.,SA)

137 LHMP20 2 LABOR FORCE PARTICIPATION RATE: MEN, 20 YRS. + $(\%, \mathrm{SA})$

138 LHMU25 2 UNEMPLOYMENT RATE: MEN, 25 TO 54 YEARS $(\%, \mathrm{SA})$

139 LHMUR 2 UNEMPLOYMENT RATE: MEN, 20 YEARS \& OVER $(\%, \mathrm{SA})$

140 LHTPTA 2 LABOR FORCE PARTICIPATION RATE: BOTH SEXES, 16-19 YRS. $(\%$, SA)

141 LHTUR 2 UNEMPLOYMENT RATE: BOTH SEXES, 16-19 YEARS $(\%, S A)$

142 LHU14 2 UNEMPLOY.BY DURATION: PERSONS UNEMPL.5 TO 14 WKS (THOUS.,SA)

143 LHU15 2 UNEMPLOY.BY DURATION: PERSONS UNEMPL.15 WKS + (THOUS.,SA)

144 LHU26 2 UNEMPLOY.BY DURATION: PERSONS UNEMPL.15 TO 26 WKS (THOUS.,SA) 


\begin{tabular}{|c|c|c|c|}
\hline 145 & LHU27 & 2 & $\begin{array}{l}\text { UNEMPLOY.BY DURATION: PERSONS } \\
\text { UNEMPL. } 27 \text { WKS + (THOUS,SA) }\end{array}$ \\
\hline 146 & LHU5 & 2 & $\begin{array}{l}\text { UNEMPLOY.BY DURATION: PERSONS } \\
\text { UNEMPL.LESS THAN } 5 \text { WKS (THOUS.,SA) }\end{array}$ \\
\hline 147 & LHU680 & 2 & $\begin{array}{l}\text { UNEMPLOY.BY DURATION: } \\
\text { AVERAGE(MEAN)DURATION IN WEEKS (SA) }\end{array}$ \\
\hline 148 & LHUFR & 2 & $\begin{array}{l}\text { UNEMPLOYMENT RATE: WOMEN, } 16 \text { YEARS } \\
\text { AND OVER }(\%, S A)\end{array}$ \\
\hline 149 & LHUMR & 2 & $\begin{array}{l}\text { UNEMPLOYMENT RATE: MEN, } 16 \text { YEARS AND } \\
\text { OVER }(\%, \text { SA })\end{array}$ \\
\hline 150 & LHUR & 2 & $\begin{array}{l}\text { UNEMPLOYMENT RATE: ALL WORKERS, } 16 \\
\text { YEARS \& OVER }(\%, \text { SA })\end{array}$ \\
\hline 151 & LHURM & 2 & $\begin{array}{l}\text { UNEMPLOYMENT RATE: MARRIED MEN, } \\
\text { SPOUSE PRESENT }(\%, \mathrm{SA})\end{array}$ \\
\hline 152 & LHURMF & 2 & $\begin{array}{l}\text { UNEMPLOYMENT RATE: MARRIED WOMEN, } \\
\text { SPOUSE PRESENT }(\%, \text { SA })\end{array}$ \\
\hline 153 & LLCPB & 5 & $\begin{array}{l}\text { UNIT LABOR COST: NONFINANCIAL CORP } \\
(1982=100, \text { SA })\end{array}$ \\
\hline & LMNM & 2 & $\begin{array}{l}\text { HOURS OF ALL PERSONS, INDEX - } \\
\text { MANUFACTURING (PC) }(\text { INDEX, } 92=100, \text { SA })\end{array}$ \\
\hline & LMNMD & 2 & $\begin{array}{l}\text { HOURS OF ALL PERSONS, INDEX - DURABLE } \\
\text { MANUFACTURING (PC) (INDEX, } 92=100, \text { SA })\end{array}$ \\
\hline & LMNMN & 2 & $\begin{array}{l}\text { HOURS OF ALL PERSONS, INDEX - } \\
\text { NONDURABLE MANUFACTURING (PC) } \\
(\text { INDEX, } 92=100, \text { SA) }\end{array}$ \\
\hline & LUINC & 2 & $\begin{array}{l}\text { AVG WKLY INITIAL CLAIMS,STATE } \\
\text { UNEMPLOY.INS.,EXC P.RICO(THOUS;SA) }\end{array}$ \\
\hline & LURSP & 2 & $\begin{array}{l}\text { INSURED UNEMPLOYMENT AS \% COVERED } \\
\text { EMPLOY.,EXC P.RICO }(\%, S A)\end{array}$ \\
\hline & LZHUR & 2 & $\begin{array}{l}\text { UNEMPLOYMENT RATE: TOTAL, } 16 \text { YRS AND } \\
\text { OVER(\%,NSA) }\end{array}$ \\
\hline
\end{tabular}

Compensation and labor cost per hour (CHI)

\begin{tabular}{|c|c|c|c|}
\hline 160 & LBCP & 5 & $\begin{array}{l}\text { COMPENSATION PER HOUR: BUSINESS SECTOR } \\
(1982=100, \mathrm{SA})\end{array}$ \\
\hline 161 & LBCPU & 5 & $\begin{array}{l}\text { COMPENSATION PER HOUR: NONFARM } \\
\text { BUSINESS SEC }(1982=100, \text { SA })\end{array}$ \\
\hline 162 & LBLCP & 5 & $\begin{array}{l}\text { UNIT LABOR COST: BUSINESS SECTOR } \\
(1982=100, \text { SA })\end{array}$ \\
\hline 163 & LBLCPU & 5 & $\begin{array}{l}\text { UNIT LABOR COST: NONFARM BUSINESS SEC } \\
(1982=100, \mathrm{SA})\end{array}$ \\
\hline 164 & LCPM & 5 & $\begin{array}{l}\text { COMPENSATION PER HOUR INDEX - } \\
\text { MANUFACTURING (PC) (INDEX,92 = 100,SA) }\end{array}$ \\
\hline 165 & LCPM7 & 5 & $\begin{array}{l}\text { COMPENSATION PER HOUR (REAL), INDEX- } \\
\text { MANUFACTURING (PC) (INDEX,92 = 100,SA) }\end{array}$ \\
\hline 166 & LCPMD & 5 & $\begin{array}{l}\text { COMPENSATION PER HOUR INDEX - DURABLE } \\
\text { MANUFACTURING (PC) (INDEX,92 = 100,SA) }\end{array}$ \\
\hline
\end{tabular}


$167 \quad$ LCPMD7 5

168 LCPMN 5

$169 \quad$ LCPMN7 5

$170 \quad$ LLCPM 5

$171 \quad$ LLCPMD 5

172 LLCPMN 5

$\frac{\text { Capacity Utilization (Util) }}{173 \text { UTL11 }}$

$174 \quad$ UTL15 2

$175 \quad$ UTL17 2

$176 \quad$ UTL21 2

$177 \quad$ UTL22 2

178 UTL29 2

179 UTL31 2

$180 \quad$ UTL32 2

$181 \quad$ UTL33 2

$182 \quad$ UTL44 2

$183 \quad$ UTL45 2

Housing (Hous)

$\overline{184 \quad \text { GSVNT }} 5$

185 HS6FR 4

186 HSMW 5

187 HSNE 5

188 HSSOU 5

189 HSWST 5
COMPENSATION PER HOUR (REAL), INDEX DURABLE MANUFACTURING (PC)

$($ INDEX, $92=100$

COMPENSATION PER HOUR INDEX -

NONDURABLE MANUFACTURING (PC)

$($ INDEX, $92=100$, SA $)$

COMPENSATION PER HOUR (REAL), INDEX -

NONDURABLE MANUFACTURING (PC)

(INDEX,92 =

UNIT LABOR COSTS INDEX-MANUFACTURING (PC) $($ INDEX,92 = 100,SA)

UNIT LABOR COSTS INDEX - NONDURABLE MANUFACTURING (PC) (INDEX,92 = 100,SA)

UNIT LABOR COSTS INDEX,

NONDURABLES;INDEX: $1992=100$, SA;SRC: BLS

CAPACITY UTILIZATION - MANUFACTURING (SIC)

CAPACITY UTILIZATION - NONMETALLIC

MINERAL PRODUCT NAICS $=327$

CAPACITY UTILIZATION - FABRICATED METAL PRODUCT NAICS $=332$

CAPACITY UTILIZATION - MOTOR VEHICLES AND PARTS NAICS $=3361-3$

CAPACITY UTILIZATION - AEROSPACE AND MISCELLANEOUS TRANSPORTATION EQ.

CAPACITY UTILIZATION - PAPERNAICS $=322$

CAPACITY UTILIZATION - PETROLEUM AND

COAL PRODUCTS NAICS $=324$

CAPACITY UTILIZATION - CHEMICAL

NAICS $=325$

CAPACITY UTILIZATION - PLASTICS AND

RUBBER PRODUCTS NAICS $=326$

CAPACITY UTILIZATION - PRIMARY \& SEMIFINISHED PROCESSING (CAPACITY)

CAPACITY UTILIZATION - FINISHED

PROCESSING (CAPACITY)

PRIVATE CONSTRUCTION:NONRESIDENTIAL TOTAL(BIL\$,SAAR)

HOUSING STARTS: TOTAL NEW PRIV HOUSING UNITS (THOUS.,NSA)

HOUSING STARTS:MIDWEST(THOUS.U.)S.A.

HOUSING STARTS:NORTHEAST (THOUS.U.)S.A.

HOUSING STARTS:SOUTH (THOUS.U.)S.A.

HOUSING STARTS:WEST (THOUS.U.)S.A. 


\begin{tabular}{|c|c|}
\hline \multicolumn{2}{|c|}{ Indexes (Ind) } \\
\hline 190 & $\overline{\text { DCOINC }}$ \\
\hline 191 & DLAGG \\
\hline 192 & DLDF1P \\
\hline 193 & DLDF6P \\
\hline 194 & DLEAD \\
\hline 195 & DRATE \\
\hline 196 & HHSNTN \\
\hline 197 & PMDEL \\
\hline 198 & PMEMP \\
\hline 199 & PMI \\
\hline 200 & PMP \\
\hline Oth & Other) \\
\hline 201 & CCIPY \\
\hline 202 & FDLALT \\
\hline 203 & FMD \\
\hline 204 & GGOFS \\
\hline 205 & GJJPAT \\
\hline 206 & GJPATX \\
\hline 207 & LBPB \\
\hline 208 & PMNV \\
\hline 209 & PZRP67 \\
\hline
\end{tabular}

COMPOSITE INDEX OF 4 COINCIDENT

INDICATORS( $87=100$, SA $)$

COMPOSITE INDEX OF 7 LAGGING

INDICATORS $(87=100$, SA $)$

DIFFUSION INDEX:12 LEAD INDICATOR

COMPONENT(\% RISING + 1-MO SPAN)

DIFFUSION INDEX:12 LEAD INDICATOR

COMPONENT(\% RISING + 6-MO SPAN)

COMPOSITE INDEX OF 11 LEADING

INDICATORS $(87=100$, SA $)$

RATIO, COINCIDENT INDEX TO LAGGING

INDEX $(87=100$, SA $)$

U. OF MICH. INDEX OF CONSUMER

EXPECTATIONS(BCD-83)

NAPM VENDOR DELIVERIES INDEX (PERCENT)

NAPM EMPLOYMENT INDEX (PERCENT)

PURCHASING MANAGERS' INDEX (SA)

NAPM PRODUCTION INDEX (PERCENT)

2 RATIO, CONSUMER INSTAL CREDIT TO

PERSONAL INCOME $(\%, S A)(B C D-95)$

DELINQ.RATE 1-4 U.RESID.MTGE:ALL

LOAN;TOTAL PAST DUE $(\%$, SA)

MORTGAGE DEBTOUTST'G:ALL PROPERTIES

(MIL\$,EOQ,NSA)

GOVT CURRENT SURPLUS/DEFICIT-

OTHER,SRC:BEA,BILLIONS OF 1992 DOLLARS

CORP PROFIT AFTER TAXES WITH IVA \& CCA

(BCD 79)

RATIO,PROFITS(AFT TAXES)WITH IVA \& CCA/

CORP DOMES.INCOME(SA)(BCD81)

UNIT PROFITS: NONFINANCIAL CORP

$(1982=100, \mathrm{SA})$

NAPM INVENTORIES INDEX (PERCENT)

PURCH POWER CONSUMER \$,URBAN WAGE

EARNERS,CLER WKRS $(67=\$ 1$, NSA $)$

\section{Financial Data}

We list the financial data used to construct factors, the endogenous variables, and other conditioning variables used to predict returns or volatility. The format is series number, mnemonic, source, and brief description. CRSP $=$ Center for Research in Security Prices, University of Chicago; FED = Federal Reserve Board; Shiller $=$ Robert Shiller's Yale web page http://www.econ.yale.edu/ shiller/data/ie_data.xls; French $=$ Kenneth French's Dartmouth web page http://mba.tuck.dartmouth.edu/pages/faculty/ken.french/; LL = Sydney 
Ludvigson's NYU web page http://www.econ.nyu.edu/user/ludvigsons/; $\mathrm{CP}=$ John Cochrane and Monika Piazzesi, University of Chicago GSB. At the bottom we list portfolios of equity returns sorted into size (market capitalization) and book-market categories. Portfolios with missing data during the sample 1960:1-2002:4 are omitted from the analysis.

\section{Category}

Prices, Yield, Dividends (PYD)

$\overline{1}$ D_log(DIV)

2

D_log(P)

3

4

D_DIVreinveste

D_Preinveste

5

d-p

$6 \quad \mathrm{P} / \mathrm{E}$

Interest rates and Spread (IRS)

8

9

10

11

12

13

RREL

Yield10y

TRM10y-3m

Yield1y

TRM10y-1y

AAA

BAA

14

DEF

15

RF

Risk Factors (RiF)

16 R15-R11

17 factor

18

CAY

19

Mkt-RF

20

SMB
Source

CRSP

CRSP

CRSP

CRSP

CRSP

Shiller

FED

FED

FED

FED

FED

FED

FED

FED

French

French

CP

LL

French

French

\section{Description}

Log difference of the sum of the dividends in the last 4 quarters (divs are not reinvested) Log difference of the CRSP portfolio price when dividends are not reinvested Log difference of the sum of the dividends in the last 4 quarters (divs are reinvested) Log difference of the CRSP portfolio price when dividends are reinvested DIVreinveste - Preinveste $=\log ($ DIV $)$ $\log (\mathrm{P})$

Price/earnings ratio

Difference b/w Risk free and its last 4 quarters average

Quarterly yield of bonds with maturity 10 years

Difference b/w 10yTbonds rate and the risk free rate

Yield from a t-bond with maturity one year (secondary mkt, nominal)

Term spread b/w 10years and 1 year t-bonds. AAA cor-porate bonds yield (Moody's seasoned)

BAA corporate bonds yield (Moody's seasoned)

AAA-BAA yield: risk default spread

One-month Treasury bill rate from French data set

Small stock value spread constructed from French database

Piazzesi-Cochrane risk factor, quarterly average (Cochrane and Piazzesi, 2005)

Lettau-Ludvigson risk factor (Lettau and Ludvigson, 2001a)

Fama-French market risk factor (Fama and French, 1993)

Fama-French risk factor (Fama and French, 1993) 


\begin{tabular}{|c|c|c|c|}
\hline 21 & HML & French & $\begin{array}{l}\text { Fama-French risk factor (Fama and French, } \\
\text { 1993) }\end{array}$ \\
\hline $\begin{array}{l}22 \\
\text { Industries }\end{array}$ & UMD & French & $\begin{array}{l}\text { Momentum risk factor, French data set } \\
\text { (Industry Returns } 4 \text { digit SIC codes, French } \\
\text { data set) }\end{array}$ \\
\hline 23 & Agric & French & \\
\hline 24 & Food & French & \\
\hline 25 & Soda & French & \\
\hline 26 & Beer & French & \\
\hline 27 & Smoke & French & \\
\hline 28 & Toys & French & \\
\hline 29 & Fun & French & \\
\hline 30 & Books & French & \\
\hline 31 & Hshld & French & \\
\hline 32 & Clths & French & \\
\hline 33 & MedEq & French & \\
\hline 34 & Drugs & French & \\
\hline 35 & Chems & French & \\
\hline 36 & Rubbr & French & \\
\hline 37 & Txtls & French & \\
\hline 38 & BldMt & French & \\
\hline 39 & Cnstr & French & \\
\hline 40 & Steel & French & \\
\hline 41 & Mach & French & \\
\hline 42 & ElcEq & French & \\
\hline 43 & Autos & French & \\
\hline 44 & Aero & French & \\
\hline 45 & Ships & French & \\
\hline 46 & Mines & French & \\
\hline 47 & Coal & French & \\
\hline 48 & Oil & French & \\
\hline 49 & Util & French & \\
\hline 50 & Telcm & French & \\
\hline 51 & PerSv & French & \\
\hline 52 & BusSv & French & \\
\hline 53 & Comps & French & \\
\hline 54 & Chips & French & \\
\hline 55 & $\mathrm{LabEq}$ & French & \\
\hline 56 & Paper & French & \\
\hline 57 & Boxes & French & \\
\hline 58 & Trans & French & \\
\hline 59 & Whlsl & French & \\
\hline 60 & Rtail & French & \\
\hline 61 & Meals & French & \\
\hline 62 & Banks & French & \\
\hline 63 & Insur & French & \\
\hline 64 & RlEst & French & \\
\hline
\end{tabular}




\begin{tabular}{|c|c|c|c|}
\hline 65 & Fin & French & \\
\hline 66 & Other & French & \\
\hline \multicolumn{3}{|l|}{ Size/BM } & (Returnson stock portfolios sorted by size \\
\hline 67 & $1 \_2$ & French & \\
\hline 68 & $1 \_4$ & French & \\
\hline 69 & $1-5$ & French & \\
\hline 70 & 16 & French & \\
\hline 71 & 17 & French & \\
\hline 72 & 18 & French & \\
\hline 73 & $1-9$ & French & \\
\hline 74 & $1^{-} \mathrm{High}$ & French & \\
\hline 75 & 2_Low & French & \\
\hline 76 & 2 & French & \\
\hline 77 & $2-3$ & French & \\
\hline 78 & 24 & French & \\
\hline 79 & $\overline{25}$ & French & \\
\hline 80 & $2-6$ & French & \\
\hline 81 & $2 \_7$ & French & \\
\hline 82 & $2 \_8$ & French & \\
\hline 83 & $2-9$ & French & \\
\hline 84 & 2_High & French & \\
\hline 85 & 3_Low & French & \\
\hline 86 & 3 & French & \\
\hline 87 & $3 \_3$ & French & \\
\hline 88 & 34 & French & \\
\hline 89 & 3 & French & \\
\hline 90 & $3-6$ & French & \\
\hline 91 & $3^{-} 7$ & French & \\
\hline 92 & 3 & French & \\
\hline 93 & 39 & French & \\
\hline 94 & $3^{-}$High & French & \\
\hline 95 & 4_Low & French & \\
\hline 96 & $4 \_2$ & French & \\
\hline 97 & $4 \_3$ & French & \\
\hline 98 & 4_4 & French & \\
\hline 99 & $4-5$ & French & \\
\hline 100 & $4 \_6$ & French & \\
\hline 101 & 4_7 & French & \\
\hline 102 & 48 & French & \\
\hline 103 & 4_9 & French & \\
\hline 104 & 4_High & French & \\
\hline 105 & 5 Low & French & \\
\hline 106 & $5 \_2$ & French & \\
\hline 107 & $5-3$ & French & \\
\hline 108 & $5 \_4$ & French & \\
\hline 109 & $5-5$ & French & \\
\hline
\end{tabular}




\begin{tabular}{|c|c|c|}
\hline 110 & $5 \_6$ & French \\
\hline 111 & $5-7$ & French \\
\hline 112 & 58 & French \\
\hline 113 & $\overline{5 \_9}$ & French \\
\hline 114 & 5_High & French \\
\hline 115 & 6_Low & French \\
\hline 116 & $6 \_2$ & French \\
\hline 117 & $6 \_3$ & French \\
\hline 118 & $6 \_4$ & French \\
\hline 119 & $6 \_5$ & French \\
\hline 120 & 6_6 & French \\
\hline 121 & $6 \_7$ & French \\
\hline 122 & 6_8 & French \\
\hline 123 & 6_9 & French \\
\hline 124 & 6_High & French \\
\hline 125 & 7-Low & French \\
\hline 126 & $7-2$ & French \\
\hline 127 & $7-3$ & French \\
\hline 128 & $7-4$ & French \\
\hline 129 & $7-5$ & French \\
\hline 130 & 7_6 & French \\
\hline 131 & $7-7$ & French \\
\hline 132 & 7_8 & French \\
\hline 133 & 7-9 & French \\
\hline 134 & 8_Low & French \\
\hline 135 & $8-2$ & French \\
\hline 136 & $8 \_3$ & French \\
\hline 137 & $8-4$ & French \\
\hline 138 & $8 \_5$ & French \\
\hline 139 & $8 \_6$ & French \\
\hline 140 & $8-7$ & French \\
\hline 141 & $8 \_8$ & French \\
\hline 142 & 8_9 & French \\
\hline 143 & 8_High & French \\
\hline 144 & 9_Low & French \\
\hline 145 & $9-2$ & French \\
\hline 146 & $9-3$ & French \\
\hline 147 & $9-4$ & French \\
\hline 148 & $9-5$ & French \\
\hline 149 & $9-6$ & French \\
\hline 150 & $9-7$ & French \\
\hline 151 & $9-8$ & French \\
\hline 152 & 9_High & French \\
\hline 153 & $1 \overline{0}$ Low & French \\
\hline 154 & 10_2 & French \\
\hline 155 & $10 \_3$ & French \\
\hline 156 & $10 \_4$ & French \\
\hline
\end{tabular}




$\begin{array}{lll}157 & 10 \_5 & \text { French } \\ 158 & 10 \_6 & \text { French } \\ 159 & 10 \_7 & \text { French }\end{array}$

\section{A.2. Additional results}

This appendix presents additional results on the modeling of the conditional mean, conditional volatility and the risk-return relation. Here we carry out three changes to assess how our results might be affected by the use of historical macro data:

(1) The financial data set is constructed from pure financial series with the exception of the consumption-wealth variable, cay. Thus, once we remove cay from this data set, the factors formed from the financial data set are based only on series that are never revised and are completely predetermined. We redo the analysis using these pure financial factors, not subject to the real-time data release issue.

(2) For the macro conditioning variables that we rely on in our statistically chosen specifications (these include cay and the first factor from the macro data set, $\widehat{F}_{1, t}$ ), we lag these variables an additional quarter, helping to alleviate concerns that the series are reported some time after the end of the quarter.

(3) We show that our main conclusions about the risk-return relation are not changed by using only financial variables, which are completely predetermined.

Table A.1

Regressions of quarterly excess returns on lagged conditioning variables and pure financial factors

\begin{tabular}{ccccc}
\hline \multicolumn{5}{c}{ Model: $m_{t+1}=\alpha_{0}+\alpha_{2}^{\prime} \widehat{G}_{t}^{*}+\beta^{\prime} Z_{t}+\varepsilon_{t+1}$} \\
\hline Row & Regressor & $(a)$ & $(b)$ & $(c)$ \\
\hline 1 & $c a y_{t}$ & & $\mathbf{1 . 8 6}$ & \\
& $(t$-stat $)$ & $(3.98)$ & $\mathbf{1 . 6 8}$ \\
2 & $c a y_{t-1}$ & & $(3.26)$ \\
3 & $(t$-stat $)$ & & $\mathbf{0 . 0 1}$ & $\mathbf{0 . 0 1}$ \\
& $\left(\widehat{G}_{1, t}^{*}\right)^{2}$ & $\mathbf{0 . 0 1}$ & $(3.80)$ & $\mathbf{0 . 0 2}$ \\
4 & $(t$-stat $)$ & $(4.00)$ & $(3.00)$ & $(2.63)$ \\
& $\widehat{G}_{3 t}^{*}$ & $\mathbf{0 . 0 2}$ & 0.15 & 0.14 \\
5 & $(t$-stat $)$ & $(3.48)$ & -2.11 & -2.08 \\
6 & $\bar{R}^{2}$ & 0.08 & -2.04 & \\
\hline
\end{tabular}

Notes: The table reports estimates from OLS regressions of excess stock returns on lagged variables named in the column 2. The dependent variable $m_{t+1}$ is the log return on the CRSP value-weighted stock market index over the 3-month Treasury bill rate. The regressors $\left(G_{1 t}^{*}\right)^{2}$ and $G_{3 t}^{*}$ are pure financial factors (i.e., formed without cay $_{t}$ ) estimated by the method of principal components using a panel of data with 208 financial series over the period 1960:1-2002:4. cay $_{t}$, is the consumption-wealth variable of Lettau and Ludvigson (2001). Newey and West (1987) corrected $t$-statistics are reported in parentheses. Coefficients that are statistically significant at the $5 \%$ level are given in italics. A constant is always included in the regression even though its estimate is not reported in the Table. The regression sample spans the period from the first quarter of 1960 to the fourth quarter of 2002 . 
Table A.2

Regressions of quarterly volatility on lagged conditioning variables and factors

\begin{tabular}{|c|c|c|c|c|}
\hline \multicolumn{5}{|c|}{ Model: $V O L_{t+1}=a_{0}+a_{1}^{\prime} \widehat{F}_{t}+b^{\prime} Z_{t}+u_{t+1}$} \\
\hline Row & Regressor & (a) & (b) & $(c)$ \\
\hline 1 & $\begin{array}{c}c a y_{t} \\
(t \text {-stat })\end{array}$ & & & \\
\hline 2 & $\begin{array}{l}d_{t}-p_{t} \\
(t \text {-stat })\end{array}$ & $\begin{array}{c}-\mathbf{0 . 0 3 5} \\
(-6.945)\end{array}$ & $\begin{array}{c}-\mathbf{0 . 0 3 5} \\
(-6.049)\end{array}$ & $\begin{array}{c}-\mathbf{0 . 0 3 3} \\
(-5.030)\end{array}$ \\
\hline 3 & $\begin{array}{l}Y I E L D_{t} \\
(t \text {-stat })\end{array}$ & $\begin{array}{c}1.152 \\
(3.592)\end{array}$ & $\begin{array}{r}1.2237 \\
(3.749)\end{array}$ & $\begin{array}{c}1.299 \\
(3.854)\end{array}$ \\
\hline 4 & $\begin{array}{c}V O L_{t} \\
(t \text {-stat })\end{array}$ & $\begin{array}{c}\mathbf{0 . 3 4 7} \\
(4.706)\end{array}$ & $\begin{array}{c}\mathbf{0 . 3 7 2} \\
(4.824)\end{array}$ & $\begin{array}{c}\mathbf{0 . 3 9 9} \\
(4.332)\end{array}$ \\
\hline 5 & $\begin{array}{c}\widehat{F}_{1 t} \\
(t \text {-stat })\end{array}$ & $\begin{array}{c}\mathbf{0 . 0 0 5} \\
(4.015)\end{array}$ & & \\
\hline 6 & $\begin{array}{c}\widehat{F}_{1 t-1} \\
(t \text {-stat })\end{array}$ & & $\begin{array}{c}0.002^{*} \\
(1.80)\end{array}$ & \\
\hline 7 & $\bar{R}^{2}$ & 0.39 & 0.35 & 0.35 \\
\hline 8 & $\mathrm{BIC}$ & -4.49 & -4.45 & -4.48 \\
\hline
\end{tabular}

Notes: The table reports estimates from OLS regressions of excess stock returns on lagged variables named in the column 2. The dependent variable $V O L_{t+1}$ is realized volatility for the CRSP value-weighted stock market index. The regressors $\widehat{F}_{i t}$ are estimated by the method of principal components using a panel of data with 159 macro series over the period 1960:1-2002:4. The exogenous conditioning variables in $Z_{t}$ are $d_{t}-p_{t}$, the CRSP log dividend-price ratio, YIELD $D_{t}$, the 1-year Treasury bill yield and lagged volatility. Newey and West (1987) corrected $t$-statistics are reported in parentheses. ${ }^{*}$ Significant at $10 \%$ level or better. Coefficients that are statistically significant at the 5\% level are given in italics. A constant is always included in the regression even though its estimate is not reported in the Table. The sample spans the period from the first quarter of 1960 to the fourth quarter of 2002 .

Tables A.1, A.2 and A.3, attached at the end of the paper, summarize the main results from these changes and show that they have no effect on our main conclusions. Consider Table A.1. Recall that our preferred specification for modeling the conditional mean used two financial factors, the "volatility" factor $G_{1 t}^{2}$, and the "risk-premium" factor $G_{3 t}$, as well as cay $_{t}$ as an additional conditioning variable. Table A.1 shows that when the volatility and risk-premium factors are formed over purely financial indicators omitting cay (now denoted $\left(G_{1 t}^{*}\right)^{2}$ and $G_{3 t}^{*}$ ), they have essentially the same predictive power for excess returns as the original factors $G_{1 t}^{2}$, and $G_{3 t}$ (compare Column (a) of Table A.1 with Column $(g)$ of Table 2 in the main text). This is not surprising since the information contained in the financial factors for future returns is largely orthogonal to that in cay. Table A.1 also shows that the two-period lagged value of cay (denoted $c a y_{t-1}$ since we are forecasting excess returns at $t+1 \%$ ) has very similar forecasting power to the one-period lagged value. Thus, specifications based on pure financial variables and two-quarter lagged cay work just as well as the original specifications.

In Table A.2, we reconsider our preferred specification for modeling conditional volatility, in which we use the three financial variables $d-p_{t}, Y I E L D_{t}$, and $V O L_{t}$ along with the single macro factor $\widehat{F}_{1, t}$. Here we find that if we lag the macro factor $\widehat{F}$ two 
Table A.3

Relation between conditional mean and conditional volatility using pure financial factors and lagged macro factors

\begin{tabular}{|c|c|c|c|c|c|c|c|c|c|c|}
\hline \multicolumn{11}{|c|}{ Model: $\mu_{t}=\delta+\beta_{1} \sigma_{t}+\beta_{2} \sigma_{t-1}+\alpha \mu_{t-1}+\gamma m_{t-1}+\varepsilon_{t+1}$} \\
\hline \multirow[b]{2}{*}{ Row } & \multirow[b]{2}{*}{$\begin{array}{c}\text { Regressand } \\
\mu_{t}=\end{array}$} & \multicolumn{7}{|c|}{ Regressor } & \multirow[b]{2}{*}{$\bar{R}^{2}$} & \multirow[b]{2}{*}{$\mathrm{BIC}$} \\
\hline & & $\begin{array}{c}\sigma_{1, t}^{*} \\
(t \text {-stat })\end{array}$ & $\begin{array}{c}\sigma_{1, t-1}^{*} \\
(t \text {-stat })\end{array}$ & $\begin{array}{c}\mu_{1, t-1}^{*} \\
(t \text {-stat })\end{array}$ & $\begin{array}{c}\mu_{2, t-1}^{*} \\
(t \text {-stat })\end{array}$ & $\begin{array}{c}\sigma_{2, t}^{*} \\
(t \text {-stat })\end{array}$ & $\begin{array}{c}\sigma_{2, t-1}^{*} \\
(t \text {-stat })\end{array}$ & $\begin{array}{c}\mu_{3, t-1}^{*} \\
(t \text {-stat })\end{array}$ & & \\
\hline 1 & $\mu_{1, t}^{*}$ & $\begin{array}{l}\mathbf{1 . 3 5} \\
(4.62)\end{array}$ & $\begin{array}{l}-1.42 \\
(-6.90)\end{array}$ & $\begin{array}{l}\mathbf{0 . 6 3} \\
(11.30)\end{array}$ & & & & & 0.43 & -4.29 \\
\hline 2 & $\mu_{2, t}^{*}$ & $\begin{array}{l}\mathbf{1 . 0 7} \\
(4.86)\end{array}$ & $\begin{array}{l}-1.15 \\
(-5.53)\end{array}$ & & $\begin{array}{l}\mathbf{0 . 5 7} \\
(11.58)\end{array}$ & & & & 0.35 & -4.26 \\
\hline 3 & $\mu_{3, t}^{*}$ & & & & & $\begin{array}{l}\mathbf{1 . 1 5} \\
(5.50)\end{array}$ & $\begin{array}{l}-\mathbf{1 . 0 1} \\
(-7.10)\end{array}$ & $\begin{array}{l}\mathbf{0 . 3 4} \\
(4.10)\end{array}$ & 0.24 & -4.53 \\
\hline
\end{tabular}

Notes: This table reports regressions of estimated conditional mean excess returns $\mu_{t} \equiv \widehat{E}_{t}\left(m_{t+1}\right)$, $m_{t+1} \equiv r_{t+1}-r_{f, t+1}$, on the CRSP value-weighted stock market index over the three-month Treasury bill rate on estimated conditional volatility $\sigma_{t} \equiv \widehat{E}_{t}\left(V O L_{t+1}\right)$ and one-period lags of these variables. The conditional mean and volatility are estimated as fitted values from regressions of excess returns and realized volatility on information variables known at time $t . \mu_{1, t}^{*}$ denotes the fitted value from a regression of excess returns on the information variables $c a y_{t},\left(G_{1 t}^{*}\right)^{2}$, and $G_{3 t}^{*}$, where the latter are pure financial factors (i.e., formed without $c a y_{t}$ ). $\mu_{2, t}^{*}$ denotes the fitted value from a regression of excess returns on $\left(G_{1 t}^{*}\right)^{2}, G_{3 t}^{*}$, and the two-period lagged value of cay, $c a y_{t-1} \cdot \mu_{3, t}^{*}$ is constructed without any macro variables and denotes the fitted value from a regression of excess returns on $\left(G_{1 t}^{*}\right)^{2}, G_{3 t}^{*} . \sigma_{1, t}^{*}$ denotes the fitted value from a regression of realized quarterly volatility, $V O L_{t+1}$, on the information variables $d_{t}-p_{t}$, the CRSP $\log$ dividend-price ratio, YIELD $D_{t}$, the one year Treasury bill yield, the two-period lagged value of $F_{1}, F_{1 t-1}$, and $V O L_{t} . \sigma_{2, t}^{*}$ is constructed without any macro variables and denotes the fitted value from a regression of realized quarterly volatility, $V O L_{t+1}$, on the information variables $d_{t}-p_{t}$, the CRSP $\log$ dividend-price ratio, YIELD $D_{t}$, the one year Treasury bill yield, and $V O L_{t}$. Newey and West (1987) corrected $t$-statistics are reported in parentheses. Coefficients that are statistically significant at the $5 \%$ level are given in italics. A constant is always included in the regression even though its estimate is not reported in the table. The sample spans the period from the first quarter of 1960 to the fourth quarter of 2002 .

quarters rather than one quarter, it is still significant at the $10 \%$ level ( $p$-value 0.074 ) but is no longer significant at the $5 \%$ level. The loss of statistical significance is to be expected because this factor is less persistent than cay, implying that much more information is discarded by throwing away the first-period lag. But notice that replacing the one-quarter lagged value of $\widehat{F}_{1}$ with the two-quarter lagged value has only a small effect on the $R$ square statistic of the volatility regression (compare Columns $a$ and $b$ of Table A.2), and has no substantive effect on the estimated risk-return relation (Table 3.A).

The final row of Table A.3 shows the estimated risk-return relation when only financial variables are used both in the construction of factors and in the construction of fitted moments. Of course, the macro variables cay $y_{t}$ and $\widehat{F}_{1 t}$ contain statistically important information about the conditional mean and volatility above and beyond that found in the pure financial factors. Thus, the results imply that these variables should remain a part of any well-specified model of fitted moments. It turns out, however, that the estimated risk-return relation is qualitatively very similar if these variables are eliminated from the analysis (Table A.3). In particular, as long as the volatility and risk premium factors $\left(G_{1 t}^{*}\right)^{2}$ and $G_{3 t}^{*}$ are included, the contemporaneous conditional risk-return relation (conditional 
on lagged values of mean and volatility) is positive and strongly statistically significant, and lead-lag relations in the estimated equation have the same sign and remain statistically important.

\section{References}

Andersen, T.G., Bollerslev, T., Diebold, F.X., 2002. Parametric and nonparametric volatility measurement. Unpublished paper, University of Pennsylvania.

Andersen, T.G., Bollerslev, T., Diebold, F.X., Labys, P., 2003. Modeling and forecasting realized volatility. Econometrica 71, 579-626.

Andersen, T.G., Bollerslev, T., Diebold, F.X., Wu, J., 2005a. Betas and the macroeconomy. Unpublished paper, University of Pennsylvania.

Andersen, T.G., Bollerslev, T., Diebold, F.X., Wu, J., 2005b. A framework for exploring the macroeconomic determinants of systematic risk. Unpublished paper, University of Pennsylvania.

Bai, J., Ng, S., 2002. Determining the number of factors in approximate factor models. Econometrica 70 (1), $191-221$.

Bai, J., Ng, S., 2005. Confidence intervals for diffusion index forecasts and inference for factor-augmented regressions. Econometrica, forthcoming.

Bernanke, B.S., Boivin, J., Eliasz, P., 2005. Should central banks respond to movements in asset prices? Quarterly Journal of Economics 120 (1).

Bollerslev, T., Engle, R., Wooldridge, J., 1988. A capital asset pricing model with time-varying covariances. Journal of Political Economy 96, 116-131.

Boudoukh, J., Richardson, M., Whitelaw, R.F., 1997. Nonlinearities in the relation between the equity risk premium and the term structure. Management Science 43 (3), 371-385.

Boyd, J.H., Hu, J., Jagannathan, R., 2005. The stock market's reaction to unemployment news: why bad news is usually good for stocks. The Journal of Finance 60 (2), 649-672.

Brandt, M.W., Kang, Q., 2004. On the relation between the conditional mean and volatility of stock returns: a latent var approach. Journal of Financial Economics 72, 217-257.

Breen, W., Glosten, L.R., Jagannathan, R., 1989. Economic significance of predictable variations in stock index returns. Journal of Finance 44 (5), 1177-1189.

Campbell, J.Y., 1987. Stock returns and the term structure. Journal of Financial Economics 18, 373-399.

Campbell, J.Y., 1991. A variance decomposition for stock returns. Economic Journal 101, 157-179.

Campbell, J.Y., Cochrane, J.H., 1999. By force of habit: a consumption-based explanation of aggregate stock market behavior. Journal of Political Economy 107, 205-251.

Campbell, J.Y., Hentschel, L., 1992. An asymmetric model of changing volatility in stock returns. Journal of Financial Economics 31, 281-318.

Campbell, J.Y., Shiller, R.J., 1989. The dividend-price ratio and expectations of future dividends and discount factors. Review of Financial Studies 1 (3), 195-228.

Campbell, J.Y., Thompson, S., 2005. Predicting the equity premium out of sample: can anything beat the historical average?, NBER Working Paper No. 11468.

Campbell, J.Y., Voulteenaho, T., 2005. Good beta, bad beta. American Economic Review 94 (5), 1249-1275.

Campbell, J.Y., Yogo, M., 2002. Efficient tests of stock return predictability. Unpublished paper, Harvard University.

Chang, G., Sundaresan, S.M., 1999. Asset prices and default-free term structure in an equilibrium model of default. Unpublished paper, Columbia University.

Clark, T., McCracken, M., 2001. Tests of equal forecast accuracy and encompassing for nested models. Journal of Econometrics 105, 85-110.

Cochrane, J.H., Piazzesi, M., 2005. Bond risk premia. The American Economic Review, forthcoming.

Connor, G., Korajczyk, R., 1986. Performance measurement with the arbitrage pricing theory: a new framework for analysis. Journal of Financial Economics 15, 373-394.

Connor, G., Korajczyk, R.A., 1988. Risk and return in an equilibrium apt: application of a new test methodology. Journal of Financial Economics 21, 255-289.

Constantinides, G.M., 1990. Habit-formation: a resolution of the equity premium puzzle. Journal of Political Economy 98, 519-543. 
Constantinides, G.M., Duffie, D., 1996. Asset pricing with heterogeneous consumers. Journal of Political Economy 104, 219-240.

Fama, E.F., French, K.R., 1988. Dividend yields and expected stock returns. Journal of Financial Economics 22, $3-27$.

Fama, E.F., French, K.R., 1989. Business conditions and expected returns on stocks and bonds. Journal of Financial Economics 25, 23-49.

Fama, E.F., French, K.R., 1992. The cross-section of expected returns. Journal of Finance 47, 427-465.

Fama, E.F., French, K.R., 1993. Common risk factors in the returns on stocks and bonds. Journal of Financial Economics 33, 3-56.

Ferson, W.E., Sarkissian, S., Simin, T.T., 2003. Spurious regressions in financial economics? Journal of Finance 58 (4), 1393-1413.

French, K., Schwert, G.W., Stambaugh, R.F., 1987. Expected stock returns and volatility. Journal of Financial Economics 19, 3-30.

Ghysels, E., Santa-Clara, P., Valkanov, R., 2005. There is a risk-return tradeoff after all! Journal of Financial Economics, forthcoming.

Glosten, L.R., Jagannathan, R., Runkle, D.E., 1993. On the relation between the expected value and the volatility of the nominal excess return on stocks. Journal of Finance 48 (5), 1779-1801.

Goyal, A., Welch, I., 2004. A comprehensive look at the empirical performance of equity premium prediction. NBER Working Paper No. 10483.

Guo, H., 2005. On the out-of-sample predictability of stock market returns. Journal of Business, forthcoming.

Hansen, L.P., Richard, S.F., 1987. The role of conditioning information in deducing testable restrictions implied by dynamic asset pricing models. Econometrica 55, 587-614.

Harvey, C.R., 1989. Time-varying conditional covariances in tests of asset pricing models. Journal of Financial Economics 24, 289-371.

Harvey, C.R., 1991. The world price of covariance risk. Journal of Finance 46, 111-117.

Harvey, C.R., 2001. The specification of conditional expectations. Journal of Empirical Finance 8 (5), 573-638.

Hodrick, R., 1992. Dividend yields and expected stock returns: alternative procedures for inference and measurement. Review of Financial Studies 5, 357-386.

Kandel, S., Stambaugh, R.F., 1990. Expectations and volatility of consumption and asset returns. Review of Financial Studies 3, 207-232.

Lettau, M., Ludvigson, S.C., 2001a. Consumption, aggregate wealth and expected stock returns. Journal of Finance 56 (3), 815-849.

Lettau, M., Ludvigson, S.C., 2001b. Resurrecting the (C)CAPM: a cross-sectional test when risk premia are timevarying. Journal of Political Economy 109 (6), 1238-1287.

Lettau, M., Ludvigson, S.C., 2003. Measuring and modeling variation in the risk-return tradeoff. Unpublished paper, New York University.

Lettau, M., Ludvigson, S.C., Wachter, J.A., 2005. The declining equity premium: what role does macroeconomic risk play? NBER Working Paper No. 10270.

Lewellen, J.W., 2004. Predicting returns with financial ratios. Journal of Financial Economics 74, 209-235.

Lintner, J., 1965. Security prices, risk and maximal gains from diversification. Journal of Finance 20, 587-615.

Pagan, A.R., Hong, Y.S., 1991. Nonparametric estimation and the risk premium. In: Barnett, W.A., Powell, J.A., Tauchen, G.E. (Eds.), Nonparametric Models in Econometrics and Statistics: Proceedings of the Fifth International Symposium in Economic Theory and Econometrics. Cambridge University Press, Cambridge, New York and Melbourne, pp. 51-75.

Sargent, T.J., 1989. Two models of measurements and the investment accelerator. Journal of Political Economy 97, 251-287.

Sargent, T.J., Sims, C.A., 1977. Business cycle modeling without pretending to have too much a priori theory. In: Sims, C.A. (Ed.), New Methods of Business Cycle Research. Federal Reserve Bank of Minneapolis, Minneapolis, MN.

Schwert, G.W., 1989. Why does stock market volatility change over time. Journal of Finance 44 (5), 1115-1153.

Schwert, G.W., 1990. Stock volatility and the crash of 87. Review of Financial Studies 3 (1), 77-102.

Sharpe, W., 1964. Capital asset prices: a theory of market equilibrium under conditions of risk. Journal of Finance $19,425-444$.

Shiller, R.J., 1981. Do stock prices move too much to be justified by subsequent changes in dividends? American Economic Review 71, 421-436. 
Stock, J.H., Watson, M.W., 1989. New indexes of coincident and leading economic indicators. In: Blanchard, O.J., Fischer, S. (Eds.), NBER Macroeconomics Annual, 1989. MIT Press, Cambridge, pp. 351-394.

Stock, J.H., Watson, M.W., 1991. A probability model of the coincident economic indicators. In: Moore, G., Lahiri, K. (Eds.), The Leading Economic Indicators: New Approaches and Forecasting Records. Cambridge University Press, Cambridge, pp. 63-90.

Stock, J.H., Watson, M.W., 2002a. Forecasting using principal components from a large number of predictors. Journal of the American Statistical Association 97 (460), 1167-1179.

Stock, J.H., Watson, M.W., 2002b. Macroeconomic forecasting using diffusion indexes. Journal of Business and Economic Statistics 20 (2), 147-162.

Stock, J.H., Watson, M.W., 2004. Forecasting with many predictors. Unpublished paper, Princeton University. Whitelaw, R.F., 1994. Time variations and covariations in the expectation and volatility of stock market returns. The Journal of Finance 49 (2), 515-541.

Whitelaw, R.F., 2000. Stock market risk and return: an equilibrium approach. Review of Financial Studies 13 (3), 521-547. 